\title{
Unravelling Climate Change in the Hindu Kush Himalaya: Rapid Warming in the Mountains and Increasing Extremes
}

\author{
Coordinating Lead Authors \\ Raghavan Krishnan, Indian Institute of Tropical Meteorology, India, e-mail: krish@ tropmet.res.in \\ Arun Bhakta Shrestha, International Centre for Integrated Mountain Development, Nepal, \\ e-mail: arun.shrestha@icimod.org (corresponding author) \\ Guoyu Ren, China Meteorological Administration and China University of Geosciences, China. \\ e-mail: guoyoo@cma.gov.cn
}

\section{Lead Authors}

Rupak Rajbhandari, Tribhuvan University, Nepal, e-mail: rupak.rajbhandari@gmail.com Sajjad Saeed, Katholieke Universiteit Leuven, Belgium; Center of Excellence for Climate Change Research (CECCR), King AbdulAziz University, Jeddah, Saudi Arabia, e-mail: sajjad.saeed@kuleuven.be Jayanarayanan Sanjay, Indian Institute of Tropical Meteorology, India, e-mail: sanjay@ tropmet.res.in Md. Abu Syed, Bangladesh Centre for Advanced Studies, Bangladesh, e-mail: abu.syed@bcas.net Ramesh Vellore, Indian Institute of Tropical Meteorology, India, e-mail: rameshv@tropmet.res.in Ying Xu, China Meteorological Administration, China, e-mail: xuying@cma.gov.cn Qinglong You, Nanjing University of Information Science \& Technology, China, e-mail: qinglong.you@nuist.edu.cn

Yuyu Ren, National Climate Centre, China Meteorological Administration, China, e-mail: renyuyu@126.com

\section{Contributing Authors}

Ashok Priyadarshan Dimri, Jawaharlal Nehru University, India, e-mail: apdimri@ hotmail.com Arthur Lutz, Future Water, the Netherlands, e-mail: a.lutz@futurewater.nl Prasamsa Singh, Nagoya University, Japan, e-mail: prasamsasingh@gmail.com Xiubao Sun, China University of Geosciences, China, e-mail: sun_2005009@126.com Yunjian Zhan, China Meteorological Administration, China, e-mail: zhanyunjian@foxmail.com

\section{Review Editor}

Valerio Lucarini, Reading University, United Kingdom, e-mail: v.lucarini@reading.ac.uk

\section{Corresponding Author}

Arun Bhakta Shrestha, International Centre for Integrated Mountain Development, Nepal, e-mail: arun.shrestha@icimod.org 


\section{Contents}

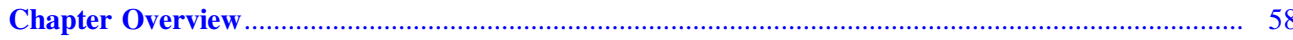

3.1 Our Understanding of the HKH Climate Needs to Be Improved ......................................... 60

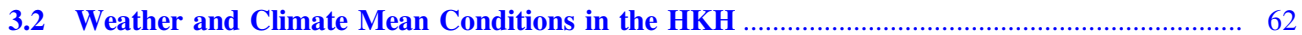

3.2.1 Major Features of Climatology: Topographic Control, Seasons, and Liquid and Solid

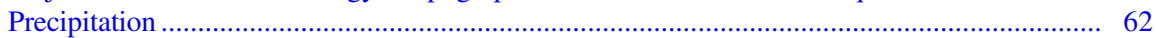

3.2.2 Climate Dominated by Monsoon ..................................................................................... 62

3.2.3 Climate Influenced by Large-Scale Climate Elements ......................................................... 63

3.3 Past HKH Climate Changes Were at Decadal to Greater Than Multi-millennial Time Scales

3.3.1 Significant Warming Characterized HKH Surface Air Temperature Trends in Past Decades

3.3.2 Precipitation Did Not Show Clear Trends in the Past Decades............................................... 67

3.3.3 Decreasing Near-Surface Wind Speed, Solar Radiation, and Sunshine Duration Indicated

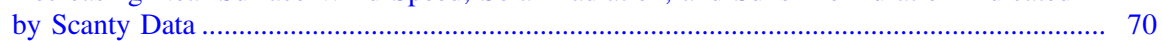

3.3.4 Significant Changes in the Temperature and Precipitation Extremes in Past Decades ........... 71

3.3.5 Progressively Greater Warming with Elevation ................................................................ 76

3.4 Climate Models Project Increases in HKH Temperature and Precipitation in the 21st Century

3.4.1 Significant Warming Projected, Greater Than Global Average ............................................ 78

3.4.2 Precipitation Projected to Increase, but with Regional Diversity .......................................... 83

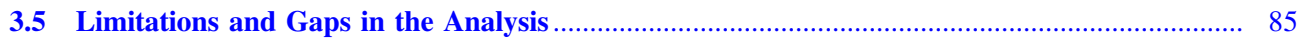

Annex 1: Data and Methods for Analysis of Past Temperature ….................................................. 86

Annex 2: Data and Methods for Analysis of Past Precipitation ........................................................ 86

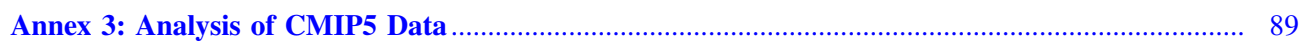

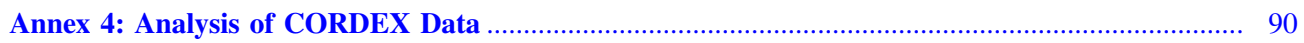

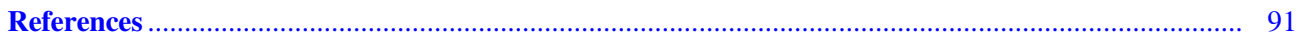

\section{Chapter Overview}

\section{Key Findings}

1. In the future, even if global warming is kept to $1.5{ }^{\circ} \mathrm{C}$, warming in the Hindu Kush Himalaya (HKH) region will likely be at least $0.3{ }^{\circ} \mathrm{C}$ higher, and in the northwest Himalaya and Karakoram at least $0.7{ }^{\circ} \mathrm{C}$ higher. Such large warming could trigger a multitude of biophysical and socio-economic impacts, such as biodiversity loss, increased glacial melting, and less predictable water availability-all of which will impact livelihoods and well-being in the HKH. The HKH has seen significant warming in the past decades nearly equal to the global average. Elevation Dependent Warming is widely observed in the region in past as well as future projections.
2. For the past five to six decades, the HKH have shown a rising trend of extreme warm events; a falling trend of extreme cold events; and a rising trend in extreme values and frequencies of temperature-based indices (both minimum and maximum). The number of cold nights reduced by 1 night per decade and the number of cold days reduced by 0.5 days per decade, while the number of warm nights increased by 1.7 nights per decade and number of warm days increased by 1.2 days per decade. These changes in extremes will continue and pose even more acute challenges to adaptation.

3. The HKH is experiencing increasing variability in western disturbances and a higher probability of snowfall in the Karakoram and western 
Himalaya, changes that will likely contribute to increases in glacier mass in those areas. This finding runs counter to many expectations in the scientific community, and more research is needed to understand the reasons for this and its potential future implications.

4. Consensus among models for the HKH region is weak-a result of the region's complex topography and the coarse resolution of global climate models. To improve evidence-based adaptation, improved climate models and downscaling strategies capable of capturing changes in extreme events are essential.

\section{Policy Messages}

1. More robust climate change analysis and adaptation planning will not be possible without improved long-term hydrometeorological monitoring in the HKH. High-altitude areas of the HKH lack long-term observational data, and the available data suffer from large inconsistencies and from high inhomogeneity. Systematic bias is also present through the urbanization effect on meteorological observations, and through the wind effect on precipitation observations.

2. For accurate cryospheric projections, more reliable projections of elevation-dependent warming are crucial. Although the evidence for elevation-dependent warming in the $\mathrm{HKH}$ is strong, the precise mechanisms underlying this phenomenon involve multiple feedbacks, such as snow-albedo interactions, water vapor-cloudradiation interactions, aerosol forcing, and warrant further research.

3. Policies and planning should focus on improved disaster warning systems, management and mitigation measures to address hydrometeorological extremes. This should include better understanding of hazard and risk, end-to-end monitoring and early warning and response systems.

Historically, the climate of the HKH has experienced significant changes that are closely related to the rise and fall of regional cultures and civilizations. Studies show wellestablished evidence that climate drivers of tropical and extra-tropical origin - such as the El Niño-Southern Oscillation (ENSO), the North Atlantic Oscillation (NAO), Indian Ocean Dipole (IOD), the Madden-Julian Oscillation (MJO), and the Arctic Oscillation (AO) - influence the region's weather and climate on multiple spatio-temporal scales. ${ }^{1}$

Although the climate of the HKH has changed significantly in the past, it is projected to change more dramatically in the near future. It is well-established that the warming in the Tibetan Plateau (TP) has been comparable in magnitude to the averages for the Northern Hemisphere and the same latitudinal zone. This regional warming continued even during the global warming hiatus - the period between 1998 and 2014 when global warming appeared to have slowed down.

Generally, from the last century through the beginning of the current one, the $\mathrm{HKH}$ has experienced warming from 1901 to 1940 ; cooling from 1940 to 1970; and warming from 1970 to the present. From 1901 to 2014, annual mean surface air temperature significantly increased in the $\mathrm{HKH}$, at a rate of about $0.10{ }^{\circ} \mathrm{C}$ per decade-while the warming rate over the last 50 years has been $0.2{ }^{\circ} \mathrm{C}$ per decade ( $p>0.05$ ). Well-established evidence suggests that extreme indices in the region have also changed over this period: occurrences of extreme cold days and nights have declined (days by 0.85 days per decade, nights by 2.40 days per decade), while occurrences of extreme warm days and nights have increased (days by 1.26 days per decade, nights by 2.54 days per decade). Warm nights have increased throughout the region, and extreme absolute temperature indices have changed significantly. Frost days show a significant declining trend in most parts of northern India and the TP. The length of the growing season has increased by 4.25 days per decade - a positive change for agriculture ( $\mathrm{p}>0.05$ ). Observed precipitation trends over the $\mathrm{HKH}$ during last five decades are inconclusive.

Evidence exists in the $\mathrm{HKH}$ for elevation-dependent warming (EDW), especially in the TP and its surrounding regions (well-established). The EDW phenomenon has been reported previously by several studies. However, the driving mechanisms of EDW are inconclusive. These mechanisms call for further investigation - in part because EDW can illuminate cryosphere dynamics, and in part also because EDW makes current efforts to contain global warming all the more important for the HKH. Conference of the Parties (COP21) in Paris in December 2015 agreed to take steps towards limiting the global mean annual surface air temperature increase to well below $2.0{ }^{\circ} \mathrm{C}$ above pre-industrial levels, and to pursue efforts towards a target of $1.5^{\circ} \mathrm{C}$. By the end of the century, if average global warming is limited to $1.5{ }^{\circ} \mathrm{C}$ above the pre-industrial period, the $\mathrm{HKH}$ will warm by $1.80 \pm 0.40{ }^{\circ} \mathrm{C}$.

\footnotetext{
${ }^{1}$ http://www.climate.rocksea.org/research/indian-ocean-warming/.
} 
While the precipitation trends for the HKH are established but inconclusive over the past century, with some analyses showing that total and extreme precipitation has increased overall over the last five decades, intense precipitation has changed markedly since 1961: rising trends appear in the intensity of annual intense precipitation and also in the frequency of annual intense precipitation day.

Ensemble outputs from the Coordinated Regional Downscaling Experiment (CORDEX) models project significant warming over the HKH region in the future (wellestablished). In the near term (2036-2065), the region is projected to warm by $1.7-2.4{ }^{\circ} \mathrm{C}$ for representative concentration pathway $4.5(\mathrm{RCP} 4.5)$ and $2.3-3.2{ }^{\circ} \mathrm{C}$ for $\mathrm{RCP} 8.5$. In the long term (2066-2095), regional warming is projected to be $2.2-3.3{ }^{\circ} \mathrm{C}$ for $\mathrm{RCP} 4.5$ and $4.2-6.5^{\circ} \mathrm{C}$ for $\mathrm{RCP} 8.5$. Increased warming during the winters is also projected. Warming during the winters is projected to warm relatively more. While the Coupled Model Intercomparison Project 5 (CMIP5) general circulation models (GCM) projections differ from (CORDEX) projections in magnitude, they do agree on trends. The TP, the central Himalayan Range, and the Karakoram will see a rise in temperature higher than average of the HKH. It is expected that EDW is projected to continue (well-established).

Most scenarios predict that an increase in precipitation is likely (established but inconclusive). Monsoon precipitation is projected to increase by $4-12 \%$ in the near future and by $4-25 \%$ in the long term. Winter precipitation is projected to increase by $7-15 \%$ in the Karakoram, but to decline slightly in the Central Himalaya.

Results on future precipitation extremes are inconclusive, across studies and across the region. Increasing precipitation extremes have been projected for the Indus basin, the TP, and the Eastern Himalaya. Increases are also expected in extreme temperatures, in tropical nights, and in the length of the growing season.

Despite the evidence outlined above and throughout this chapter, analyses of past trends are subject to uncertainty because of limitations in what has been observed. One of the sources of uncertainty comes from urbanization, which has caused a systematic bias in historical temperature data (observation sites may be located in urban areas or be engulfed by them as settlements expand). Besides global warming, other regional forcing elements like anthropogenic aerosols and land-use changes appear to have influenced the South Asian monsoon precipitation variations during the post-1950s. Many multi-model projections agree on the direction of future climactic and weather changes; nevertheless, differences appear in the magnitude of the changes and in their spatial distribution. There are also inherent challenges in accurately capturing monsoon precipitation variations in climate models over the HKH region, because of the strong internal dynamics associated with precipitation processes (e.g., aerosol-cloud-radiation interactions, convective and cloud microphysical processes, representation of atmosphere-land-ocean coupling, among others) and the complexities in representing multi-scale interactions.

\section{Climate Change and Sustainable Development Goals}

The aim of SDG 13 is to "take urgent action to combat climate change and its impact." Strengthening resilience and adaptive capacity to climate-related hazards and natural disasters in all countries and integrating climate change measures into national policies, strategies and planning are two major targets of SDG 13. By understanding the past and potential future of climate change in the $\mathrm{HKH}$ - on the basis of robust scientific analysis - we can better comprehend the region's present and future risks. Our finding that the warming in the HKH region in the future will be greater than the global average warming supports the need to take urgent action. We can more effectively support HKH countries, helping them strengthen resilience and adaptive capacity in the face of climate-related hazards and natural disasters. And we can integrate climate change adaptation measures into national policies, strategies, and plans. It will help in achieving the $\mathrm{HKH}$ relevant target on integrating mountain-specific climate change measures into national policies, strategies, and planning.

\subsection{Our Understanding of the HKH Climate Needs to Be Improved}

The Himalayan climate is mostly alpine but varies significantly with elevation from snow-capped higher elevations to tropical/subtropical climates at lower elevations, and varied vegetation exists over the HKH. Climatically, the HKH play an important role in global weather patterns. They serve as a heat source in summer and heat sink in winter ( $\mathrm{Wu}$ and Zhang 1998; Yanai et al. 1992; Yanai and Li 1994; Ye 1981). The HKH, together with the elevated TP, exert significant influence on the Asian summer monsoon system (Nan et al. 2009; Wu et al. 2004; Zhou et al. 2009).

The Himalaya are sensitive to climate change and variability (Shrestha and Aryal 2011; Xu et al. 2008). Most of the warming observed during the last few decades of the $20^{\text {th }}$ century is attributed to the increase in anthropogenic greenhouse gas (GHG) concentrations (IPCC 2007, 2013; You et al. 2017). With increased emission of anthropogenic GHG, the cryosphere processes-coupled with the 
hydrological regimes of this region - are under stress from a warming climate (see Chaps. 7 and 8). Increased temperature causes more evaporation, leading to increased atmospheric moisture content, thus bringing changes in future spatial and temporal precipitation patterns. This can adversely affect the supply of water to humans and agriculture, especially in the dry season. Localized weather events over the complex topography of the HKH pose a greater risk because of cloudbursts, flash floods, snowstorms, high winds, and landslides in the region (See Chap. 11). More frequent flood-inducing rain occurrences at higher altitudes can accelerate glacier melting and flood discharge, thus posing major risks of disasters in the region. Furthermore, changes in water flow regimes have implications for hydropower generation, biodiversity systems/forestry, and the agriculture- and natural resources-based livelihoods of the $\mathrm{HKH}$ (see Chaps. 5, 8, and 9). Climate change can have profound consequences for mountain agriculture, agrobiodiversity, and resilience of crop diseases, since many crop species in the HKH - namely wheat, rice, and soybeans - are sensitive to increasing levels of heat-trapping GHG (e.g., Chap. 9; Hoffmann 2013; Porter et al. 2014).

Intense monsoon rainfall in northern India and western Nepal in 2013, which led to landslides and one of the worst floods in history, has been linked to increased loading of GHG and aerosols (Cho et al. 2016). Winter precipitation in the HKH is brought about by synoptic weather disturbances moving from west to east. The passage of the disturbances is directed by a westerly jet stream, which is blocked by the $\mathrm{HKH}-\mathrm{TP}$; therefore, winter snowfall is concentrated in the western side of the region (Hasson et al. 2014). Further to the east the jet stream is located south of the Himalaya in winter. Several years of drought conditions in western Nepal since 2000, which culminated in severe drought during 2008-09, have been related to natural variability and anthropogenic influences (Wang et al. 2013).

Robust estimates of the observed variability and long-term changes in climate over the HKH are inadequate owing to sparse and discontinuous observations (Ren and Shrestha 2017). Further, reliable projections of climate over the HKH are crucial for assessment of the impacts of climate change. While people in the region are adapting autonomously to current stresses, each country in the HKH must design and implement effective strategies to adapt to climate change impact to achieve economic and social progress. Adapting to long- and short-term climate-related problems requires a thorough understanding of climate changes in the past and possible changes in the future (You et al. 2017). This chapter presents a broad overview of weather and climate elements pertaining to the $\mathrm{HKH}$, focusing more specifically on the linkage of large-scale drivers to climate variability in the $\mathrm{HKH}$, past and present regional climate variations, and likely projections of future regional climate using high-resolution regional climate models that are capable of resolving the Himalayan topography. While this chapter takes stock of previous studies, the major part of the chapter is based on original analysis, as studies in the HKH domain (Fig. 3.1), as identified by the Hindu Kush Himalayan Monitoring and Assessment Programme (HIMAP) (Sharma et al. 2016), have not been conducted in the past. A concluding section synthesizes major gap areas and future directions for diverse and multidisciplinary solutions for climate change impact in the HKH. During the development of this chapter, the authors published seven articles based on
Fig. 3.1 RegCM4 elevation (in $\mathrm{km}$ ) with three regions of interest defined by grid cells in each box above $2,500 \mathrm{~m}$ a.s.1. (non-greyscale): northwestern Himalaya and Karakoram (HKH1); central Himalaya (HKH2); southeastern Himalaya and Tibetan Plateau (HKH3). The Hindu Kush Himalaya $(\mathrm{HKH})$ boundary is shown with a dashed line (Source Sanjay et al. 2017b)

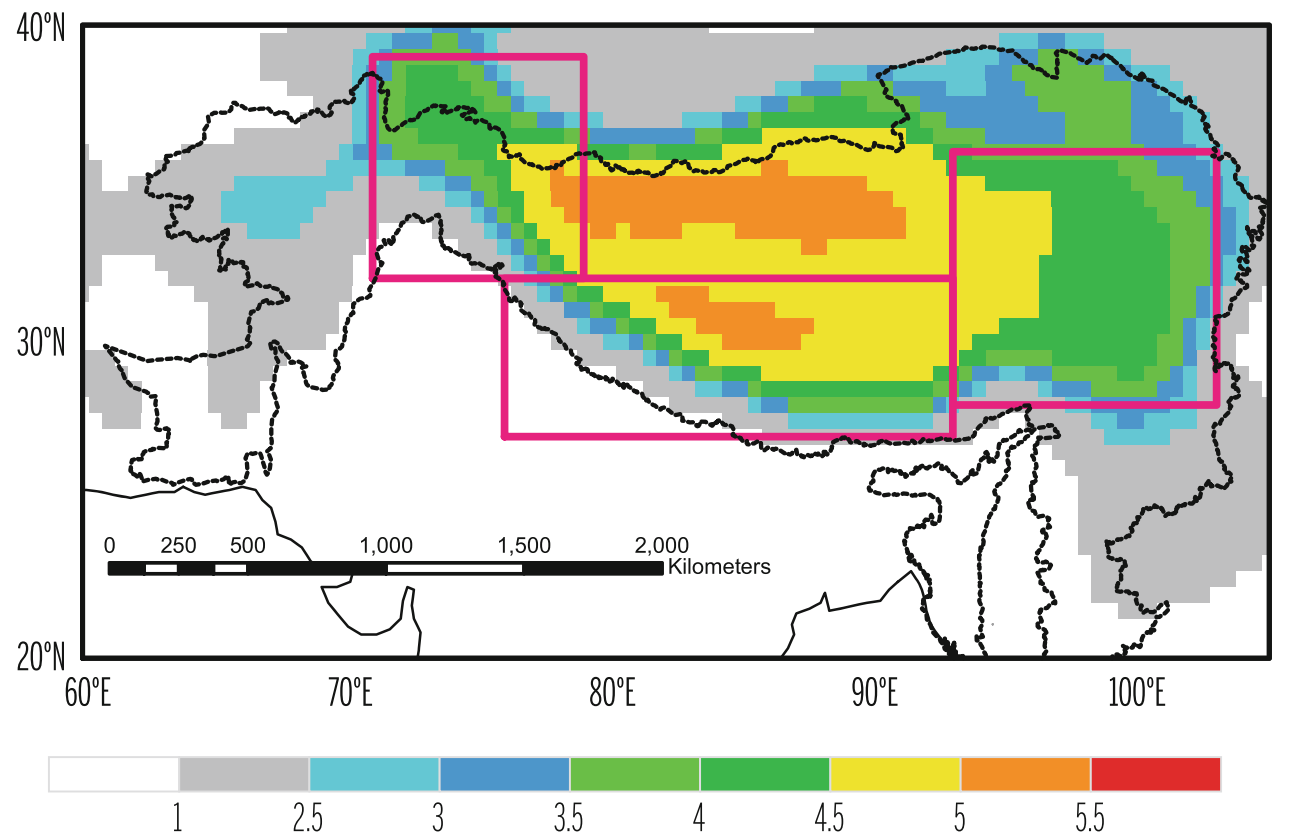


the original analysis (Rajbhandari et al. 2017; Ren et al. 2017; Sanjay et al. 2017b; Sun et al. 2017b; Wu et al. 2017; You et al. 2017; Zhan et al. 2017).

\subsection{Weather and Climate Mean Conditions in the HKH}

\subsubsection{Major Features of Climatology: Topographic Control, Seasons, and Liquid and Solid Precipitation}

Topographic variations, the annual cycle of seasons, and variability of weather patterns have strong controls on the spatial pattern of temperatures across different geographic regions of the $\mathbf{H K H}$. While the average summer and winter temperatures are about 30 and $18{ }^{\circ} \mathrm{C}$ in the southern foothills, the middle Himalayan valleys experience mean summer temperatures between 15 and $25{ }^{\circ} \mathrm{C}$ and very cold winters. Regions having elevations above $4800 \mathrm{~m}$ experience winter temperatures below freezing point and receive precipitation largely in the form of snow. The mean end-of-summer regional snow line altitude (SLA) zones in the upper Indus Basin of Pakistan range from 3000 to $5000 \mathrm{~m}$ a.s.l. (Hasson et al. 2014). Records of observed surface temperature from Pakistani stations in the elevated Karakoram indicate that the average maximum temperature is about $20{ }^{\circ} \mathrm{C}$ during July and the average minimum temperature is about $-3{ }^{\circ} \mathrm{C}$ in February (Kapnick et al. 2014). The regions of Ladakh and Zanskar, situated on the northern flank of the Himalayan range, experience dry conditions, with surface temperatures between 3 and $35^{\circ} \mathrm{C}$ in summer and between -20 and $-35^{\circ} \mathrm{C}$ in winter with accompanying heavy winter snowfall, thus amounting to average annual rainfall of a few centimetres. Hill stations of the western Himalaya like Shimla, Kullu Valley, Kangra, and Chamba; some regions in Uttaranchal such as Kumaon and Garhwal; and areas like Darjeeling and Sikkim in the eastern $\mathrm{HKH}$, largely experience the Indian summer monsoon precipitation. Thus, the Himalayan climate exhibits diverse geographical variability, which is closely linked to the varying topographic distribution of the region (Bookhagen and Burbank 2006).

The bulk of precipitation from the southwestern Indian summer monsoon, falling as frozen precipitation at higher elevations and liquid precipitation at lower elevations and adjacent plains of the Himalaya, constitutes an important ingredient of the major Himalayan river basins and associated hydrological cycle. From the sparse rain gauge network, the southern slopes of the Himalaya typically experienced large annual precipitation totals as high as $400 \mathrm{~cm} \mathrm{yr}^{-1}$ during the period of 1998-2007 (Bookhagen and Burbank 2010). The contributions of summer and winter monsoon circulation is not evenly distributed over the Himalaya, the summer (winter) rainfall is typically the greatest contributor over the southeastern (northwestern) part of the HKH. Monsoon precipitation is found to be the highest over the Siwalik and Pir Panjal ranges of the lower Himalaya, while it reduces northwards into the high Himalaya, Zanskar, Ladakh, and Karakoram ranges. Rainfall estimates from the Tropical Rainfall Measurement Mission (TRMM) satellite reveal two distinct bands of high rainfall that stretch parallel over the length of the HKH: (1) along the southern margin of the Lesser Himalaya; and (2) along the southern flank of the HKH (Bookhagen and Burbank 2006). Heavy rainfall in the HKH during summer is often associated with westnorthwestward-passing synoptic-scale monsoon low-pressure systems and depressions and their interactions with the subtropical westerly winds (e.g., Vellore et al. 2015), as well as during break-monsoon situations (e.g., Dhar et al. 1984; Rao 1976; Vellore et al. 2014). Flooding in the mountainous Himalaya and adjacent low-relief areas is generally attributed to heavy or extreme rainfall events associated with synoptic climate patterns (e.g., Shrestha 2008a).

The western side of the Karakoram Himalaya is prone to large amounts of snowfall in winter from frequent passage of extra-tropical synoptic-scale disturbances known as the western disturbances, emanating from the upper tropospheric westerlies (e.g., Dimri et al. 2015; Madhura et al. 2015; see Box 3.1). Studies have found that teleconnection related to flood events - for example, the Pakistan flood of 2010 and the Russian drought at the same time-is caused by a standing Rossby wave (e.g., Lau and Kim 2012). More than $80 \%$ of annual precipitation in the central-eastern part of the Himalaya is from the summer monsoon. Thus, precipitation over the Himalayan river basins is highly variable, and the annual mean precipitation over the Indus, the Ganges, and the Brahmaputra river basins is estimated as 435, 1094, and $2143 \mathrm{~mm}$, respectively (Nepal and Shrestha 2015).

\subsubsection{Climate Dominated by Monsoon}

The monsoon climate over much of South Asia is dominated by seasonal reversing winds that carry moist air over the Indian Ocean into South Asia during the northern hemisphere summer; whereas cool and dry winds blow southward from the Asian continent towards the Indian Ocean during the winter months. The presence of the $\mathrm{HKH}$ topographic barrier restricts upper-level subtropical westerly winds to latitudes poleward of $30^{\circ} \mathrm{N}$ during the boreal summer months, thus allowing warm and moist summer monsoon circulation to extend northward into the Indian subcontinent. The onset of southwest summer monsoon rains over northeastern India typically occurs around 6 June 
and later advances towards Bhutan and Nepal. The summer monsoon rains last for more than 4 months over the $\mathrm{HKH}$ region and typically withdraw from northeastern India round 15 October (Singh and Ranade 2010). On the other hand, the northern and northwestern regions of India experience the onset and withdrawal of summer monsoon rains typically around 8 July and 19 September, respectively (Singh and Ranade 2010). Thus, the length of the summer monsoon rainy season is significantly longer in the eastern Himalaya as compared to the western Himalaya (Shrestha et al. 2008a).

\section{Summer monsoon precipitation over the Gangetic Valley} and along the southern slopes of the Himalaya is strongly influenced by the mean position of the monsoon trough. When the monsoon depressions formed over the Bay of Bengal travel in a west-northwestward direction, precipitation is distributed across the Indian landmass (Rao 1976). During "breaks" in the Indian summer monsoon (i.e., shifting of the monsoon trough towards the southern slope of the Himalaya), the central and eastern Himalaya often experience heavy precipitation together with flooding in the Brahmaputra and its tributaries (Dhar et al. 1984; Vellore et al. 2014), while the plains of the Indian subcontinent suffer deficit rainfall (e.g., Krishnan et al. 2000, 2006, 2009; Rajeevan et al. 2010; Ramamurthy 1969). The monsoon heat low that forms over the northwestern parts of India and Pakistan during the summer plays an important role in the modification of monsoon rainfall over the northwestern parts of the HKH. The eastward-propagating upper-level mid-latitude systems associated with global teleconnection influence the monsoon heat low and associated rainfall over the northwestern HKH and Karakoram region during the summer (Saeed et al. 2010, 2011). While local factors as well as global teleconnections influence the strength of the summer monsoon circulation, rainfall predictions over the $\mathrm{HKH}$ beyond a few days are challenging. Intense or extreme rainfall in the $\mathrm{HKH}$ is influenced by orographic effects, synoptic scale systems, monsoon convection, and also by a combination of monsoon and extratropical circulation interactions (e.g., Bookhagen and Burbank 2010; Houze et al. 2007, 2011; Medina et al. 2010; Vellore et al. 2014, 2015).

\section{Box 3.1 Westerly disturbance and its linkage with agriculture and glacier dynamics}

Winter precipitation in the Himalaya is predominantly from synoptic weather systems known as western disturbances, which propagate eastward from the Mediterranean region (Dimri et al. 2015; Dimri and Chevuturi 2016; Hasson et al. 2014; Madhura et al. 2015). The western disturbances are large-amplitude wave disturbances that travel along the subtropical westerly jet stream and influence HKH precipitation during winter and early spring. Annual winter snowfall amounts are seen to range from a few hundred to several hundreds of centimetres at different elevations, with the maximum over the Karakoram. The western disturbances also significantly impact temperature patterns of the Himalaya besides precipitation. The winter climate conditions over the $\mathrm{HKH}$ are favourable for cultivation of wheat and other winter crops. The changes in the westerly disturbance are also believed to increase the mass of some glaciers in the Karakoram and western Himalaya, popularly known as the "Karakoram Anomaly" (e.g., Forsythe et al. 2017; Hewitt 2005), which is likely to continue into the future (e.g., Ridley et al. 2013; Krishnan et al. 2018; see Chap. 7).

\subsubsection{Climate Influenced by Large-Scale Climate Elements}

Recent studies highlight the role of climate drivers of both tropical and extra-tropical origin in influencing the weather and climate of the $\mathrm{HKH}$ on multiple spatio-temporal scales. Examples of such climate drivers are El Niño-Southern Oscillation ${ }^{2}$ (ENSO), North Atlantic Oscillation $^{3}$ (NAO), Madden-Julian Oscillation ${ }^{4}$ (MJO), Arctic Oscillation, ${ }^{5}$ Indian Ocean dipole ${ }^{6}$ and Indian Ocean warm pool $^{7}$ (e.g., Barlow et al. 2005; Bhutiyani et al. 2009; Cannon et al. 2015, 2017; Yadav et al. 2009, 2010). Significant positive correlations have been identified between NAO and precipitation variability over the Karakoram Himalaya during winter (Archer and Fowler 2004), which are often mediated through the activity of western disturbances (Cannon et al. 2015; Dimri and Chevuturi 2016; Hasson et al. 2014). Likewise, anomalous westward shifts of the summer Pacific anticyclone during $\mathrm{La} \mathrm{Niña}^{8}$ episodes can be critical to severe precipitation activity over the Indo-Pakistani mountainous areas (Mujumdar et al. 2012), besides the classical pathway of ENSO-monsoon teleconnections through the equatorial Walker circulation (Krishna Kumar et al. 2006).

Despite the studies mentioned above, there is considerable ambiguity about how the HKH would respond to background

\footnotetext{
${ }^{2}$ https://iridl.ldeo.columbia.edu/maproom/ENSO/ENSO_Info.html. ${ }^{3} \mathrm{http}: / / \mathrm{www} .1 d$ eo.columbia.edu/res/pi/NAO/.

${ }^{4}$ http://www.cpc.ncep.noaa.gov/products/precip/CWlink/MJO/MJO_ 1page_factsheet.pdf.

${ }^{5}$ https://www.ncdc.noaa.gov/teleconnections/ao/.

${ }^{6} \mathrm{http} / / /$ www.bom.gov.au/climate/enso/history/ln-2010-12/IOD-what. shtml.

${ }^{7}$ http://www.climate.rocksea.org/research/indian-ocean-warming/.

${ }^{8}$ http://www.pmel.noaa.gov/elnino/what-is-la-nina.
} 
changes in large-scale circulation in a warming environment, especially given the spatially heterogeneous temperature increase during recent decades. Several studies have documented the elevation dependency of the climate warming signal which gives rise to pronounced warming at higher elevations rather than at lower elevations (see Diaz and Bradley 1997; Duan et al. 2006; Liu and Chen 2000; Liu et al. 2009a; Shrestha et al. 1999; Thompson et al. 2003). Observations indicate that the annual-mean and winter-mean temperatures at high elevation sites $(>2,000 \mathrm{~m})$ of the eastern TP have increased at a rate of about $0.42{ }^{\circ} \mathrm{C}$ per decade and 0.61 ${ }^{\circ} \mathrm{C}$ per decade, respectively, during $1961-2006$. On the other hand, the low-elevation sites $(<500 \mathrm{~m})$ have warmed at a rate of about $0.2{ }^{\circ} \mathrm{C}$ per decade during the same period (Liu et al. 2009a). Those trends are significant at 0.001 level.

Madhura et al. (2015) recently reported that the observed pattern of a mid-tropospheric warming trend over westcentral Asia in recent decades has consequences for the increasing variability of western disturbances and a higher propensity for heavy winter precipitation events over the western Himalaya. The implications of the climate warming signal on the hydrological cycle of the HKH are not yet adequately clear. In contrast to many places across the globe which have experienced decreases in snowfall amounts and glacial extent during recent decades, the Karakoram Himalaya appear to have slightly gained glacial mass in the early 21 st century (see Gardelle et al. 2012; Hewitt 2005). Climate model simulations indicate that changes in winter frozen precipitation over the Karakoram Himalaya appear to shield this region from glacier thickness losses under a warming climate (Kääb et al. 2015; Kapnick et al. 2014). The changes in the westerly disturbance is also attributed to an increase in the mass of some glaciers in the Karakoram and western Himalaya (Forsythe et al. 2017).

\subsection{Past HKH Climate Changes Were at Decadal to Greater Than Multi-millennial Time Scales}

\footnotetext{
Box 3.2 Paleoclimate of the HKH: climate was always changing

Knowledge of the paleoclimate is important to finding a climate analogy in the past and understanding causal relationships, which can help in understanding and planning for the future (USGS 2010). The climate of HKH has always been changing. Paleoclimate in the HKH has been inferred from limited proxy sources such as ice cores, tree rings, lake sediments, peats, and cave sediments within the region, as well as from land- and marine-based proxy sources
}

outside the region. There is general consensus that the Asian monsoon was established around 23-7 Ma before present (BP) and is related to the tectonics of the region (Singhvi and Krishnan 2014). Since then, both the precipitation and thermal regimes of the region have gone through significant fluctuation, mainly driven by orbital changes and associated changes in solar radiation (Kutzbach and Otto-Bliesner 1982; Prell and Kutzbach 1987). Around 150-100 ka $\mathrm{BP}$, the monsoon was similar to the present; from 100 to $70 \mathrm{ka} \mathrm{BP}$ the monsoon fluctuated considerably, and it was much drier and colder from 70 to $60 \mathrm{ka} \mathrm{BP}$. The monsoon circulation strengthened around $13 \mathrm{ka} \mathrm{BP}$, attributed to orbital factors and increased solar radiation (An et al. 2005; Kutzbach 1981). During the period 20 to $19 \mathrm{ka} \mathrm{BP}$, known as the last glacial maximum (LGM), the region experienced drier monsoons and an overall colder climate (Ashahi and Watanabe 2004).

Many reconstructions have been done of the last 2,000 years of the TP using tree ring data and ice-core records. Yadav et al. (2004) looked at 15-16 tree ring sides and found several cold and warm episodes between 1573 and 1846, including the little ice age (LIA) period between 1560 and 1750. Cook et al. (2003) found linkage between temperature in the eastern Himalaya and volcanic eruptions. Shao et al. (2005) found that annual precipitation underwent a large multi-decadal variability in the northeastern part of the Qaidam Basin, TP, over the past 1,000 years, with the $20^{\text {th }}$ century precipitation obviously higher than that in any other century. Liu et al. (2005) showed that the annual mean temperature experienced remarkable fluctuation in the Qilan Mountains of the $\mathrm{TP}$, with the signals of the LIA and the continuous warming during the $20^{\text {th }}$ century. However, other studies did not find particularly abnormal $20^{\text {th }}$-century warming in tree ring-based reconstructions in the TP region, despite the fact that the $20^{\text {th }}$ century was indeed warmer than most centuries of the last several hundred years to 1,000 years (e.g., Chu et al. 2005; Yang et al. 2002; Yao 1997). Therefore, whether the $20^{\text {th }}$ century warming was unprecedented in the last 1,000 years in the TP is an unresolved issue.

Fluctuations in the climate in the HKH and beyond have been found to be closely related to the culture and civilization in the region (e.g., An et al. 2005; Dixit et al. 2015; Staubwasser et al. 2003; Weiss and Bradley 2001). Dixit et al. (2015) suggested that the weakening in the monsoon around $4.1 \mathrm{ka} \mathrm{BP}$ was related to the decline in the Indus urban culture. 


\subsubsection{Significant Warming Characterized HKH Surface Air Temperature Trends in Past Decades}

Analyses show significant warming in recent decades and the last century, despite the warming rates estimated from various research groups being somewhat different and not uniform in all parts of the $\mathrm{HKH}$. Analyses of surface air temperature change based on varied data sets, including observations and reanalyses, have been conducted for a few of areas of the HKH, including the TP (Du et al. 2001; Duan and Xiao 2015; Fan et al. 2015; Kang et al. 2010; Kuang and Jiao 2016; Liu and Chen 2000; Liu et al. 2006, 2009; Ren et al. 2005, 2017; Wang et al. 2008, 2014, 2016; Yao et al. 2012b; You et al. 2013a, 2016, 2017).

Previous studies have reported large and significant warming in the TP region during the last five to six decades, with night-time warming being especially remarkable. For example, the linear rates of increase over the entire TP during 1955-96 were about $0.16{ }^{\circ} \mathrm{C} /$ decade for the annual mean temperature and $0.32{ }^{\circ} \mathrm{C} /$ decade for the winter mean temperature, which marginally exceeded the averages for the northern hemisphere and the same latitudinal zone (Liu and Chen 2000). A recent study (Yan and Liu 2014) reported a warming trend of $0.316{ }^{\circ} \mathrm{C} /$ decade in annual mean temperature in the TP for the period 1961-2012, which is almost twice the previous estimate by Liu and Chen (2000). Recent studies using updated observations and historical CMIP5 outputs (Kang et al. 2010; You et al. 2013a, 2016) show that the annual mean surface temperatures in the TP have doubled the previous warming rate. This rapid warming in the TP is primarily owing to the warmer conditions for the last decade and during the global warming hiatus period (Kosaka and Xie 2013; You et al. 2016). The warming in the TP from the observation and CMIP5 models is more sensitive and accelerated during the hiatus period (You et al. 2016). Meanwhile, the asymmetric pattern of greater warming trends in minimum temperature than in maximum temperature is found in the TP (Duan and Wu 2006; Liu et al. 2006, 2009a). The accelerated climate warming on the TP has caused significant glacial retreat, snow melt, and permafrost degradation (Kang et al. 2010; Yao et al. 2012a, b), and will also lead to significant changes in the form of precipitation (solid to liquid) and changes in hydrology and water resources on the TP (Immerzeel et al. 2010; Immerzeel and Bierkens 2012; Kuang and Jiao 2016; Yang et al. 2014).

Significant warming of the winter and annual temperature was also observed over the western Himalaya in the last century (Bhutiyani et al. 2007; Kothawale and Rupa Kumar
2005). The temperature increase over the western Himalaya is supported by more rapid growth of tree rings in high-altitude tree-ring chronologies of the region (Borgaonkar et al. 2009). This warming trend over the region in the last few decades is consistent with the increase in northern hemispheric temperatures (Mann et al. 1999) and follows the pattern of global warming in the $20^{\text {th }}$ century. There is greater concern about observed unusually large temperature rises in the high-elevation Himalayan regions-for example, the warming is estimated to be nearly two to three times the global average (Liu and Chen 2000; Shrestha et al. 1999) and the issue of rising temperatures in a warming world is important in more fragile and delicate cryospheric environments. The warming rate is reported to be rather more substantial in winter compared to other seasons in most parts of the HKH (Bhutiyani et al. 2007; Shrestha and Devkota 2010).

During 1901-2014, annual mean surface air temperature increased significantly in the $\mathrm{HKH}$ at a rate of about 0.104 ${ }^{\circ} \mathrm{C} /$ decade. A region-averaged surface air temperature anomaly series of the past century or decades for the HKH as a whole has not been produced. The authors of this chapter made a special analysis of observed climate change in the region by using global land surface air temperature (GLSAT) data sets developed recently by the China Meteorological Administration (CMA). Details of the methodology are given in Annex 1. Based on the CMA GLSAT data set (Ren et al. 2014; Sun et al. 2017a; Xu et al. 2014), annual and seasonal mean surface air temperature in the last 114 years exhibit a significant increase in the entire HKH (Ren et al. 2017). The annual mean surface air temperature series in the HKH since 1901 is shown in Fig. 3.2a, b. For the full period of record (1901-2014), annual temperature trends show significant upward trends $(\mathrm{p}<0.05)$, and the increase rates of Tmean, Tmax, and Tmin are $0.104{ }^{\circ} \mathrm{C} /$ decade, $0.077{ }^{\circ} \mathrm{C} /$ decade, and $0.176{ }^{\circ} \mathrm{C} / \mathrm{dec}$ ade, respectively (Table 3.1). For details of the number of stations used, refer to Annex 1. The diurnal temperature range (DTR) shows a significant negative trend of $-0.101{ }^{\circ} \mathrm{C} / \mathrm{dec}$ ade, due to the much larger rise in minimum temperature than in maximum temperature in the region (Ren et al. 2017). Locally, deviations from the general pattern described above have been found in the Karakoram region, where decreasing temperatures (most notably in summer) have been measured. Possible mechanisms for such an anomaly have been discussed recently in Forsythe et al. (2017).

The trends of annual mean temperature in the HKH show general agreement with the global land surface temperature trends for different periods, with small differences (Table 3.1). During the period 1901-2014, the HKH 

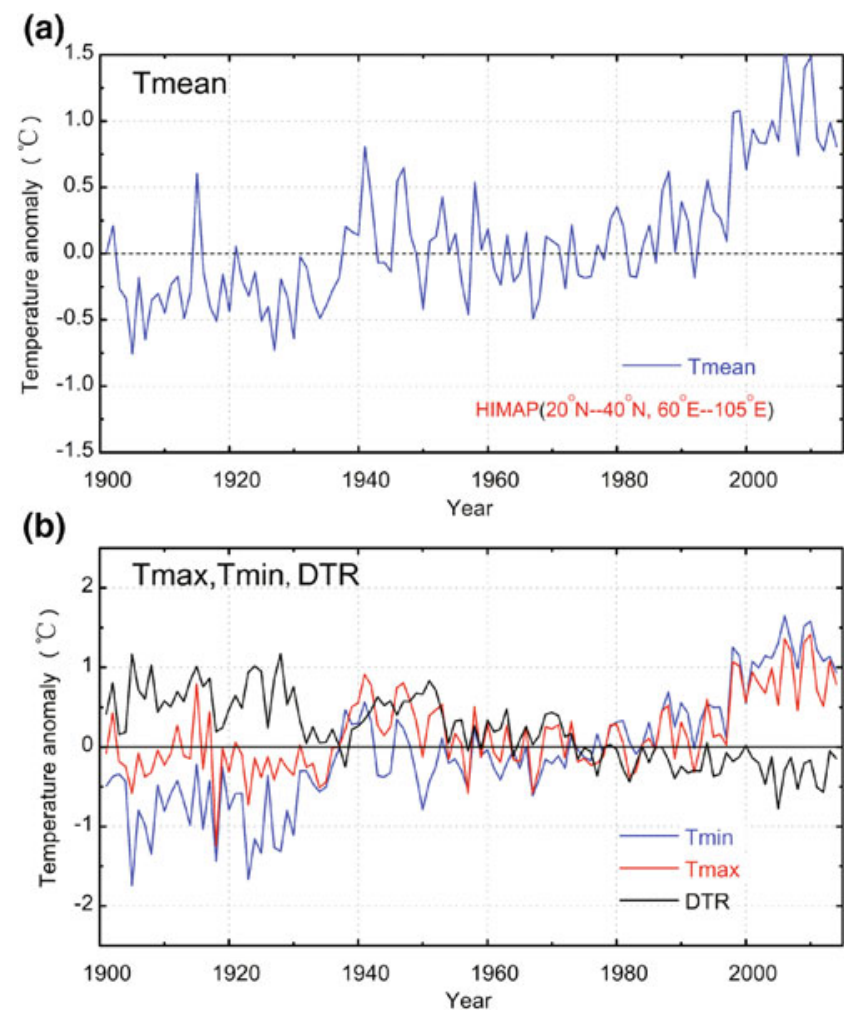

Fig. 3.2 Annual mean temperature anomaly series $\left({ }^{\circ} \mathrm{C}\right)$ relative to 1961-90 mean values for (a) Tmean and (b) Tmax, Tmin, and DTR for the Hindu Kush Himalaya between 1901 and 2014 (Data source CMA GLSAT; Ren et al. 2017)

exhibited trends similar to the global land surface. The annual mean warming rates during the period 1901-2020 was $0.19{ }^{\circ} \mathrm{C} /$ decade, while during the period $1951-2014$ it was $0.20^{\circ} \mathrm{C} /$ decade (Ren et al. 2017). For the period 19512014 the trend of annual mean Tmax in the HKH was lower, while the trend of annual mean Tmin was higher than that of the global land surface (Sun et al. 2017b).
The regional average annual mean temperature series of the HKH shows a large decadal to multi-decadal variability during the last more than 100 years. In terms of Tmean change, there are obviously three different stages in the HKH (as shown in Fig. 3.2a). From 1901 to the early 1940s, most of the years showed negative anomalies, and Tmean increased only slightly. From the 1940s to the late 1970s, a relatively cold period for the northern hemisphere, the HKH temperature series showed a significant decreasing trend. After the 1970s, however, a rapid warming appeared in the HKH. The decadal to multi-decadal variations in the warming and cooling episodes are generally consistent with previous studies of the TP and other areas of the HKH (Tang and Ren 2005), as well as in Nepal (Shrestha et al. 1999). In addition, the period from 1998 to 2014 witnessed the warmest years in the past 100 years, in spite of the fact that the annual mean warming trend in this period had slowed down, which is consistent with observations over the globe and northern hemisphere (Trenberth et al. 2014). The warmest 2 years in the period 1901-2014 in the HKH were 2007 and 2010 (Ren et al. 2017).

The annual mean time series of Tmax and Tmin in the HKH exhibited similar decadal to multi-decadal variations with the Tmean series. The annual mean Tmin anomalies were always lower than Tmax before the 1960s, and were generally higher than Tmax afterwards (Table 3.1). The annual mean DTR showed relatively stable change before the 1940s, but a significant decline in the post-1940s period. After the 1960s, although the Tmax anomaly was significantly lower than Tmin, it underwent a large increase compared to the Tmin (Table 3.1). Because of the poor station coverage before the 1940s, the temperature anomaly time series showed strong inter-annual fluctuations, indicating a relatively large sampling uncertainty during the period.

Table 3.1 Annual mean surface temperature trends during 1901-2014 and 1951-2014 in the Hindu Kush Himalaya (HKH) and globally $\left({ }^{\circ} \mathrm{C} /\right.$ decade) (Ren et al. 2017; Sun et al. 2017a)

\begin{tabular}{|c|c|c|c|c|c|c|}
\hline \multirow[t]{2}{*}{ Region } & \multirow[t]{2}{*}{ Data source } & \multirow[t]{2}{*}{ Period } & \multicolumn{4}{|l|}{ Trend } \\
\hline & & & Tmax & Tmin & DTR & Tmean \\
\hline \multirow[t]{2}{*}{ HKH } & \multirow[t]{2}{*}{ CMA } & $1901-2014$ & $0.077^{*}$ & $0.176^{*}$ & $-0.101^{*}$ & $0.104^{*}$ \\
\hline & & $1951-2014$ & $0.156^{*}$ & $0.278^{*}$ & $-0.123^{*}$ & $0.195^{*}$ \\
\hline \multirow[t]{2}{*}{ Globe (Land + Oceans) } & \multirow[t]{2}{*}{ GHCN } & $1901-2014$ & & & & $0.084^{*}$ \\
\hline & & $1951-2014$ & & & & $0.129^{*}$ \\
\hline \multirow[t]{2}{*}{ Globe (Land) } & \multirow[t]{2}{*}{ CMA } & $1901-2014$ & $0.100^{*}$ & $0.142^{*}$ & $-0.036^{*}$ & $0.104^{*}$ \\
\hline & & $1951-2014$ & $0.186^{*}$ & $0.238^{*}$ & $-0.054^{*}$ & $0.202^{*}$ \\
\hline
\end{tabular}

* Statistically significant at the 0.05 confidence level

CMA China Meteorological Administration; DTR diurnal temperature range; GHCN Global Historical Climatology Network 
Fig. 3.3 The grid-averaged trends of annual mean temperature in the Hindu Kush Himalaya (HKH) since 1901. The values on the top right corner are the number of grid boxes; white grid boxes indicate the missing data (Data source CMA GLSAT; Ren et al. 2017)

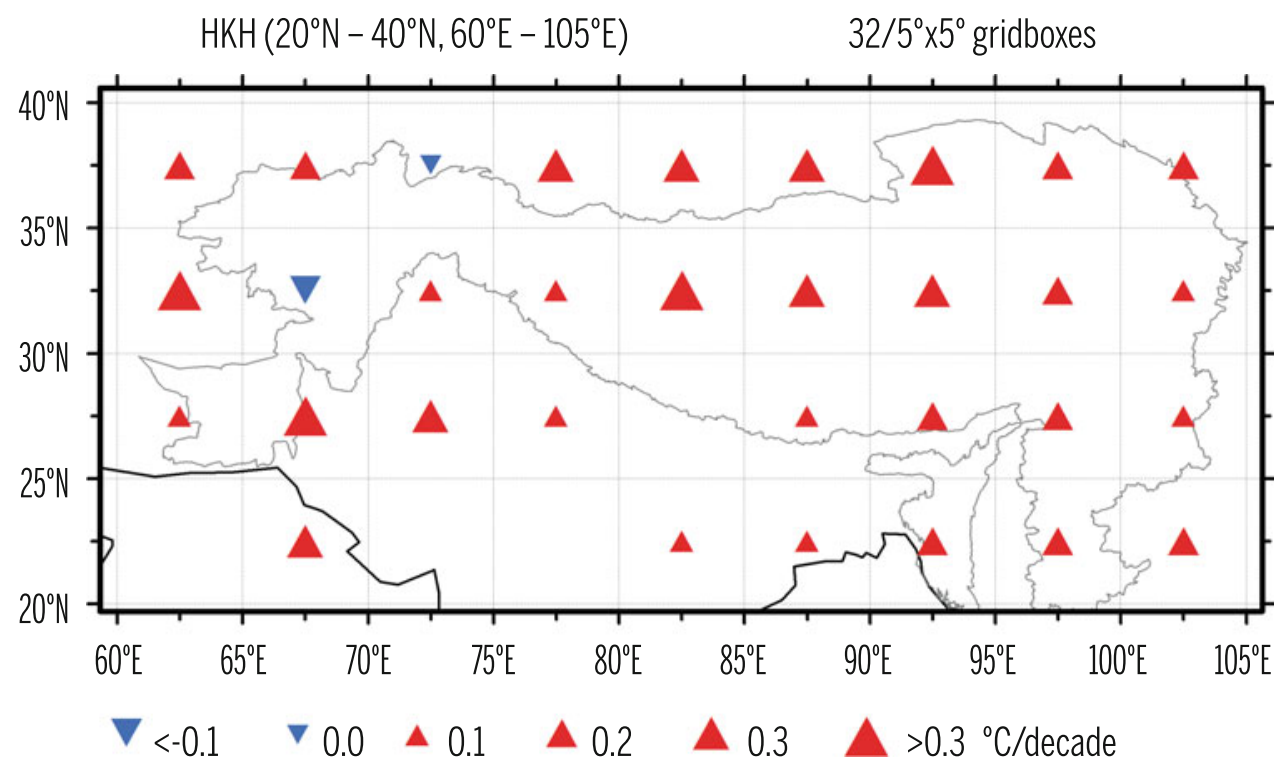

The climate warming was more than $0.20{ }^{\circ} \mathrm{C} /$ decade in the TP and southern Pakistan. This can be seen in Fig. 3.3, which shows the spatial patterns of trends of annual mean temperature during 1901-2014 in the HKH. Overall, a majority of the grids consistently showed annual warming trends. However, the warming rates exhibit large differences. The larger change occurred in the region of the TP and southern Pakistan, with the warming rates higher than $0.20^{\circ}$ C/decade (Ren et al. 2017). The annual warming rates seemed to increase with the rise in altitude, which is similar to what was found in some analyses (e.g., Liu et al. 2009a), supporting the claim that an altitude-dependent warming trend exists in the HKH (Ren et al. 2017). Northern India and the Sichuan Basin of China showed the weakest warming trend, with annual warming rates below $0.10{ }^{\circ} \mathrm{C} / \mathrm{decade}$. Notably, there were fewer available data for the Indian and Nepali regions for the centennial scale analysis, and this may have caused a larger uncertainty in estimating the long-term trend of temperature. A recent study suggests cooling summer temperature over the Karakoram and attributes it to the Karakoram Anomaly (Forsythe et al. 2017).

\subsubsection{Precipitation Did Not Show Clear Trends in the Past Decades}

Annual and cold-season precipitation in the TP has increased over past decades. The increase has been found to be a part of a broader climatic moistening trend observed in western China, including the TP and northwestern China (Qin et al. 2005; Ren et al. 2000, 2005, 2015; You et al. 2015). The increase in annual precipitation in the northeastern TP seems abnormal in terms of the tree ring-based paleo-reconstruction of precipitation in the last 1,000 years (Shao et al. 2010). Over the last four to five decades, the precipitation increase mainly occurred in winter and spring. Increasing trends in winter precipitation have also been reported over a few stations in the Indus basin since the post-1960s, although there was no spatially coherent pattern of long-term precipitation change over the region (Archer and Fowler 2004). Palazzi et al. (2013) summarized the trends in precipitation in the $\mathrm{HKH} /$ Karakoram region, and reported a generally decreasing trend in the Himalaya in summer for the last six decades, but no statistically significant trend was found for winter.

The longer-term (1901-2013) trend of annual precipitation in the entire HKH did not show a positive trend. The authors of this chapter made a special analysis of observed change in precipitation in the region by using Global Land Monthly Precipitation (GLMP) and Global Land Daily Precipitation (GLDP) data sets developed recently by the CMA. Details of the methodology are given in Annex 2. Figure 3.4a displays the regional average annual precipitation standardized anomalies (PSA) and annual precipitation percent anomaly (PPA) from 1901 to 2013 (Zhan et al. 2017). The regional average PSA are fluctuating from one year to another, but the fluctuation became relatively larger from 1930 to 1960, and the overall trend was negative for the HKH. Figure $3.4 \mathrm{~b}$ shows the spatial distribution of the trends of annual PSA during the period 1901-2013. The trend in the TP was not calculated owing to the lack of precipitation records before 1951. The PSA reduced slightly in southwestern China and most parts of northern India, but increased in the northeastern part of West Asia. All the trends were small and not significant at the 0.05 confidence level. The reduction in annual precipitation in northern India seems consistent with the reported weakening of the Indian summer monsoon over the past century (Ren et al. 2017). 


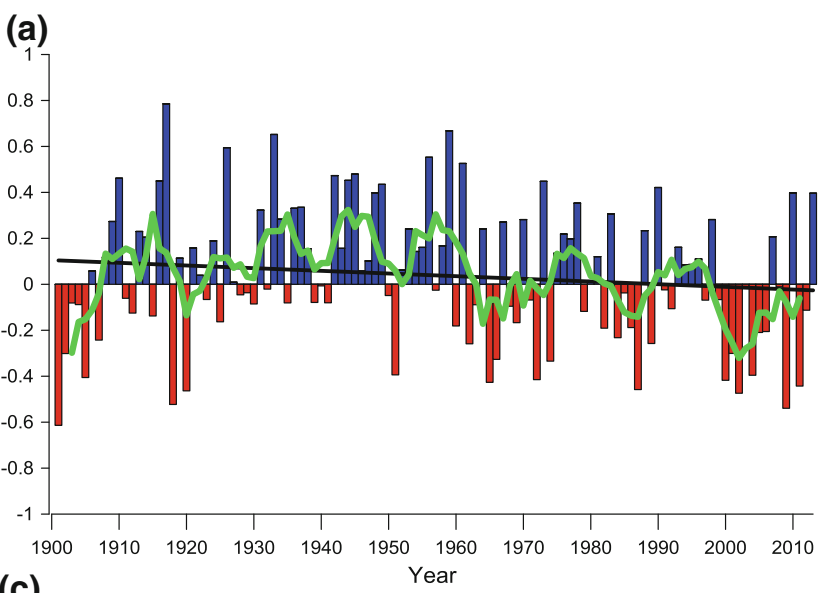

(c)

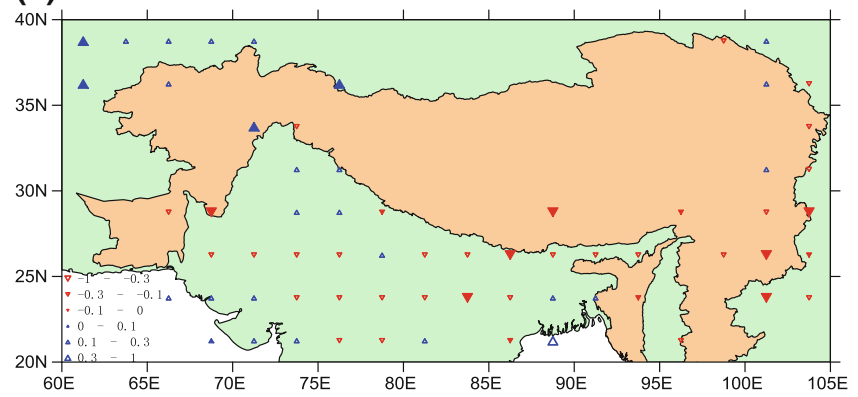

Fig. 3.4 Regional average annual (a) precipitation standardized anomalies (PSA), and (b) precipitation percentage anomaly (PPA) during 1901-2014 in the HKH (with green line denoting five-year moving

There are some limitations to be noted related to the use of standardized indices in a region where the spatial variation in the statistics is enormous. In particular, trends might be weakly related to actual trends in precipitated water.

In the HKH the annual precipitation and the annual mean daily precipitation intensity of roughly the last 60 years have increased. Figure 3.5 shows the regional average annual PSA, PPA, wet-day anomalies (WDA), and the daily precipitation intensity anomalies (DPIA) from 1951 to 2013 for the HKH (Zhan et al. 2017). During this period, the coverage of stations in the TP improved significantly, which is why it exhibited a different trend from the longer time period shown in Fig. 3.5. The regional average PSA and PPA were mostly positive in the 1950s and fluctuant from the 1960s to the1980s, but increased notably after the 1990s, especially for the PPA. The annual PPA had a rapid upward trend for the time period, with the highest value in 2007. Overall, the trend in regional average PPA increased at a rate of about $5 \%$ per decade, which is significant at the 0.01 significance level (Zhan et al. 2017). However, the annual PSA exhibited an insignificant upward trend, despite the fact that it did increase more rapidly from the mid-1980s. As mentioned above, the analysis result of the precipitation change for the region is generally supported by the previous studies, especially for the

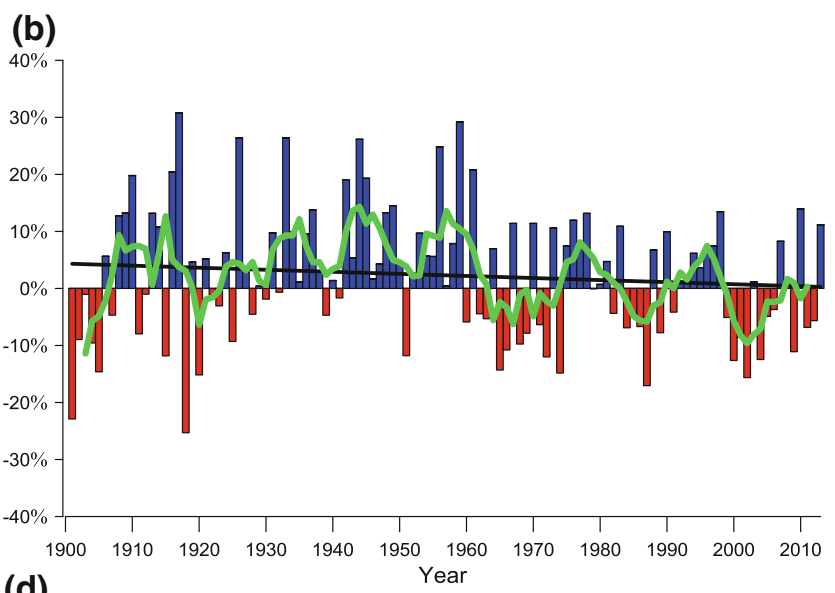

(d)

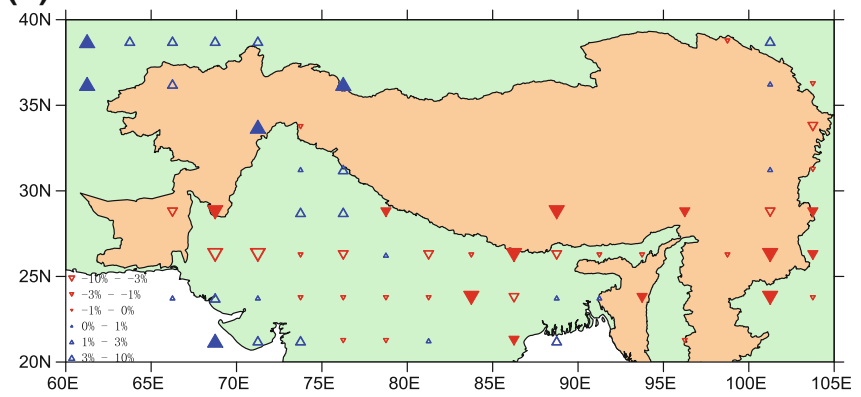

average and black line the linear trend); spatial distribution of linear trends in (c) PSA, and (d) PPA from 1901 to 2014. Source Ren et al. (2017) (Data source CMA GLMP)

TP region and the Indus basin (Archer and Fowler 2004; Ren et al. 2015; You et al. 2015; Zhan et al. 2017).

Wet day anomaly (WDA) or precipitation day anomaly experienced a slight and non-significant decline over the last 53 years. Before 1990, the change in regional average WDA was similar to the PSA. However, the WDA did not change notably after 1990, and even reduced slightly after 2005, reaching its lowest level in 2013 in the HKH as a whole. The change in the whole period showed a slight reduction, but the linear trend was only -0.63 days per decade, which does not pass the 0.05 confidence test (Zhan et al. 2017). This result is different from most of the studies conducted for mainland China, which reported a significant decrease in wet days (Ren et al. 2015).

The region-averaged annual mean daily precipitation intensity anomaly (as indicated by DPIA) decreased slightly from the 1950s to the 1980s, with small values of anomalies. However, the DPIA had an abnormally high value period in the early 1990s, although this dropped after 1994. The change during the whole assessment period exhibited a relatively strong downward trend, however, and the change rate was $-0.075 \mathrm{~mm} / \mathrm{d}$ per decade, which is not significant at the 0.05 level (Zhan et al. 2017). 
(a)

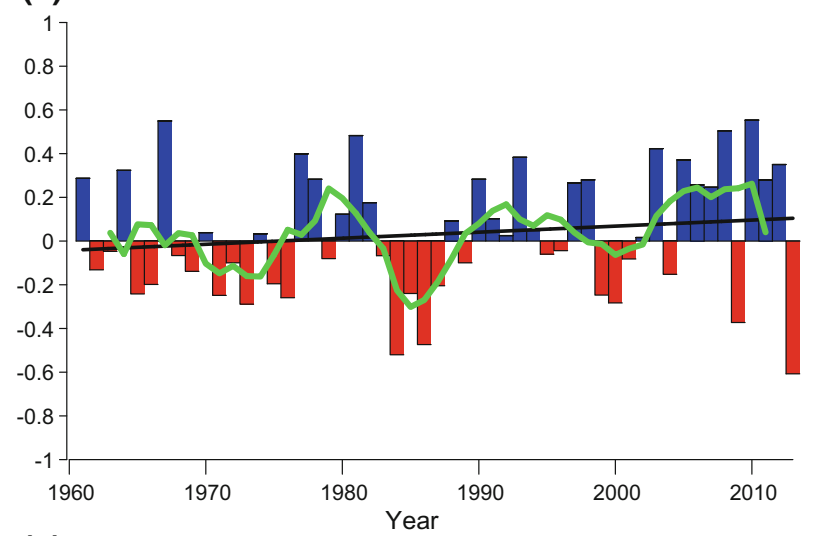

(c)

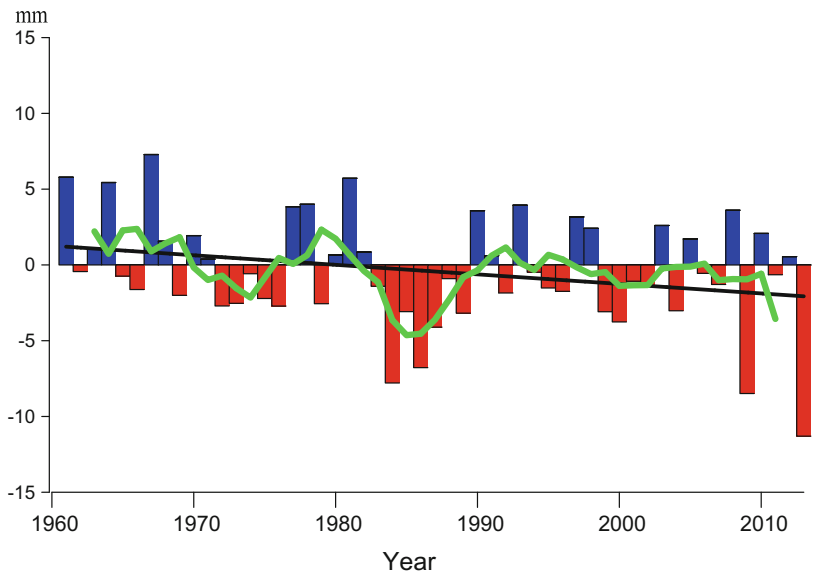

Fig. 3.5 The regional average annual precipitation standardized anomaly (PSA) (a) precipitation percentage anomaly (PPA); (b) wet day anomaly (WDA) (unit: $\mathrm{mm}$ ); (c) and daily precipitation intensity anomaly (DPIA) (unit: mm/day); (d) series over 53 years (1961-2013)

The annual precipitation undergoes a clear shift in the HKH after 1990. Although the WDA had a fluctuating feature and a weak downward trend, the PPA showed a significant increase during slightly more than the last two decades (Zhan et al. 2017). The temporal characteristics of precipitation variation appear to have entered a mode of greater inter-annual variability and more frequent intense rain and less frequent light rain.

The TP region experienced an increase in all three precipitation indicators, especially for PPA and DPIA, but northern India exhibited an increase in PPA and DPIA but a decrease in WDA over the past 53 years (Zhan et al. 2017). Figure 3.6 shows the spatial distribution of the trends of annual PPA, WDA, and DPIA during the period 1961-2013. The positive PPA trends were statistically significant for some of the grids in the TP region, but the annual PPA generally decreased in southwestern China, the northeastern part of India, and the most northeastern part of the $\mathrm{HKH}$ (Ren et al. 2017). The PPA showed a significant increase in a (b)

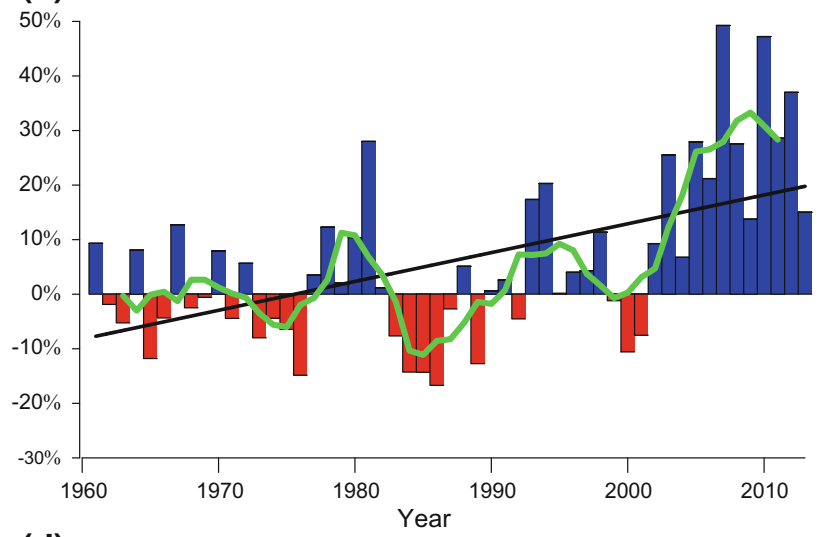

(d)

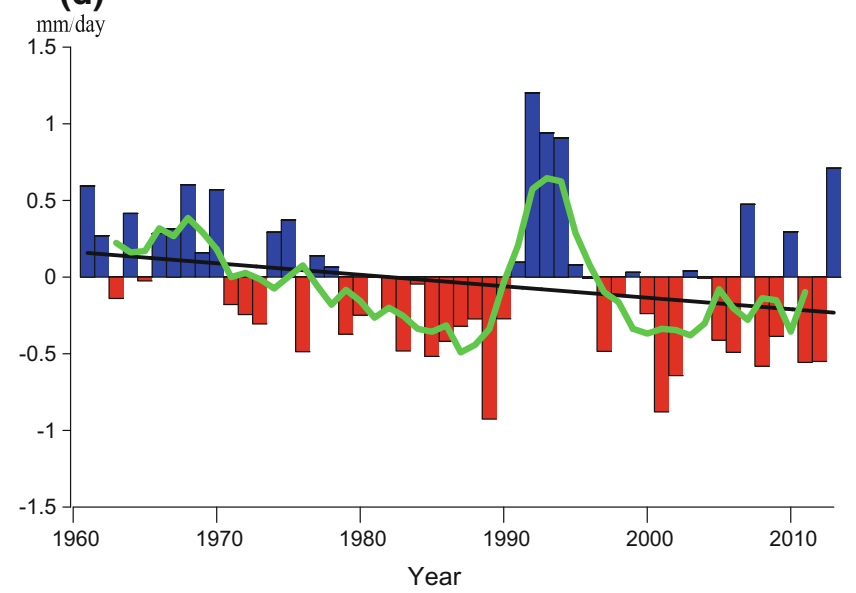

in the Hindu Kush Himalaya. Bar indicates values of PSA, PPA, WDA, and DPIA; green lines are 5-year moving averages, and black lines are linear trends (Data source CMA GLMP; Zhan et al. 2017)

few grids in India, but a significant decrease in some parts of southwestern China and Myanmar.

The WDA had a strong rise in most parts of India and northern TP, but a strong decline in southwestern China and Myanmar. WDA and DPIA exhibited approximately an opposite pattern of long-term trends during the assessment period, especially in southern and southeastern areas of the HKH. In most parts of India and northern TP, for example, the WDA increased notably, but the DPIA decreased remarkably, and southwestern China and Myanmar witnessed a significant decline in WDA and a significant rise in DPIA (Ren et al. 2017).

A more significant increase in annual mean daily precipitation intensity over past decades appeared in the higheraltitude areas, including the TP. Compared to WDA trends, the spatial distribution pattern of the DPIA has a better relationship with the elevation. The annual DPIA increased 
Fig. 3.6 The change trends in annual precipitation percentage anomaly (PPA, unit: \% decade ${ }^{-1}$ ) (a) wet day anomaly (WDA, unit: mm decade ${ }^{-1}$ ); (b) and daily precipitation intensity anomaly (DPIA, unit: $\mathrm{mm} /$ day decade $^{-1}$ ); (c) in the Hindu Kush Himalaya over 53 years (1961-2013). Filled symbols represent statistically significant data at 0.05 confidence level (Data source CMA GLMP; Zhan et al. 2017)
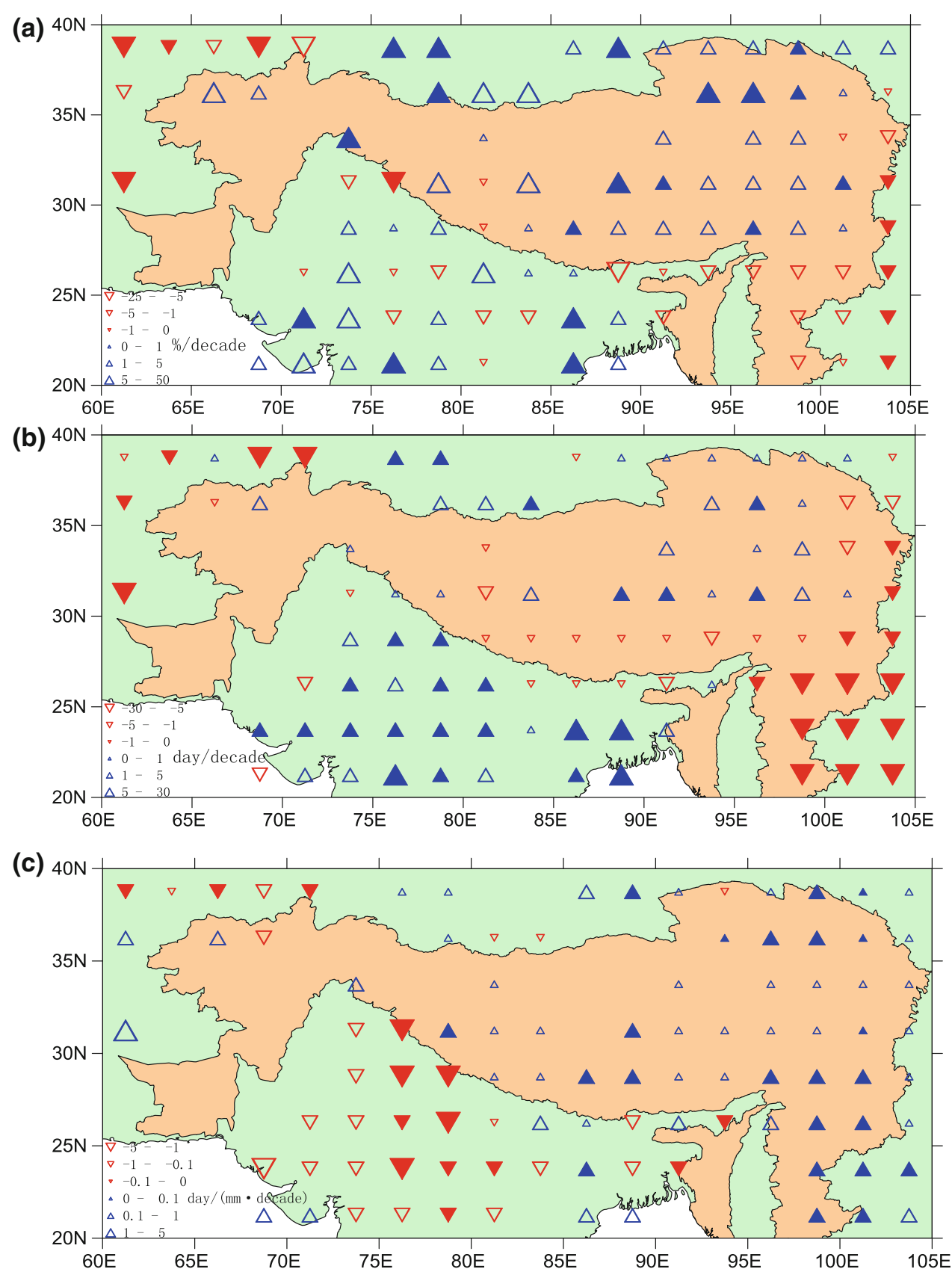

significantly in the highlands region, such as the TP and the Yunnan-Guizhou Plateau, but reduced significantly and consistently in India and probably in other areas south of the Himalaya. It is unclear what caused such a spatial pattern in annual DPIA change in the HKH (Zhan et al. 2017).

\subsubsection{Decreasing Near-Surface Wind Speed, Solar Radiation, and Sunshine Duration Indicated by Scanty Data}

The near-surface wind speed decreased over most areas of the TP region. No wind and solar radiation observation data were available for the whole region, and only the studies for the TP region were assessed in this chapter. During 19802005, both the surface stations and National Centers for Environmental Prediction (NCEP) reanalysis in the TP showed significant decreasing trends, at rates of $-0.24 /$ decade and $-0.13 \mathrm{~m} /$ decade, respectively, especially evident in spring and summer. One of the likely causes of the diminishing wind speed is the asymmetrically decreasing latitudinal surface temperature and pressure gradients over the TP and the surrounding regions, including the Indian Ocean, which may be part of a large-scale atmospheric circulation shift (Ding and Ren 2008; You et al. 2010a). Another major factor affecting the near-surface wind speed 
was urbanization and the increased sheltering effect around the observational grounds (Liu et al. 2009b; Ren and Zhou 2014; Zhang et al. 2009). However, it is unclear to what extent urbanization had affected the near-surface wind speed decline in the HKH as a whole during the past two and half decades. Furthermore, the increase in wind speed after the 2000s to the present may indicate an overall change in atmospheric circulation mode over East Asia (Yang et al. 2014). It is noted that there is some uncertainty in the NCEP data because of their low spatial.

Solar radiation and sunshine duration both declined significantly in the TP region over the past six decades. Surface observational data, reanalyses, and ensemble simulations with the global climate model ECHAM5-HAM show that the mean annual all-sky surface solar radiation (SSR) series in the TP decreased at a rate of $-1.00 \mathrm{Wm}^{-2}$ decade $^{-1}$, primarily in autumn and secondly in summer and winter. Annual clear-sky SSR series exhibit an even stronger decrease of $-2.80 \mathrm{Wm}^{-2}$ decade $^{-1}$, especially during winter and autumn (You et al. 2013b). The temporal evolution of the mean annual sunshine duration series showed a significant increase from 1961 to 1982 at a rate of $49.8 \mathrm{~h} /$ decade, followed by a decrease from 1983 to 2005 at a rate of $-65.1 \mathrm{~h} /$ decade, with an overall significant decrease at a rate of -20.6 h/decade during the whole of the 1961-2005 period; this was due mainly to the decline in summer and spring seasons. This confirms the evidence that sunshine duration in the TP ranges from brightening to dimming in accordance with sunshine duration trends in the rest of mainland China (Ding and Ren 2008; Ren et al. 2005; You et al. 2010c). Total and low-level cloud amounts in the TP showed contrasting trends during day and night, with decreases during the day but increases (especially low-level cloud) at night (Duan and $\mathrm{Wu} 2006$ ), although at the global level dimming due to aerosols and cloud is reported (e.g., Wild 2012; also see Chap. 10).

\subsubsection{Significant Changes in the Temperature and Precipitation Extremes in Past Decades}

\begin{abstract}
Most parts of the HKH underwent significant long-term changes in frequencies of extreme temperature events over the last decades. In this chapter, assessment of changes in the extreme temperature indices of the TP and the HKH for the period 1961-2014 were mainly based on the CMA global land daily surface air temperature data set. Studies conducted for different parts of the HKH showed a generally significant change in the various extreme temperature indices, with the minimum-temperature-related indices witnessing a significant rise and the maximum-temperature-related
\end{abstract}

indices a significant decline over the last decades (Choi et al. 2009; Qian et al. 2007; Ren et al. 2012; Zhai et al. 1999, 2005; Zhou and Ren 2011).

Almost all the extreme temperature indices in the TP region showed statistically significant trends over the past half century. During the period 1961-2014, temperature extremes in the TP showed patterns consistent with warming, with a large proportion of stations showing statistically significant upward or downward trends for all of the temperature indices analyzed (Sun et al. 2017b). Stations in the northwestern, southwestern, and southeastern part of the TP showed greater trends. Overall, the incidence of extreme cold days and nights in the TP decreased by -0.85 and $-2.38 \mathrm{~d} / \mathrm{decade}$, respectively. Over the same period, the incidence of extreme warm days and nights increased by 1.26 and $2.54 \mathrm{~d} /$ decade, respectively. The number of frost days (FD) and ice days decreased significantly at the rates of -4.32 and -2.46 $\mathrm{d} /$ decade, respectively. The length of the growing season has statistically increased by $4.25 \mathrm{~d} /$ decade. The annual mean DTR showed a statistically decreasing trend at a rate of -0.20 ${ }^{\circ} \mathrm{C} /$ decade. The extreme temperature indices also exhibited statistically significant increasing trends. In general, minimum temperature indices showed greater warming trends in comparison to maximum temperature indices (Sun et al. 2017b; You et al. 2008a; Zhou and Ren 2011).

Extreme cold events significantly decreased and extreme warm events significantly increased over the whole $\mathrm{HKH}$ during the past six decades. Annual mean anomaly time series of the percentile-based (Fig. 3.7a-d) and absolute (Fig. 3.7e-h) temperature extreme indices since 1961 for the whole HKH, based on the CMA GLSAT data set, were calculated for this chapter (Fig. 3.4; Sun et al. 2017b). The trends were calculated only for the grid boxes with at least 40 years of data during the study period, with the last year of the data series no earlier than 2000 (Alexander et al. 2006). Table 3.2 also shows the decadal trend values for extreme indices of the region for the period 1961-2014. Although the percentile-based temperature indices were calculated in percentages, the units were converted into days for ease of understanding, as suggested by Alexander et al. (2006). As in the TP region, the extreme cold events significantly decreased for the whole HKH during the past six decades (Fig. 3.7a, b), while the extreme warm events significantly increased (Fig. 3.7c, d). However, the trends in warm events were larger in magnitude than cold events (Table 3.2), and there was a dramatic increase since the mid-1980s, especially for warm nights (Tn90p). Moreover, the trends of the extreme events related to minimum temperature were greater in magnitude than those related to maximum temperature. Similar results were found in the Koshi Basin by Rajbhandari et al. (2017). 

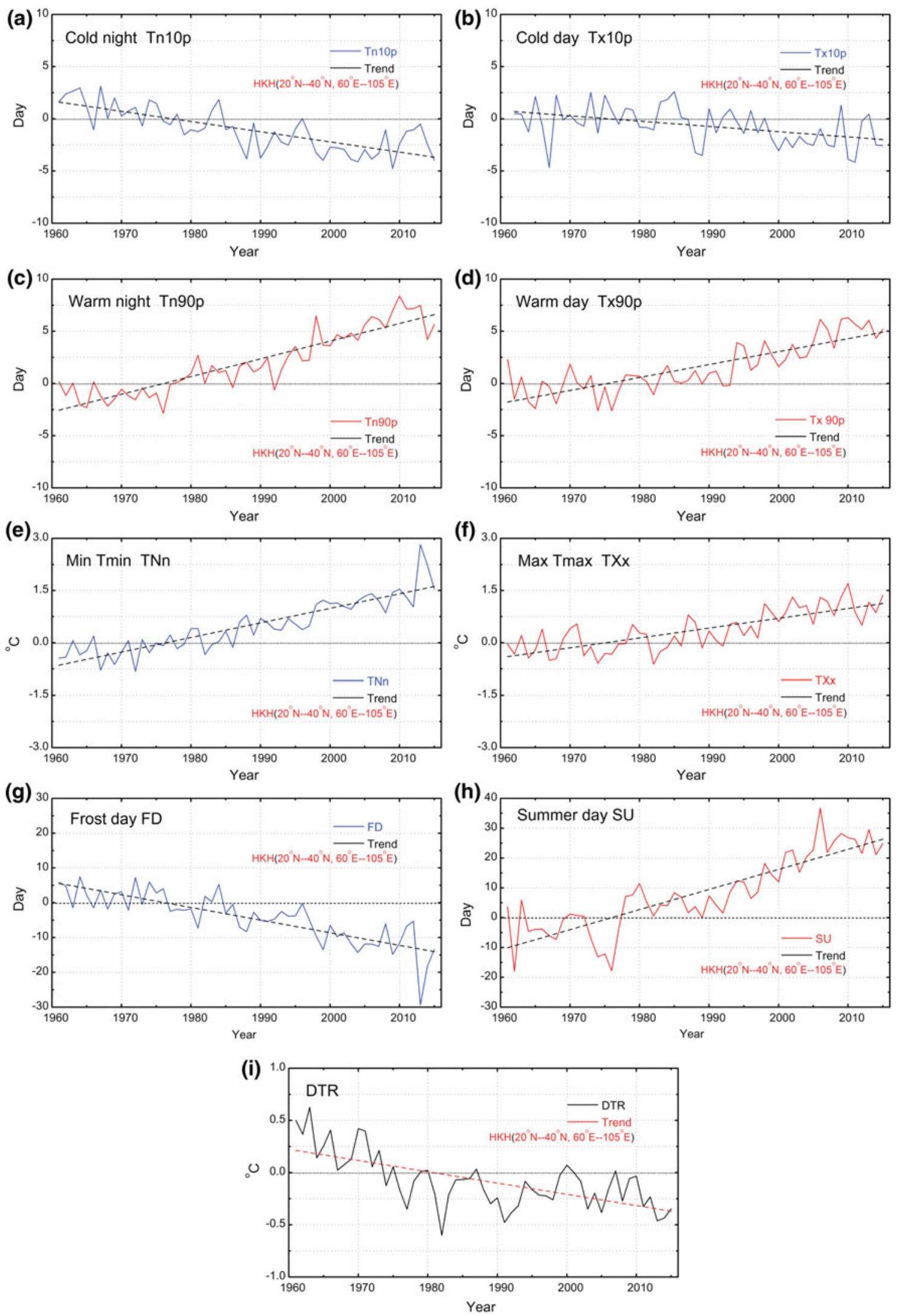

Fig. 3.7 Annual mean anomaly series of extreme temperature indices of the Hindu Kush Himalaya (HKH) for 1961-2014 for (a) cold nights (TN10p); (b) cold days (TX10p); (c) warm nights (TN90p); (d) warm days (TX90p); (e) monthly maximum value of daily maximum temperature (TXx); (f) monthly minimum value of daily minimum temperature (TNn); (g) frost days (FD); (h) summer days (SU); and (i) diurnal temperature range (DTR) (relative to 1961-90 mean values). The trends are calculated only for the grid boxes with sufficient data, as explained in the text (Data source CMA GLASAT; Sun et al. 2017b) 
Table 3.2 Trends of percentile-based and absolute extreme temperature indices of the Hindu Kush Himalaya between 1961 and 2014

\begin{tabular}{l|l|l|r}
\hline Index & ID & Unit & Trend \\
\hline Cold night & TN10p & day/decade & $-0.977^{*}$ \\
\hline Cold day & TX10p & day/decade & $-0.511^{*}$ \\
\hline Warm night & TN90p & day/decade & $1.695^{*}$ \\
\hline Warm day & TX90p & day/decade & $1.239^{*}$ \\
\hline Max Tmax & TXx & ${ }^{\circ}$ C/decade & $0.282^{*}$ \\
\hline Min Tmin & TNn & ${ }^{\circ}$ C/decade & $0.419^{*}$ \\
\hline Frost day & FD & day/decade & $-3.636^{*}$ \\
\hline Summer day & SU & day/decade & $6.741^{*}$ \\
\hline Diurnal temperature range & DTR & ${ }^{\circ}$ C/decade & $-0.108^{*}$
\end{tabular}

(Data source CMA GLSAT; Sun et al. 2017a)

*Statistically significant at the 0.05 confidence level

Extreme values and frequencies of the absolute temperature-based indices ${ }^{9}$ also experienced a generally significant change in the HKH during the past six decades. For the temperature indices (Fig. 3.7e-h), both extreme values of the highest Tmax (TXx) and the lowest Tmin (TNn) showed increasing trends in the $\mathrm{HKH}$, and the rising rate of TNn was more than twice that of TXx (Sun et al. 2017b; Table 3.2). However, the rising rate of TNn was dominated by the very large positive anomalies after the 1980s. The summer day (SU) frequency also increased, and the rising rate reached 6.74 day/decade, which is related to the dramatic positive anomalies after 1990. During 1989 and 1998 , SU increased by about 20 days, which is far more than the average rising rate. Annual FD frequency decreased, with a change rate of -3.63 day/decade. In the HKH as a whole, the annual mean DTR anomaly series showed a significantly decreasing trend before the 1980s and a slight increase after the mid-1980s. The overall decline was mainly a result of the much larger rate in annual mean Tmin increase than of annual mean Tmax (Sun et al. 2017b).

Extreme cold events significantly decreased in most parts of the eastern HKH, especially in southwestern China and TP, while extreme warm events increased over the whole HKH. Figure 3.8 shows the spatial distribution of linear trends of extreme temperature indicators for every grid in the HKH. The cold nights (TN10p) and cold days (TX10p) decreased significantly in most parts of the eastern HKH and showed an upward trend in a few of the gridboxes of the western HKH. The warm nights and warm days (TN90p and TX90p) increased significantly in most parts of the HKH, especially in its western part. The Karakoram, in

\footnotetext{
${ }^{9}$ The extreme temperature indices used in this chapter are based on Expert Team on Climate Change Detection and Indices (ETCCDI). For more information on the indices refer to http://www.climdex.org/ indices.html.
}

northwestern Pakistan, is anomalous for its cold nights (TN10p) and cold days (TX10p) (Sun et al. 2017b).

Extreme absolute temperature indices also experienced a generally significant change in the HKH. FD showed significant decreasing trends in most parts of northern India and the TP, and SU showed a significant increase between $60^{\circ} \mathrm{E}$ and $80^{\circ} \mathrm{E}$. The highest Tmax/Min Tmin (TXx/TNn) showed increases over the whole HKH, but the lowest Tmin showed a larger trend of increase in the TP region than did the highest Tmax. Along the Himalaya the DTR had an increasing trend, while most of the other regions showed a significant decrease, with the downward trend especially large in the TP region (Sun et al. 2017b).

Previous studies identified a clear change in extreme precipitation events in the $\mathrm{HKH}$ in recent periods. Western China, including the TP region, experienced a major change in extreme precipitation events over the past five decades, as reported in many studies (e.g., Ren et al. 2012; You et al. 2015), consistent with the increase in annual total precipitation during the same period. Some stations over the western Himalaya and the Karakoram region have also shown a significant increase in the number of wet days and extreme rain events during the past few decades (Choi et al. 2009; Klein Tank et al. 2006). In the eastern Himalaya, though, the total amount of precipitation did not change much, and the number of rainy days decreased, which meant a higher amount of rainfall in a short period of time. This torrential rain may cause flash floods and landslides in the eastern Himalaya and hilly regions (Syed and Al Amin 2016)

There has been remarkable change in both the light and intense precipitation since 1961, with annual intense precipitation days (frequency) and annual intense precipitation intensity experiencing increasing trends. Figure 3.9 displays the regional average annual amount, and day and annual intensity anomalies, for the percentile-based light (below the 50th percentile), moderate (between the 50th and 90th percentiles), and intense (beyond the 90th percentile) precipitation in the HKH over the period 1961-2013 (Zhan et al. 2017). Table 3.3 shows the linear trends of the annual amount, days, and intensity of the light, moderate, and intense precipitation, and the test results of the significance. The significant increase in annual intense precipitation amount, days, and intensity ( $5.28 \mathrm{~mm}$ per decade, 0.14 day per decade, and $0.39 \mathrm{~mm} /$ day per decade, respectively), and the significant decline in annual light precipitation days and intensity ( -0.80 day per decade and $-0.02 \mathrm{~mm} /$ day per decade, respectively), are notable. No detectable change appears for the moderate precipitation amount, frequency, and intensity over the assessment period (Fig. 3.9). The 
Fig. 3.8 The change trends of extreme temperature indices of the Hindu Kush Himalaya for 1961-2014 for (a) cold nights, (b) cold days, (c) warm nights, (d) warm days, (e) frost day, (f) summer day, (g) monthly maximum value of daily maximum temperature,

(h) monthly minimum value of daily minimum temperature, and (i) diurnal temperature range (relative to 1961-90 mean values) (Data source CMA GLSAT; Sun et al. 2017b) (a) Cold night, TN10p (day/decade)

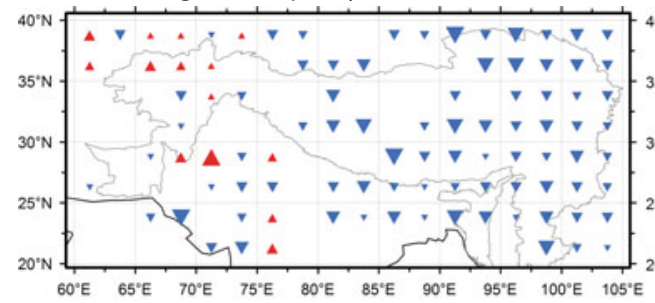

(c) Warm night, TN90p (day/decade)

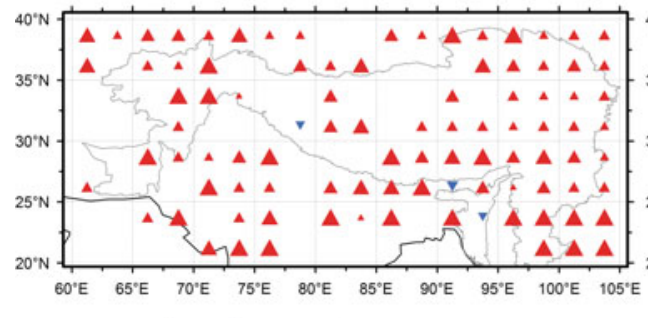

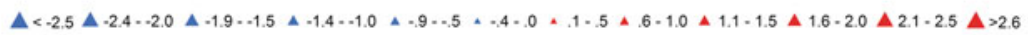

(e) Frost days, FD (day/decade)

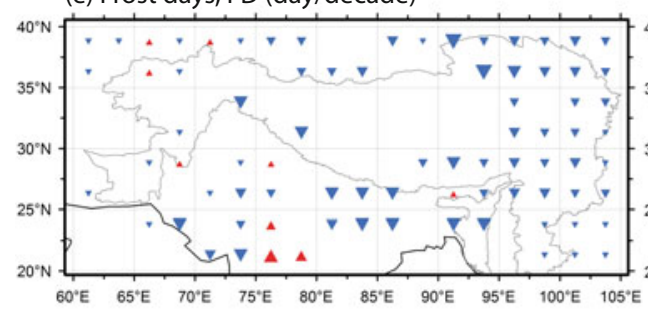

(b) Cold day, TX10p (day/decade)

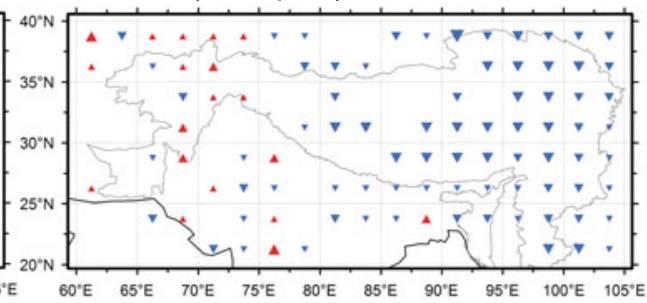

(d) Warm day, TX90p (day/decade)

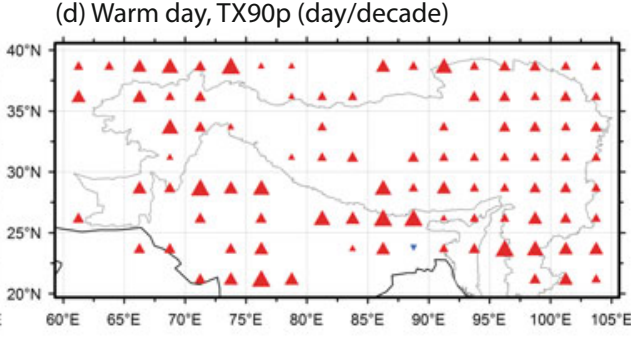

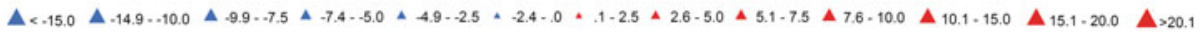

(g) Max Tmax, TXx (day/decade)

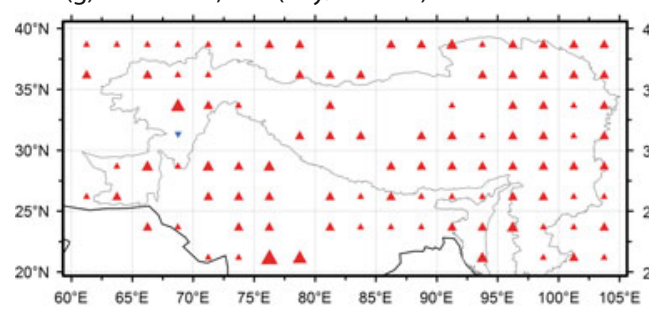

(h) Min Tmin, $\mathrm{TNn}\left({ }^{\circ} \mathrm{C} /\right.$ decade)

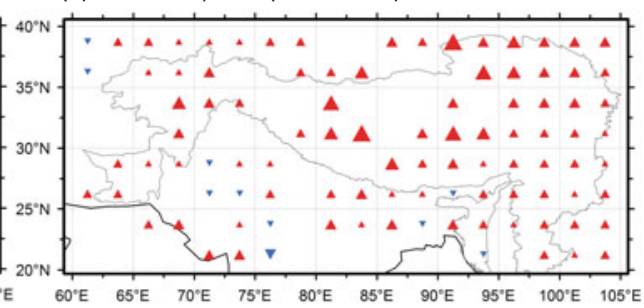

(i) Diurnal temperature range, DTR $\left({ }^{\circ} \mathrm{C} /\right.$ decade)

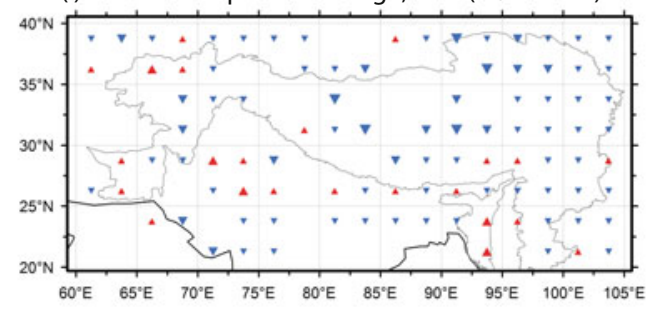

$\boldsymbol{\Delta}<-1.3 \Delta-1.2-1.0 \Delta-.9--.8 \Delta-.7-.5 \Delta-.4--3+-.2-.0+.1-.3 \Delta, 4-.5 \Delta .6-.8 \Delta, 9-1.0 \Delta \mathbf{\Delta} 1.1-1.3 \Delta>1.4$ definition of light, moderate, and intense rainfall is given in Annex 2, Table 3.11.

Light precipitation frequency and intensity significantly decreased in the HKH over the past 53 years, but its amount had an insignificant upward trend (Table 3.3). The regional average annual light precipitation amount increased over the period 1961-2013, but the change rate was only $0.482 \mathrm{~mm}$ per decade, which did not pass the significance test at the 0.05 confidence level. The annual light precipitation days and intensity reduced significantly over the same period, however, with the change rate being 

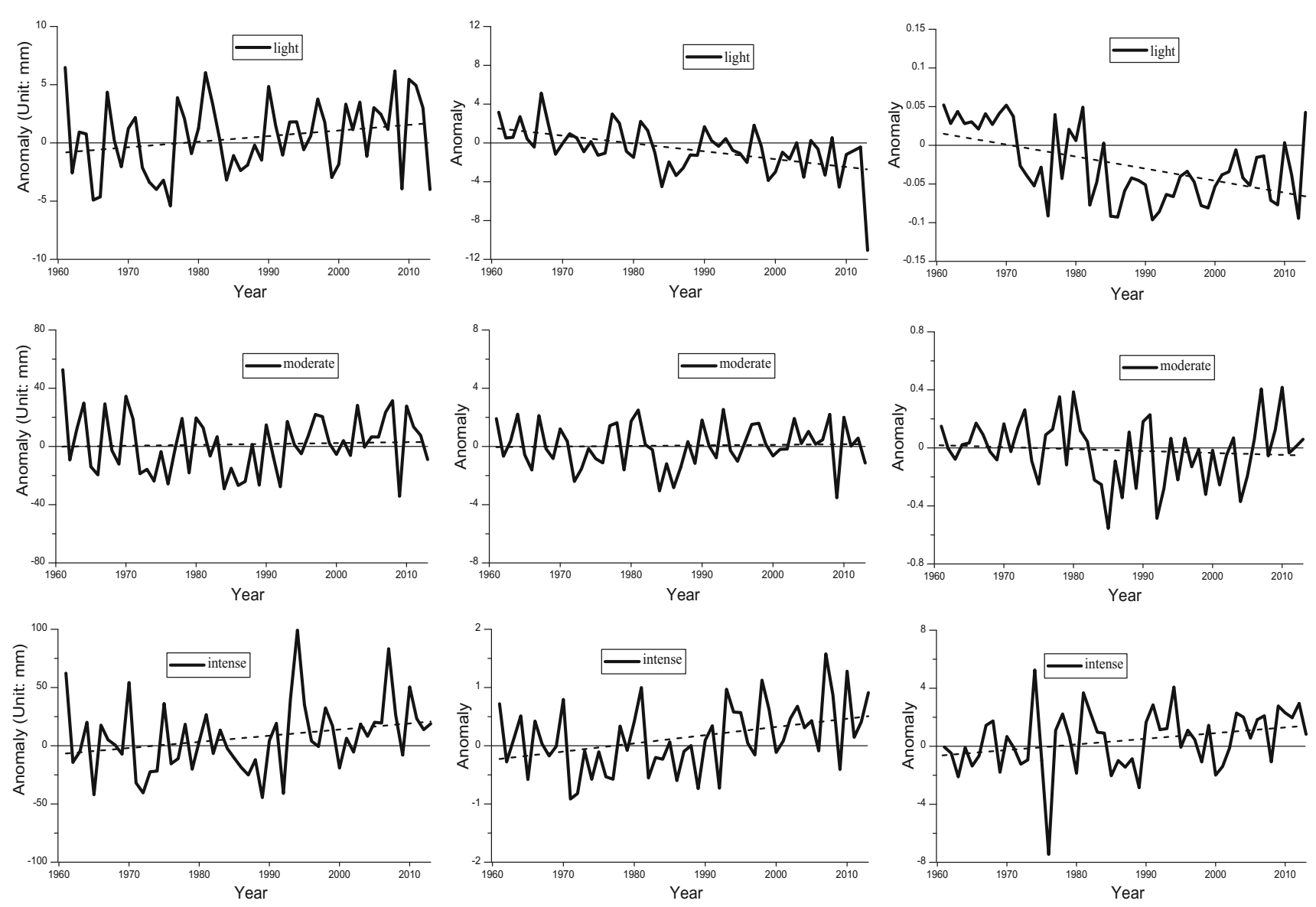

Fig. 3.9 The regional average anomaly time series of extreme precipitation indices for annual amount (unit: $\mathrm{mm}$ ) (left); days (unit: day) (central); and intensity (unit: $\mathrm{mm} /$ day) (right) of light (above),

moderate (middle), and intense (below) precipitation over the last 53 years (1961-2013) in the Hindu Kush Himalaya. Dashed lines represent linear trends (Data source CMA GLDP; Zhan et al. 2017)

Table 3.3 Linear trends of different categories of precipitation for the period 1961-2013 in the Hindu Kush Himalaya

\begin{tabular}{l|c|c|c|c}
\hline & Light & Moderate & Intense & Total \\
\hline PAA (mm decade - 1) & 0.482 & 0.623 & $5.284^{*}$ & 6.389 \\
\hline WDA (day decade - 1) & $-0.800^{* *}$ & 0.040 & $0.141^{* *}$ & -0.629 \\
\hline $\begin{array}{l}\text { DPIA } \\
\text { (mm/day decade - 1) }\end{array}$ & $-0.016^{* *}$ & -0.013 & $0.391^{*}$ & -0.075 \\
\hline
\end{tabular}

(Data source CMA GLDP; Zhan et al. 2017)

${ }^{*}$ Statistically significant at the 0.05 confidence level. ${ }^{* *}$ Statistically significant at the 0.01 confidence level. PAA precipitation amount anomaly; WDA wet day anomaly; DPIA daily precipitation intensity anomaly

-0.81 day/decade and $-0.02 \mathrm{~mm} / \mathrm{d}$ per decade, respectively; both were statistically significant at the 0.01 confidence level (Table 3.3). The change may be attributed to the decreasing amplitude of fluctuation in the frequency and intensity after 1985 (Fig. 3.9) with the linear trend of the amount opposite to those of the frequency and intensity. The regional average annual moderate precipitation amount and days increased slightly, while the intensity decreased slightly, but all the changes were non-significant (Zhan et al. 2017).
The regional average annual amount, frequency, and intensity of intense precipitation increased significantly over the period 1961-2013 (Table 3.3). The linear trends for the regional average annual intense precipitation amount, intense precipitation days, and intense precipitation intensity were $\quad 5.48 \mathrm{~mm} /$ decade, 0.14 day/decade, and $0.39 \mathrm{~mm} /$ day/decade, respectively. All trends passed the 0.05 significance test, with the increase in intense precipitation days passing the 0.01 significance test. The increasing trends of annual intense precipitation frequency and intensity in the HKH were approximately consistent with those found in other mid- to high-latitude regions. The annual total precipitation amount in the $\mathrm{HKH}$ increased over the 53 years, which was not significant at the 0.05 level, but the annual total precipitation days and intensity exhibited a very weak declining trend (Table 3.3; Zhan et al. 2017).

The annual amount and frequency of light precipitation increased significantly in most parts of India and the northwestern TP. Figure 3.10 shows the spatial distribution of linear trends of standardized precipitation indicators for 
(a1)

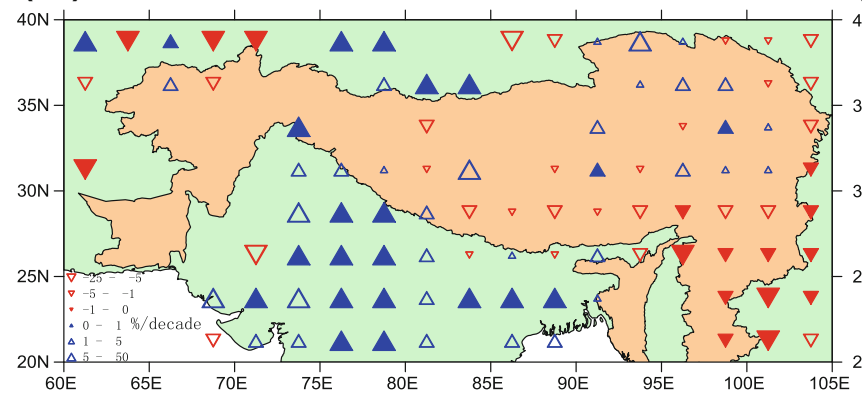

(b1)

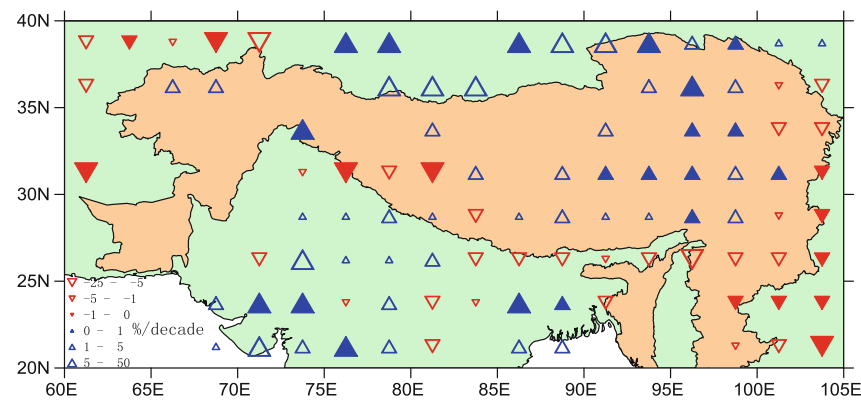

(c1)

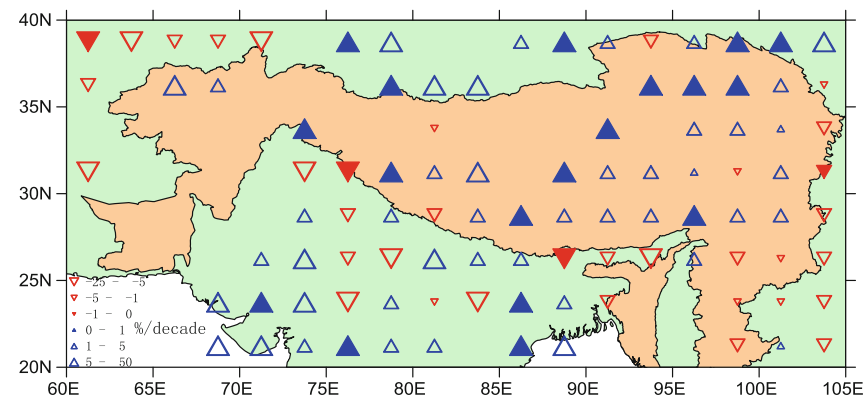

Fig. 3.10 The change trends of annual precipitation amount percent anomaly (PPA) (1/left) and annual precipitation day anomaly (WDA) (2/right) for light (a) moderate; (b) and intense; (c) precipitation

every grid in the HKH. The annual PSA of light precipitation increased significantly in most parts of India, and also in the northwestern TP. Southwestern China had a significantly downward trend, but it did not change much in northeastern West Asia. The annual WDA of light precipitation also increased significantly in most parts of India and in the northwestern TP, and it significantly reduced in the southeastern part of the TP and southwestern China (Zhan et al. 2017).

The amount and frequency of intense precipitation and moderate precipitation mostly increased significantly in the $T P$, but showed heterogeneous change in the other areas of the HKH (Fig. 3.10). The spatial patterns in linear trends of the annual moderate and intense precipitation indicators were similar, and they mostly increased significantly in the (a2)

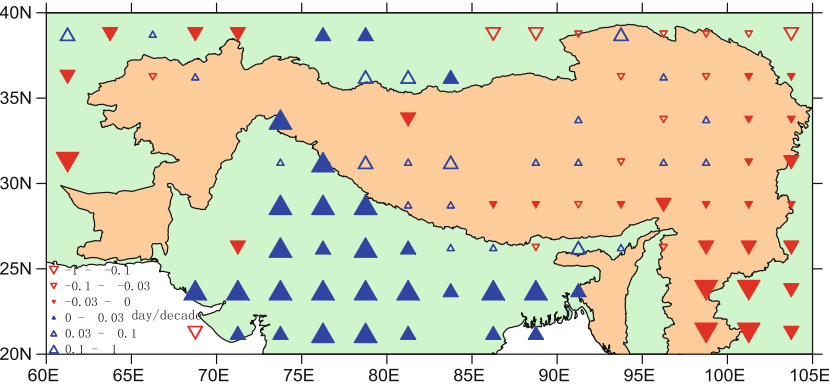

(b2)

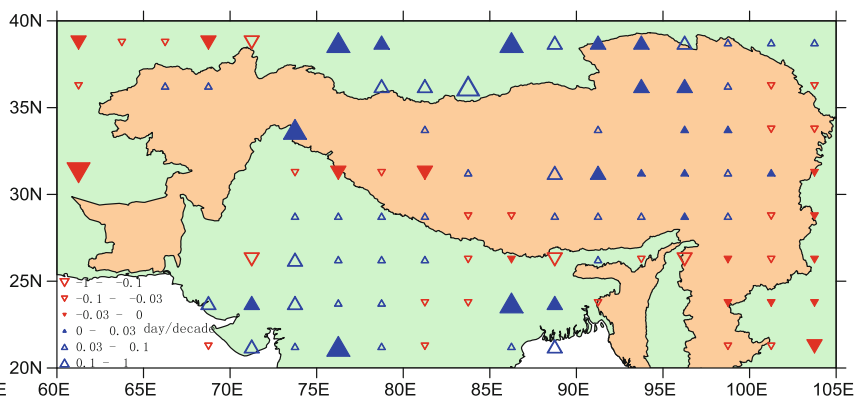

(c2)

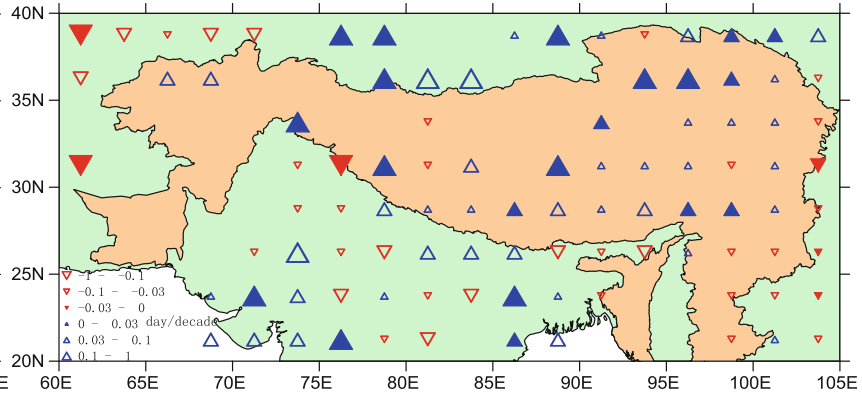

over the last 53 years (1961-2013) in the Hindu Kush Himalaya. Filled symbols represent statistically significant trends at the 0.05 confidence level (Data source CMA GLDP; Zhan et al. 2017)

$\mathrm{TP}$, especially in areas north of $30^{\circ} \mathrm{N}$, and decreased in southwestern China, northern South-east Asia, and northeastern West Asia. In particular, both intense precipitation amount and days increased in the TP, with those trends in most grids being significant. The annual intense precipitation amount and days in the TP increased (Fig. 3.10; Zhan et al. 2017).

\subsubsection{Progressively Greater Warming with Elevation}

The elevation-dependent warming (EDW) phenomenon in the $\mathrm{HKH}$, particularly in the TP and its surrounding regions, has been reported by many research groups (Duan and Xiao 2015; Guo et al. 2016; Liu and Chen 2000; 
Mountain Research Initiative EDW Working Group 2015; Pepin et al. 2015; Shrestha 2008b; Shrestha et al. 1999; Sun et al. 2017b; Wang et al. 2014, 2016; Yan and Liu 2014; Yan et al. 2016; You et al. 2016) but the association of warming trends with elevations is still an unresolved question. The EDW in the HKH seems clear, as seen in Fig. 3.3. The grids with annual mean warming larger than $0.2^{\circ}$ C/decade during the period 1901-2014 are mostly distributed in the TP region, but they also occur in low-lying southern Pakistan and western India. The lowest warming or even cooling is seen in eastern Afghanistan and the Karakoram Mountains.

In the TP and its surrounding regions, however, the EDW seems clearer, as reported in previous studies, though there is still some debate on this (Duan and Xiao 2015; Guo et al. 2016; Mountain Research Initiative EDW Working Group 2015; Pepin et al. 2015; Yan and Liu 2014; Yan et al. 2016; You et al. 2016). For example, Yan and Liu (2014) analysed the change trends of mean, maximum, and minimum temperatures over the TP and reported a warming trend of $0.316^{\circ}$ $\mathrm{C} /$ decade in annual mean temperature over the TP for the period 1961-2012, based on data from 73 stations above the elevation of $2,000 \mathrm{~m}$. Liu and Chen (2000) found higher warming at high elevations compared to low elevation regions in the TP. This result was later confirmed by numerical experiments (Chen et al. 2003), suggesting that such a phenomenon may continue in future climate change scenarios (Liu et al. 2009a). The varied conclusions are probably because of the differing data sets, periods of analysis, and lowland stations used for comparison (Kang et al. 2010). Using temperature trend magnitudes at 71 surface stations with elevations above 2,000 m a.s.l. in the eastern and central TP, for example, You et al. (2008b) failed to find an elevation dependency in the trends of temperature extremes in the eastern and central TP; nor did Ding and Zhang (2008) find the EDW phenomenon by analysing the change of temperature for mainland China as a whole. Wang et al. (2014, 2016) and You et al. (2017) indicate that analysis based on simple linear trend may not a good tool for the analysis of EDW on either the global scale or regional scale, probably because the warming in a high-elevation region is related not only to altitude but also to latitude.

Recent study shows that change in extreme cold events in the $\mathrm{HKH}$ in the last decades appear to be more sensitive to elevation, with cold nights and cold days decreasing with elevation, and the change in warm extremes showed no detectable relationship with elevation (Sun et al. 2017b). During 1961-2015, FD and minimum Tmin also had a good relationship with elevation, and the trend in FD decreased with an increase in elevation while the trend in minimum Tmin increased with an increase in elevation (Ren and Shrestha 2017; Sun et al. 2017b). This shows that the EDW in the HKH over the last decades may have been represented by the dependence of minimum temperature on elevation.

The exact driving mechanisms responsible for $\mathrm{EDW}$ are unclear and need further investigation. Yan et al. (2016) concentrated on EDW mechanisms over the TP, and concluded that the increase in surface net radiation resulted in EDW over the TP. One possible reason for the continued (and accelerated) warming in the TP is the positive feedback associated with a diminishing cryosphere, particularly the snow cover. You et al. (2010b) summarized the factors determining the recent climate warming in the TP: anthropogenic GHG emissions, the snow/ice-albedo feedback, and changes in environmental elements (such as cloud amount, specific humidity, Asian brown clouds, and land use changes). Furthermore, although it is currently difficult to determine the relative contribution of each of these factors, the anthropogenic GHG emission is regarded as the main cause of the climate warming in the $\mathrm{HKH}$, and impacts there are probably larger than in the rest of the world (Kang et al. 2010; You et al. 2010b). The HKH has the largest extent of cryosphere (glaciers and ice caps, snow, river and lake ice, and frozen ground) outside the polar regions (Kang et al. 2010). The glaciers have exhibited a rapid shrinkage in both length and area in recent decades (Yao et al. 2012b), coinciding with the rapid warming in the region (see Chap. 7).

\subsection{Climate Models Project Increases in HKH Temperature and Precipitation in the 21 st Century}

The potential impact of climate change on the various resources of the $\mathrm{HKH}$ is of great concern (Ericsson et al. 2009) as a large population across the region relies on monsoon rainfall. Hence, it is necessary to understand the nature of future climate change. Many climate modelling groups have performed future simulations under IPCC's emission scenarios (IPCC 2000; Meinhausen et al. 2011; Panday et al. 2014; Van Vuuren et al. 2011). With global warming, future rainfall and temperature are likely to change in different ways in various ecological regions (Goswami et al. 2006). The impact of climate change on the cryosphere and hydrological regime of the HKH will be marked, because of sharp altitudinal differences, particularly owing to the EDW phenomenon. Eastern HKH river basins are heavily influenced by monsoon rainfall, whereas in western 
rivers the flow is derived from the melting of snow and glaciers (Immerzeel et al. 2009; Lutz et al. 2014). The changes in temperature and precipitation in the HKH will have serious and far-reaching consequences for climate-dependent sectors such as agriculture, water resources, and health (Shrestha et al. 2015).

\subsubsection{Significant Warming Projected, Greater Than Global Average}

Based on past studies throughout the HKH, temperature is expected to rise (Kulkarni et al. 2013; Kumar et al. 2011; Rajbhandari et al. 2015, 2016). A study carried out at river-basin scale over the eastern HKH showed the greatest warming over high-altitude regions (Rajbhandari et al. 2016). A similar basin-scale study carried out over the western HKH by Rajbhandari et al. (2015) reported temperature progressively warming over the western Himalaya with minimum temperature trend slightly greater than maximum temperature trend. Kulkarni et al. (2013) reported that significant warming is expected throughout the $\mathrm{HKH}$ towards the end of the present century. Overall temperature across the mountainous $\mathrm{HKH}$ will increase by about $1-2{ }^{\circ} \mathrm{C}$ (in places by up to $4-5^{\circ} \mathrm{C}$ ) by 2050 (Shrestha et al. 2015).

The HKH region is projected to warm over the 21st century. This is based on the analyses we performed for this chapter on future projections of annual mean surface temperature change relative to 1976-2005, based on a CMIP5 multi-model ensemble mean (a subset of 25 models listed in Table 3.4). These projected changes in surface temperature are higher than the likely ranges reported for global and South Asian regions by the recent IPCC assessment. They indicate continuous warming over the entire $\mathrm{HKH}$ in the 21 st century (Fig. 3.11a). The projected temperature change is $2.5 \pm 1.5^{\circ}$ $\mathrm{C}$ for the moderate scenario corresponding to RCP4.5 (Van Vuuren et al. 2011). For the more extreme scenario of $\mathrm{RCP} 8.5$, the projected temperature increase is $5.5 \pm 1.5$ by the end of the 21 st century. The simulation data of the CMIP5 models suggest that the projected changes in the surface mean temperature over the $\mathrm{HKH}$ are larger compared to the global mean change by the end of the 21st century (Fig. 3.11).

For the first time we used projected changes in near-surface air temperature based on high resolution $\left(0.5^{\circ}\right.$ longitude-latitude resolution) dynamically downscaling of $\mathrm{CMIP5}^{10}$ general circulation models
Table 3.4 Coupled Model Intercomparison Project 5 models used for temperature and precipitation projection over the Hindu Kush Himalaya

\begin{tabular}{|c|c|c|c|}
\hline IPCC ID of the model & RCP4.5 & RCP8.5 & Country \\
\hline BCC-CSM1.1 & $*$ & $*$ & China \\
\hline BCC-CSM1.1 M & $*$ & $*$ & China \\
\hline BNU-ESM & $*$ & $*$ & China \\
\hline CanESM2 & $*$ & $*$ & Canada \\
\hline CMCC-CM & $*$ & $*$ & Italy \\
\hline CMCC-CMS & $*$ & $*$ & Italy \\
\hline CSIRO-ACCESS-1 & $*$ & * & Australia \\
\hline CSIRO-ACCESS-3 & $*$ & $*$ & Australia \\
\hline CSIRO-MK36 & $*$ & $*$ & Australia \\
\hline EC-EARTH & $*$ & $*$ & European Union \\
\hline FIO-ESM & $*$ & $*$ & China \\
\hline GFDL-ESM2G & $*$ & * & USA \\
\hline GISS-E2-R & $*$ & $*$ & USA \\
\hline HadGEM2-AO & $*$ & $*$ & South Korea \\
\hline HadGEM2-CC & $*$ & $*$ & UK \\
\hline HadGEM2-ES & $*$ & $*$ & UK \\
\hline INMCM4 & $*$ & $*$ & Russia \\
\hline IPSL-CM5A-LR & $*$ & * & France \\
\hline IPSL-CM5A-MR & $*$ & $*$ & France \\
\hline IPSL-CM5B-LR & $*$ & * & France \\
\hline MIROC5 & $*$ & $*$ & Japan \\
\hline MPI-ESM-LR & * & $*$ & Germany \\
\hline MPI-ESM-MR & $*$ & $*$ & Germany \\
\hline MRI-CGCM3 & $*$ & * & Japan \\
\hline NCAR-CESM1-BGC & $*$ & $*$ & USA \\
\hline NCAR-CESM1-CAM5 & $*$ & $*$ & USA \\
\hline NorESM1-M & $*$ & $*$ & Norway \\
\hline NorESM1-ME & $*$ & $*$ & Norway \\
\hline
\end{tabular}

For details see Annex 3, Table 3.12

(GCM) using regional climate models (RCM). Regional climate projections over South Asia were generated using the models listed in Annex 3, Table 3.12, based on the protocols of the CORDEX ${ }^{11}$ initiative. The CORDEX regional climate models RCM reliably capture the overall increasing trend of surface temperature variations over the South Asian region (Sanjay et al. 2017a). Multi-model ensembles of climate projections over the HKH for the near future (2036-65) and far future (2066-95), based on the CORDEX RCM relative to 1976-2005 (see Annex 3), are shown in Figs. 3.12 and 3.13, respectively. The magnitude

\footnotetext{
${ }^{10} \mathrm{http}: / / \mathrm{cmip}-$ pcmdi.1lnl.gov/cmip5/.
}

${ }^{11} \mathrm{http} / / /$ www.meteo.unican.es/en/projects/CORDEX. 

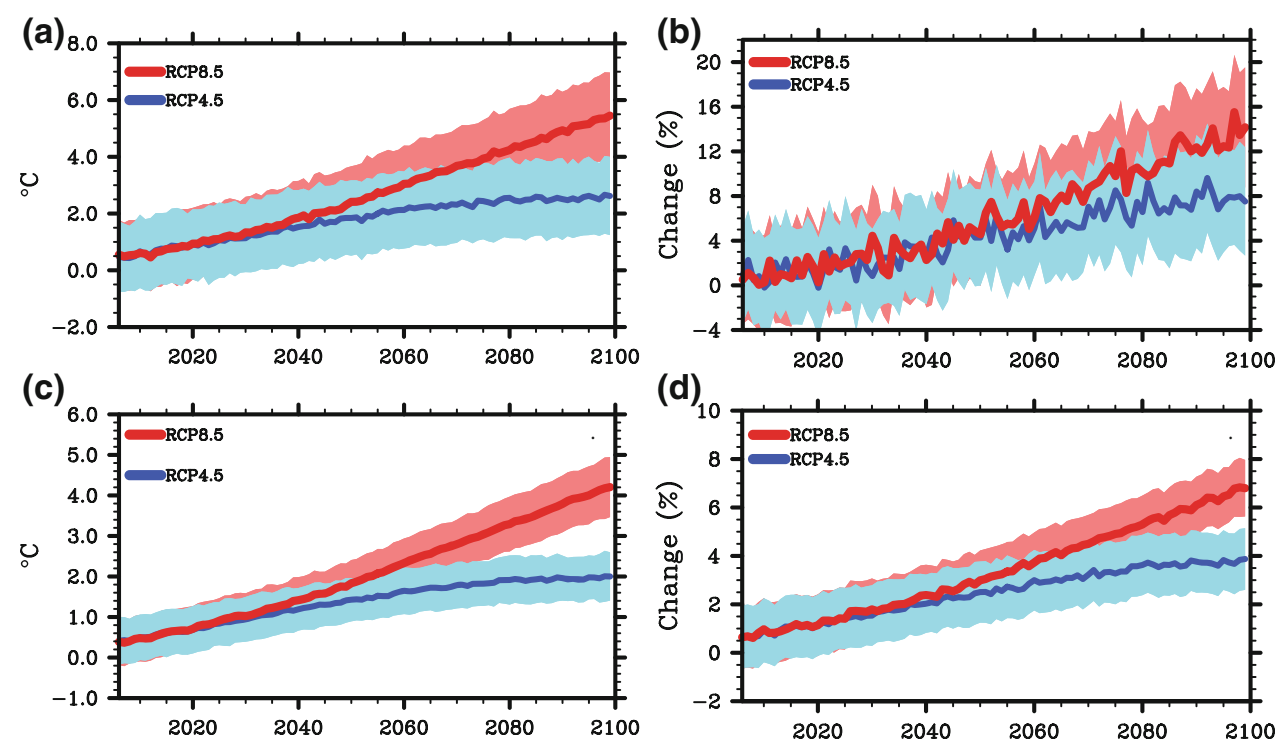

Fig. 3.11 (a) Annual mean surface air temperature change (in ${ }^{\circ} \mathrm{C}$ ) from 2006 to 2100 relative to 1976-2005 averaged over the Hindu Kush Himalaya for RCP4.5 (blue) and RCP8.5 (red) scenarios. The multi-model ensemble mean is shown by a solid line and the colour shading indicates the multi-model ensemble mean \pm one inter-model

of the projected seasonal warming is found to vary with region, season, averaging period, and scenario. The projected warming differs by more than $1{ }^{\circ} \mathrm{C}$ between the eastern and western $\mathrm{HKH}$, with relatively higher values in winter (Sanjay et al. 2017b). The highest warming is projected to be over the central Himalaya for the far-future period with the RCP8.5 scenario (Fig. 3.13f).

The projected temperature changes with RCP4.5 and RCP8.5 scenarios for 2036-65 and 2066-95 relative to 1976-2005 in three HKH subregions (defined by grid cells within each subregion above 2,500 $m$ a.s.l., see Fig. 3.1) suggest that during summer (winter) relatively higher (lower) warming will occur over the hilly regions of the northwestern Himalaya and Karakoram (HKH1) than in the central Himalaya (HKH2) and southeastern Himalaya and TP (HKH3). Table 3.5 presents the seasonal ensemble mean projected changes in near-surface air temperature based on the 13 CORDEX RCM and 10 CMIP5 global climate models (GCM) used to provide initial and lateral boundary conditions for the CORDEX RCM. For the far-future period, the summer season ranges among the three $\mathrm{HKH}$ subregions for the higher resolution CORDEX RCM of 2.2-2.6 ${ }^{\circ} \mathrm{C}$ (RCP4.5) and 4.2-4.9 ${ }^{\circ} \mathrm{C}$ (RCP8.5) are lower than the corresponding ranges for the CMIP5 GCM of 2.5$3.3{ }^{\circ} \mathrm{C}(\mathrm{RCP} 4.5)$ and $4.4-5.7^{\circ} \mathrm{C}(\mathrm{RCP} 8.5)$. While the winter

standard deviation; (b) same as (a) except for precipitation. The precipitation change is expressed as percent/month; (c), (d) same as (a), (b), except showing the global mean change for (c) surface air temperature change (in ${ }^{\circ} \mathrm{C}$ ) and (d) precipitation from 2006 to 2100 relative to $1976-2005$

season temperature change range among the three $\mathrm{HKH}$ subregions in the CORDEX RCM for the RCP4.5 scenario of $3.1-3.3{ }^{\circ} \mathrm{C}$ is also lower than that for the corresponding CMIP5 GCM of $3.0-3.6{ }^{\circ} \mathrm{C}$ for this period, the CORDEX winter range of $5.4-6.0{ }^{\circ} \mathrm{C}$ in the RCP8.5 scenario is higher than the corresponding range for the CMIP5 GCM of 5.1$5.8{ }^{\circ} \mathrm{C}$ for the far-future period. Overall, future projections of surface temperature from the CMIP5 models and CORDEX RCM seem to agree on the overall warming trends over the HKH region, although there are differences in magnitude.

We should note that these seasonal ensemble mean projected changes in near-surface temperature over the three HKH subregions for the near-future and far-future periods are relatively higher than the seasonal global means based on the same subset of CMIP5 GCM (Table 3.6). The summer season global mean projected change for the far-future period is $1.9{ }^{\circ} \mathrm{C}(\mathrm{RCP} 4.5)$ and $3.3{ }^{\circ} \mathrm{C}(\mathrm{RCP} 8.5)$, while for the winter season the global mean projected changes are $2.0^{\circ} \mathrm{C}$ (RCP4.5) and $3.5^{\circ} \mathrm{C}$ (RCP8.5).

A more detailed analysis of future projections over the Tibetan region, based on a larger subset of 24 CMIP5 models (Annex 3), also indicates an increase in temperature over the HKH (Fig. 3.14), with higher magnitudes in the RCP8.5 scenario by the end of the 21 st century. The maximum values are projected in the western part of the Tibetan region. 
(a) T JJAS RCP4.5 Near-future change

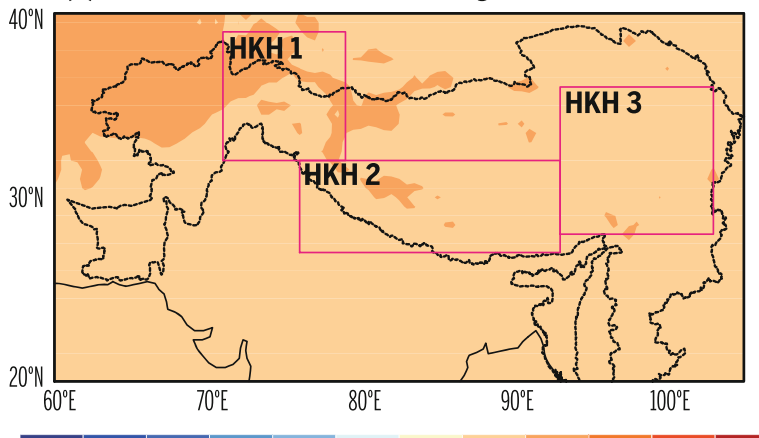

$\begin{array}{lllllllllll}-5 & -4 & -3 & -2 & -1 & 0 & 1 & 2 & 3 & 4 & 5 C\end{array}$

(c) P JJAS RCP4.5 Near-future change

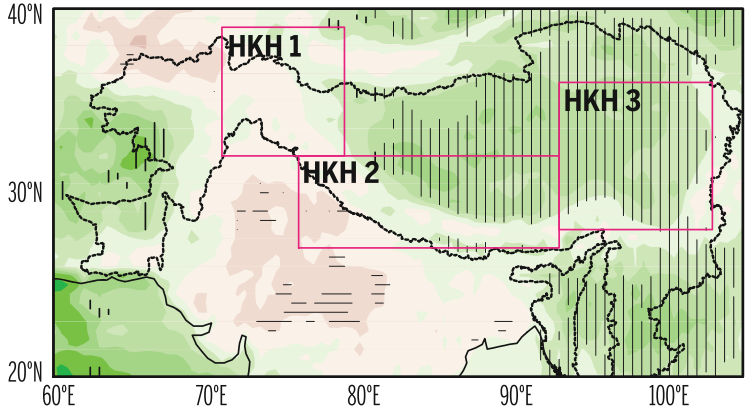

$\begin{array}{lllllllllll}-30 & -20 & -15 & -10 & -5 & 0 & 5 & 10 & 15 & 20 & 30 \%\end{array}$

(e) T DJF RCP4.5 Near-future change
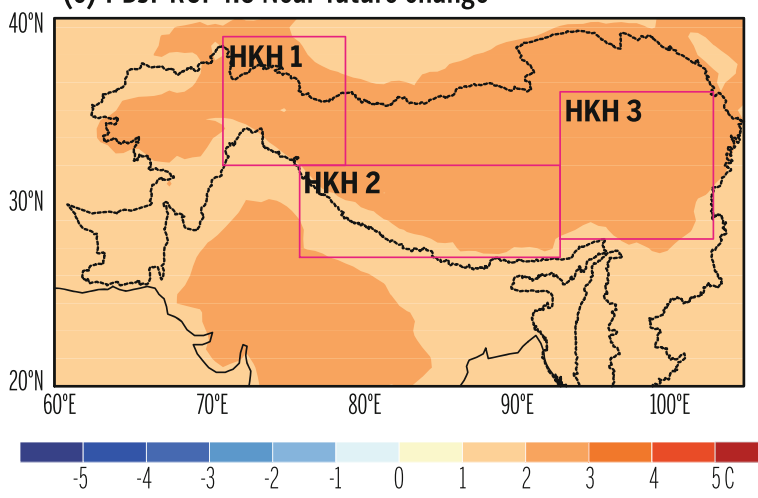

(g) P DJF RCP4.5 Near-future change

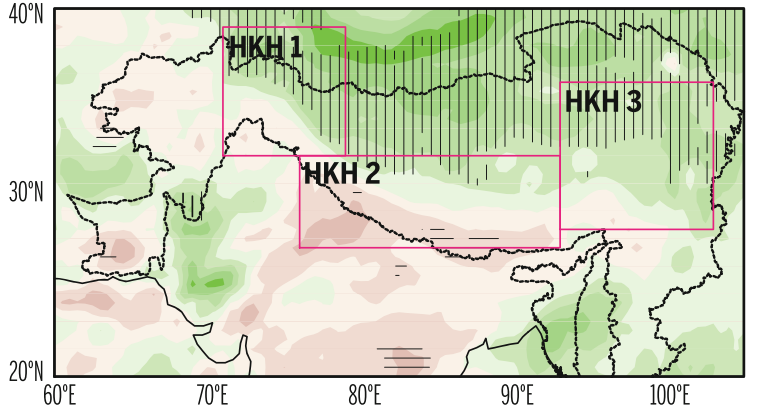

$\begin{array}{lllllllllll}-30 & -20 & -15 & -10 & -5 & 0 & 5 & 10 & 15 & 20 & 30 \%\end{array}$

Fig. 3.12 Seasonal ensemble mean climate change in the Hindu Kush Himalaya $(\mathrm{HKH})$ in the near future ([2036-65] with respect to [19762005]) for (top panels) surface air temperature $\left({ }^{\circ} \mathrm{C}\right)$ and (bottom panels) total precipitation (\%), with scenarios (first and third column) RCP4.5 and (second and fourth column) RCP8.5, during (a-d) summer monsoon (JJAS) and (e-h) winter (DJF) seasons. Ensemble mean of

\section{(b) T JJAS RCP8.5 Near-future change}

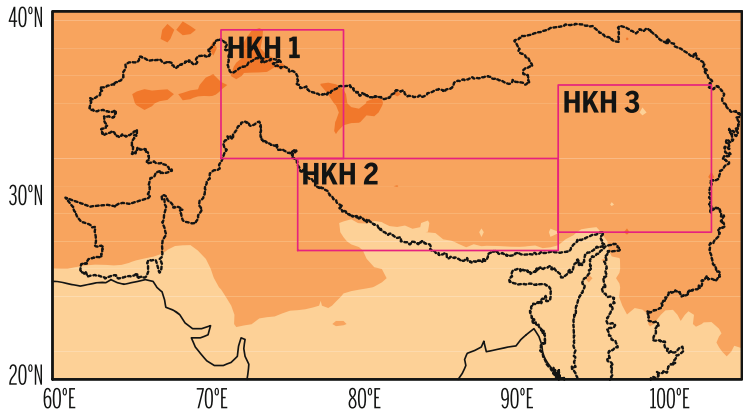

(d) P JJAS RCP8.5 Near-future change

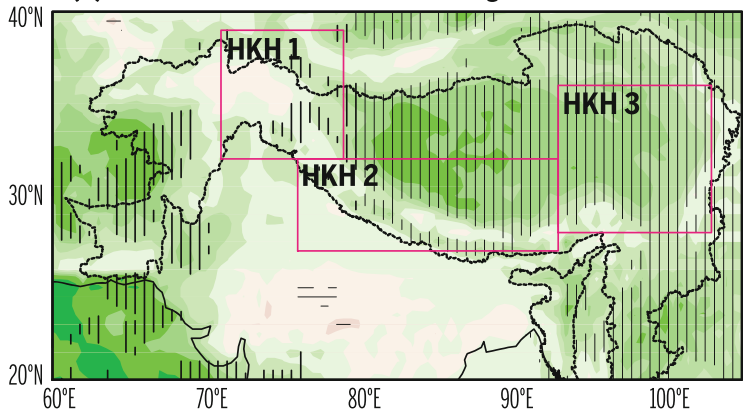

(f) T DJF RCP8.5 Near-future change

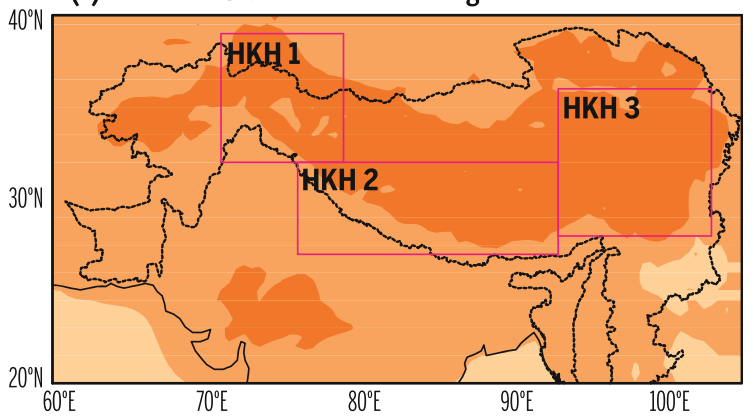

(h) P DJF RCP8.5 Near-future change

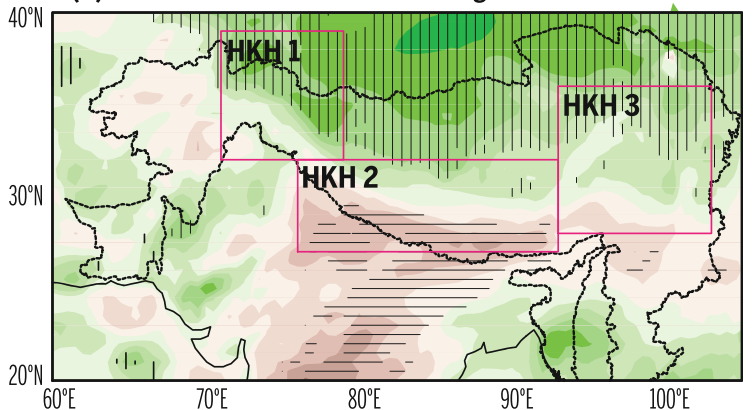

downscaling CMIP5 GCM with CORDEX South Asia RCM (listed in Table 3.5). Striping in bottom panels indicates where at least 10 of the 13 realizations concur on an increase (vertical) or decrease (horizontal) in RCPs. The HKH boundary is shown with dashed line. The boxes represent the three HKH sub-regions used for detailed analysis (see text) (Source Sanjay et al. 2017b) 
(a) T JJAS RCP4.5 Far-future change

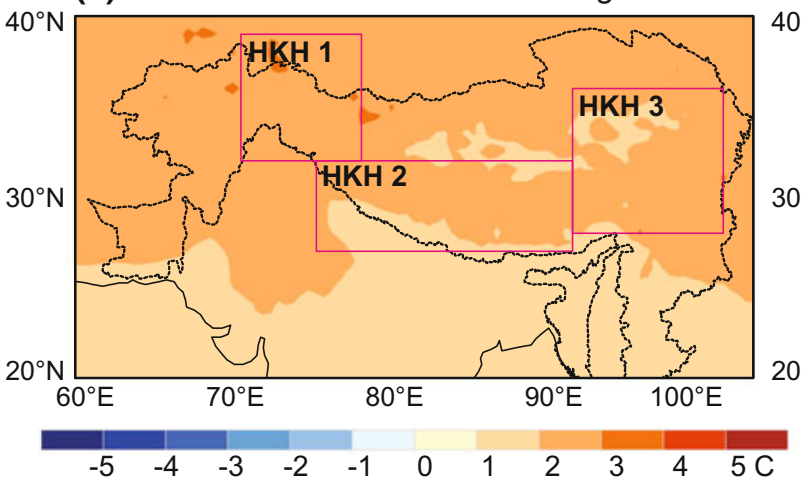

(c) P JJAS RCP4.5 Far-future change

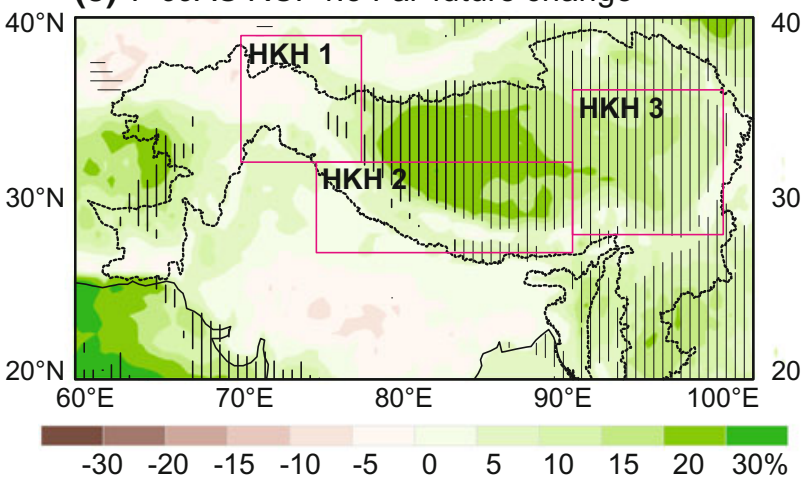

(e) T DJF RCP4.5Far-future change
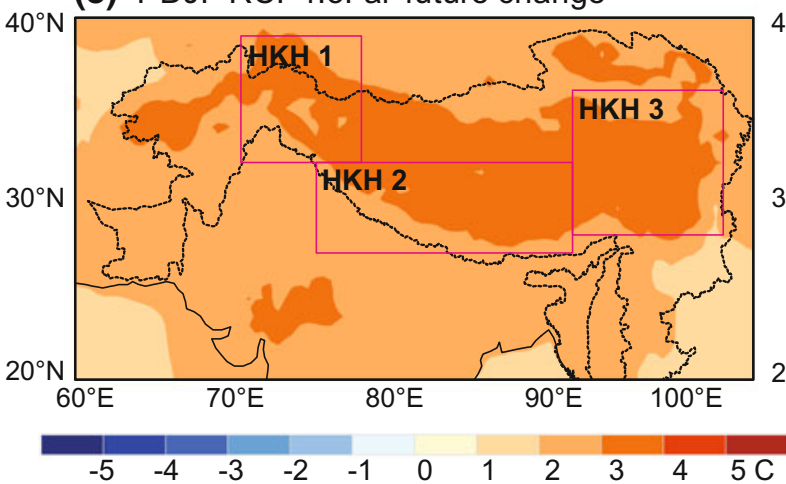

(g) P DJF RCP4.5 Far-future change

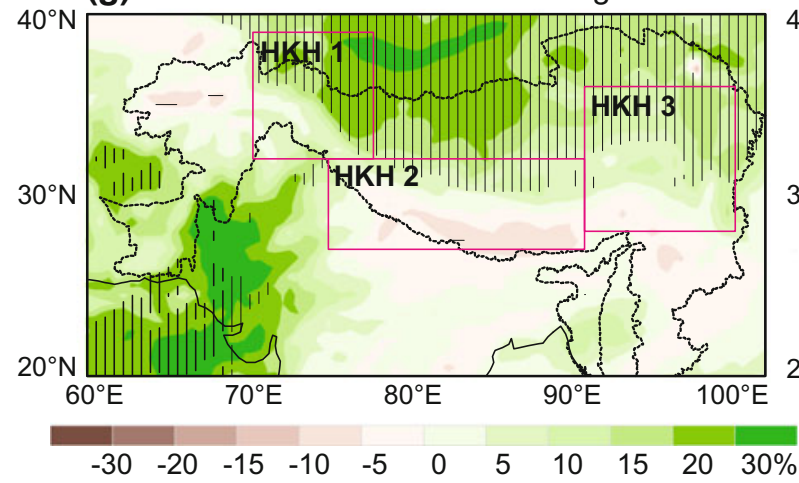

(b) T JJAS RCP8.5 Far-future change

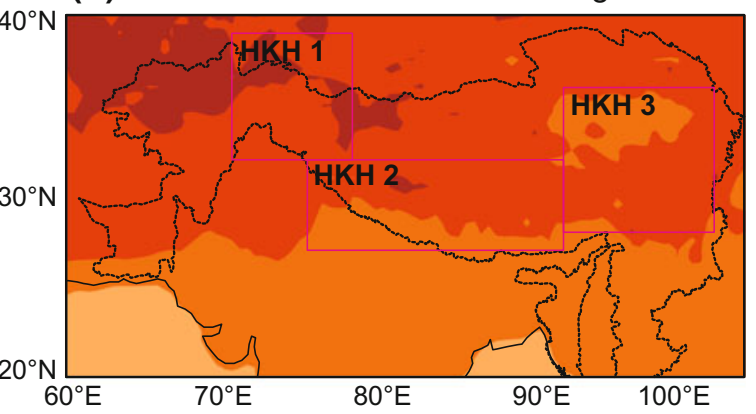

(d) P JJAS RCP8.5 Far-future change

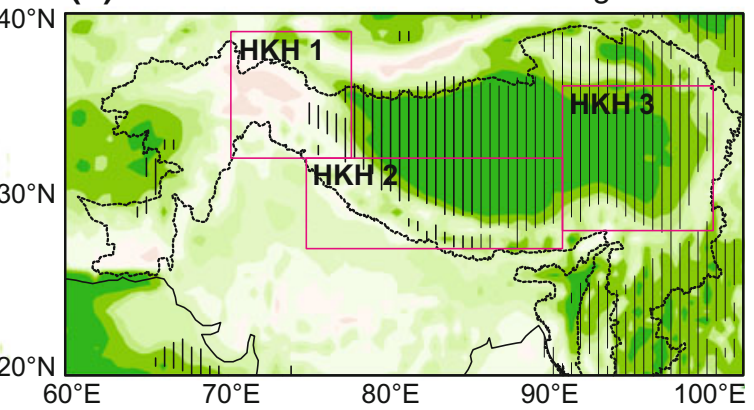

(f) T DJF RCP8.5 Far-future change

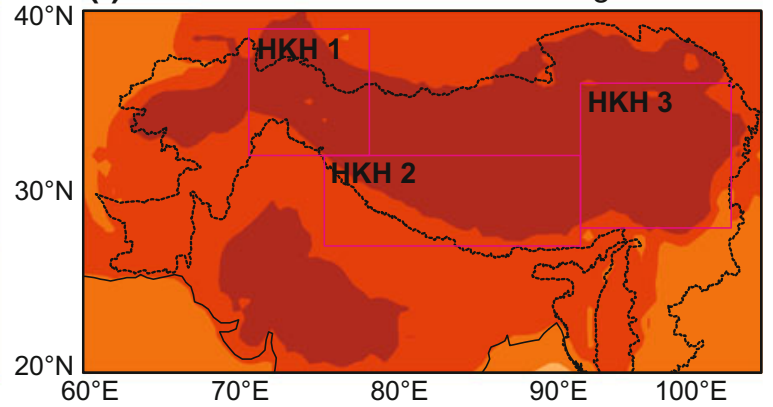

(h) P DJF RCP8.5 Far-future change

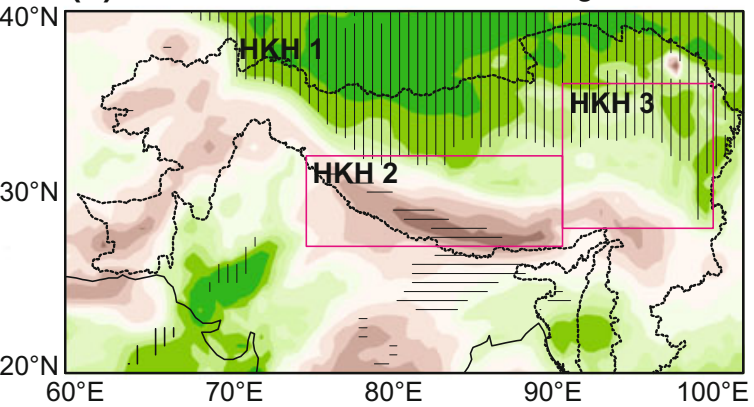

Fig. 3.13 Seasonal ensemble mean climate change in the Hindu Kush Himalaya (HKH) in the far future ([2066-2095]-[1976-2005]) for (top panels) surface air temperature $\left({ }^{\circ} \mathrm{C}\right)$ and (bottom panels) total precipitation (\%), with scenarios (first and third column) RCP4.5 and (second and fourth column) RCP8.5, during (a-d) summer monsoon (JJAS) and (e-h) winter (DJF) seasons. Ensemble mean of downscaling
CMIP5 GCM with CORDEX South Asia RCM (listed in Annex 4 and Table 3.5). Striping in bottom panels indicates where at least 10 of the 13 realizations concur on an increase (vertical) or decrease (horizontal) in RCPs. The HKH boundary is shown by a dashed line. The boxes represent three HKH sub-regions used for detailed analysis (see text) (Source Sanjay et al. 2017b) 
Table 3.5 Seasonal ensemble mean projected changes in near-surface air temperature $\left({ }^{\circ} \mathrm{C}\right)$ relative to $1976-2005$ in three Hindu Kush Himalaya $(\mathrm{HKH})$ subregions defined by grid cells within each subregion above 2,500 m a.s.l. (see Fig. 3.1): northwestern Himalaya and Karakoram (HKH1); central Himalaya (HKH2); southeastern Himalaya and Tibetan Plateau (HKH3). The ranges for the 10 general circulation models and 13 regional climate models (listed in Annex 3, Table 3.12) analysed are given in brackets

\begin{tabular}{|c|c|c|c|c|c|c|c|c|}
\hline \multirow[t]{2}{*}{ Scenario } & \multirow[t]{2}{*}{ Period } & \multirow[t]{2}{*}{$\begin{array}{l}\text { Multi-model ensemble } \\
\text { mean }\end{array}$} & \multicolumn{3}{|c|}{$\begin{array}{l}\text { Summer monsoon season (June-September) } \\
\left({ }^{\circ} \mathrm{C}\right)\end{array}$} & \multicolumn{3}{|c|}{ Winter season (December-February) $\left({ }^{\circ} \mathrm{C}\right)$} \\
\hline & & & HKH1 & $\mathrm{HKH} 2$ & HKH3 & HKH1 & HKH2 & HKH3 \\
\hline \multirow[t]{4}{*}{$\mathrm{RCP} 4.5$} & \multirow[t]{2}{*}{$2036-65$} & $\begin{array}{l}\text { Downscaled CORDEX } \\
\text { RCM }\end{array}$ & $2.0(1.2,3.3)$ & $1.7(1.1,2.4)$ & $1.7(1.2,2.2)$ & $2.3(1.4,3.2)$ & $2.4(1.4,3.4)$ & $2.4(1.4,3.1)$ \\
\hline & & Driving CMIP5 GCM & $2.6(1.7,3.3)$ & $2.1(1.6,2.7)$ & $2.0(1.6,2.4)$ & $2.1(1.2,3.2)$ & $2.7(1.6,3.9)$ & $2.5(1.4,3.3)$ \\
\hline & \multirow[t]{2}{*}{$2066-95$} & $\begin{array}{l}\text { Downscaled CORDEX } \\
\text { RCM }\end{array}$ & $2.6(1.4,3.7)$ & $2.2(1.4,3.2)$ & $2.2(1.7,2.9)$ & $3.1(2.2,4.1)$ & $3.3(2.3,4.5)$ & $3.1(2.0,4.8)$ \\
\hline & & Driving CMIP5 GCM & $3.3(2.5,4.1)$ & $2.7(2.1,3.2)$ & $2.5(1.9,2.9)$ & $3.0(2.1,3.4)$ & $3.6(2.4,4.6)$ & $3.3(2.1,4.1)$ \\
\hline \multirow[t]{4}{*}{$\mathrm{RCP} 8.5$} & \multirow[t]{2}{*}{$2036-65$} & $\begin{array}{l}\text { Downscaled CORDEX } \\
\text { RCM }\end{array}$ & $2.7(1.7,4.3)$ & $2.3(1.4,3.2)$ & $2.3(1.5,2.9)$ & $3.2(1.8,4.4)$ & $3.3(2.1,4.6)$ & $3.2(2.0,4.6)$ \\
\hline & & $\begin{array}{l}\text { Driving } \\
\text { CMIP5 GCM }\end{array}$ & $3.3(2.5,4.3)$ & $2.7(2.0,3.4)$ & $2.5(1.9,3.0)$ & $3.0(2.2,3.9)$ & $3.4(2.3,4.7)$ & $3.2(2.1,4.2)$ \\
\hline & \multirow[t]{2}{*}{$2066-95$} & $\begin{array}{l}\text { Downscaled CORDEX } \\
\text { RCM }\end{array}$ & $4.9(3.0,7.7)$ & $4.3(3.1,6.1)$ & $4.2(3.1,5.4)$ & $5.4(3.9,8.2)$ & $6.0(4.4,9.0)$ & $5.6(4.2,8.4)$ \\
\hline & & Driving CMIP5 GCM & $5.7(4.0,7.1)$ & $4.7(3.9,5.6)$ & $4.4(3.5,5.3)$ & $5.1(3.8,6.3)$ & $5.8(4.2,7.8)$ & $5.4(3.8,6.9)$ \\
\hline
\end{tabular}

Table 3.6 CMIP5 seasonal ensemble global mean projected changes in near-surface surface air temperature $\left({ }^{\circ} \mathrm{C}\right)$ relative to $1976-2005$. The range for the $10 \mathrm{GCM}$ analysed (listed in Annex 4, Table 3.13) is given in brackets

\begin{tabular}{|c|c|c|c|c|}
\hline \multirow[t]{2}{*}{ CMIP5 global mean projected change } & \multicolumn{2}{|c|}{$\begin{array}{l}\text { Summer monsoon season } \\
\text { (June-September) }\left({ }^{\circ} \mathrm{C}\right)\end{array}$} & \multicolumn{2}{|c|}{$\begin{array}{l}\text { Winter season (December-February) } \\
\left({ }^{\circ} \mathrm{C}\right)\end{array}$} \\
\hline & $\mathrm{RCP} 4.5$ & RCP8.5 & RCP4.5 & RCP8.5 \\
\hline $2036-2065$ & $1.4(0.9,1.9)$ & $1.9(1.3,2.4)$ & $1.5(1.1,1.9)$ & $2.0(1.5,2.5)$ \\
\hline $2066-2095$ & $1.9(1.2,2.4)$ & $3.3(2.3,4.1)$ & $2.0(1.4,2.4)$ & $3.5(2.5,4.2)$ \\
\hline
\end{tabular}

Fig. 3.14 The spatial distributions of annual mean temperature change $\left({ }^{\circ} \mathrm{C}\right)$ over the Hindu Kush Himalaya (top panels) for the period $2036-65$ for (a) representative concentration pathway 4.5 (RCP4.5) and (b) RCP8.5 and (bottom panels) for the period 2066-96 for (c) RCP4.5 and (d) RCP8.5

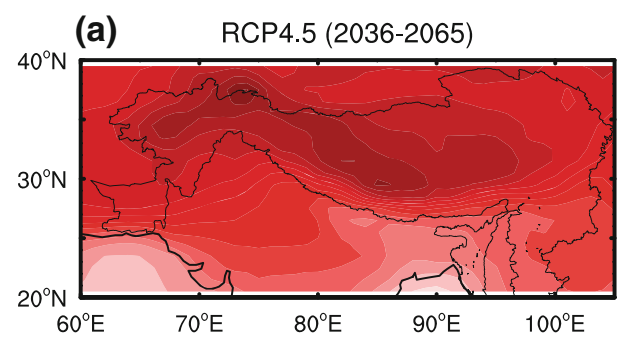

(c) RCP4.5 (2066-2095)

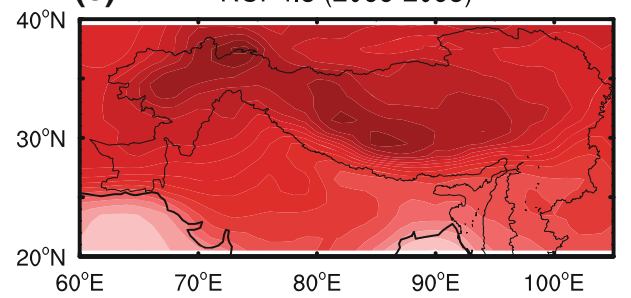

(b) RCP8.5 (2036-2065)

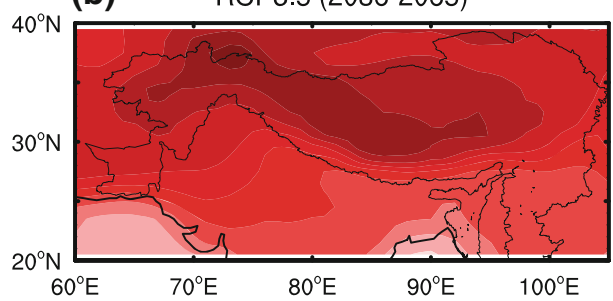

(d) RCP8.5 (2066-2095)

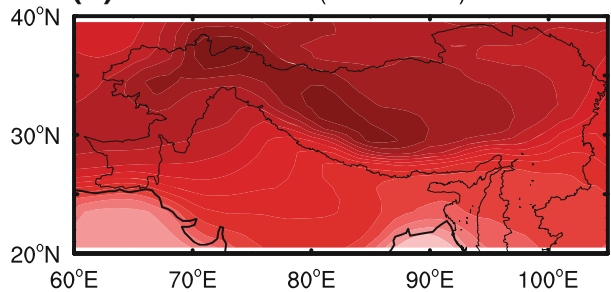

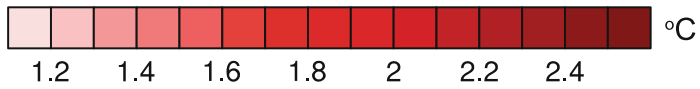


Box 3.3 What does a $1.5{ }^{\circ} \mathrm{C}$ rise in global average temperature mean for the HKH? Analysis of an ensemble of five GCM runs projecting a global temperature increase of $1.5^{\circ} \mathrm{C}$ by the end of the 21 st century, compared to the pre-industrial global mean temperature, reveals what this global $1.5^{\circ} \mathrm{C}$ increase implies for the High Mountain Asia region. According to this ensemble, for the complete HIMAP domain a $1.5{ }^{\circ} \mathrm{C}$ global temperature increase would mean a temperature increase of $1.8 \pm 0.4{ }^{\circ} \mathrm{C}$ averaged over the region (Table 3.7). Looking solely at the mountain ranges, this enhanced warming is even more pronounced. For the Karakoram, central Himalaya, and southeastern Himalaya, a $1.5^{\circ} \mathrm{C}$ global temperature increase would imply regional temperature increases of $2.2{ }^{\circ} \mathrm{C} \pm 0.4{ }^{\circ} \mathrm{C}, 2.0^{\circ}$ $\mathrm{C} \pm 0.5^{\circ} \mathrm{C}$, and $2.0{ }^{\circ} \mathrm{C} \pm 0.5{ }^{\circ} \mathrm{C}$, respectively.

Table 3.7 Comparison results of models projecting a $1.5^{\circ} \mathrm{C}$ increase in near-surface air temperature $\left({ }^{\circ} \mathrm{C}\right)$ globally and for the Hindu Kush Himalaya $(\mathrm{HKH})$ and the three sub-domains. The temperature changes are for the end-of-century from the pre-industrial period (2071-2100 vs. $1851-80)$

\begin{tabular}{l|l|l|l|l|l|l|l}
\hline RCP & Model & Global & HKH & HKH1 & HKH2 & HKH3 \\
\hline RCP2.6 & GISS-E2-R_r1i1p3 & 1.48 & 1.82 & 1.87 & 1.73 & 2.35 \\
\hline RCP2.6 & MIROC5_r1i1p1 & 1.48 & 1.95 & 2.54 & 2.46 & 2.28 \\
\hline RCP2.6 & NorESM1-ME_r1i1p1 & 1.44 & 1.68 & 2.05 & 1.85 & 1.63 \\
\hline RCP2.6 & HadGEM2-AO_r1i1p1 & 1.57 & 1.47 & 2.04 & 1.49 & 1.50 \\
\hline RCP2.6 & MPI-ESM-MR_r1i1p1 & 1.58 & 2.16 & 2.58 & 2.42 & 2.11 \\
\hline MEAN & & 1.51 & 1.82 & 2.22 & 1.99 & 1.97 \\
\hline RANGE & & 0.14 & 0.69 & 0.71 & 0.97 & 0.85 \\
\hline SD & & 0.06 & 0.26 & 0.32 & 0.43 & 0.39
\end{tabular}

\subsubsection{Precipitation Projected to Increase, but with Regional Diversity}

\section{There is a divergence among models in projecting future} changes in precipitation. No ideal model captures South Asian monsoon behaviour. Unlike temperature, the precipitation response to climate change over the HKH region is subject to larger uncertainties both in the CMIP and CORDEX models (e.g., Choudhary and Dimri 2017; Hasson et al. 2013, 2015; Mishra, 2015; Sanjay et al. 2017b). Evaluating 20 CMIP5 GCM, Hasson et al. (2015) analysed the seasonal cycle of precipitation in the main river basins of the $\mathrm{HKH}$, and emphasized that the inter-model spread on monsoonal precipitation is more in the western parts of the region com-pared to the eastern parts of the region. CMIP5 models are more skillful in terms of simulating patterns, but the intra-seasonal variability remains problematic (Sperber et al. 2013). Climate models have considerable difficulty in simulating the observed pattern because of extremes in topography. Even with multi-model evaluation of global changes in mean precipitation per degree of warming (22 atmosphere-ocean general circulation models (AOGCM) projection), there is an increase in precipitation over the south and southeastern Asian region during the summer season, but over the Himalaya fewer models are in agreement (IPCC 2007). Hasson et al. (2013) reported large uncertainties in the way CMIP3 models describe the future water budget in large $\mathrm{HKH}$ river basins, with a clearer tendency for wetter conditions in the eastern basins.

Regional climate model (PRECIS) analysis carried out on a river basin scale (Indus Basin) by Rajbhandari et al. (2015) could not establish any trends in precipitation changes in the future in the western HKH. However, in the eastern Himalaya (Koshi Basin), based on the eight GCM downscaled using the delta method, the authors reported for both RCP4.5 and RCP8.5 a 10-20\% increase in rainfall during the summer monsoon and about a 5\% increase in the winter season over the trans-Himalayan part of the basin (Rajbhandari et al. 2016). Similarly, Bharati et al. (2016) reported an increase in future precipitation over trans-mountain sub-watersheds in the 2030s and 2050s. A study carried out by Kulkarni et al. (2013) over the HKH using PRECIS reported a $20-40 \%$ increase in monsoon rainfall towards the end of the 21 st century. The precipitation is not simulated as well at regional scales by global climate models used in CMIP5 experiments for the IPCC Assessment Report 5 (AR5), and the assessment is hampered by observational uncertainties (IPCC 2013). The AR5 highlights that the projected changes in the water cycle at regional scale will be strongly influenced by natural internal variability and may be affected by anthropogenic aerosol emissions. This assessment further notes that while the South Asian summer monsoon winds are likely to weaken, monsoon precipitation is likely to intensify due to the increase in atmospheric moisture (e.g., Kitoh 2017; Krishnan et al. 2013). 
Table 3.8 Seasonal ensemble mean projected changes in total precipitation (\%) relative to 1976-2005 in three Hindu Kush Himalaya $(\mathrm{HKH})$ subregions defined by grid cells within each subregion above 2,500 m a.s.l. (see Fig. 3.1): northwestern Himalaya and Karakoram (HKH1); central Himalaya (HKH2); southeastern Himalaya and TP (HKH3). The range for the 10 GCM and 13 RCM (listed in Table 3.13 in Annex 4) analysed is given in brackets

\begin{tabular}{|c|c|c|c|c|c|c|c|c|}
\hline \multirow[t]{2}{*}{ Scenario } & \multirow[t]{2}{*}{ Period } & \multirow[t]{2}{*}{$\begin{array}{l}\text { Multi-model ensemble } \\
\text { mean }\end{array}$} & \multicolumn{3}{|c|}{$\begin{array}{l}\text { Summer monsoon season (June- } \\
\text { September) }(\%)\end{array}$} & \multicolumn{3}{|c|}{ Winter season (December-February) $(\%)$} \\
\hline & & & HKH1 & $\mathrm{HKH} 2$ & HKH3 & HKH1 & HKH2 & HKH3 \\
\hline \multirow[t]{4}{*}{$\mathrm{RCP} 4.5$} & \multirow[t]{2}{*}{$2036-65$} & $\begin{array}{l}\text { Downscaled CORDEX } \\
\text { RCM }\end{array}$ & $\begin{array}{l}-0.1 \\
(-11.6,19.7)\end{array}$ & $\begin{array}{l}4.4 \\
(-4.5,15.1)\end{array}$ & $\begin{array}{l}6.8 \\
(-5.5,11.9)\end{array}$ & $\begin{array}{l}7.0 \\
(-13.9,21.9)\end{array}$ & $\begin{array}{l}-0.7 \\
(-18.6,15.0)\end{array}$ & $\begin{array}{l}3.1 \\
(-16.4,19.5)\end{array}$ \\
\hline & & Driving CMIP5 GCM & $\begin{array}{l}0.8 \\
(-17.1,35.1)\end{array}$ & $\begin{array}{l}6.7 \\
(-0.8,22.1)\end{array}$ & $\begin{array}{l}4.6 \\
(-1.4,10.2)\end{array}$ & $\begin{array}{l}1.0 \\
(-10.2,18.0)\end{array}$ & $\begin{array}{l}-7.7 \\
(-21.0,2.9)\end{array}$ & $\begin{array}{l}2.1 \\
(-7.8,14.8)\end{array}$ \\
\hline & \multirow[t]{2}{*}{$2066-95$} & $\begin{array}{l}\text { Downscaled CORDEX } \\
\text { RCM }\end{array}$ & $\begin{array}{l}3.5 \\
(-9.8,29.3)\end{array}$ & $\begin{array}{l}10.5 \\
(-4.9,29.9)\end{array}$ & $\begin{array}{l}10.4 \\
(-3.4,20.4)\end{array}$ & $\begin{array}{l}14.1 \\
(-4.9,34.4)\end{array}$ & $\begin{array}{l}1.5 \\
(-19.3,36.7)\end{array}$ & $\begin{array}{l}3.7 \\
(-19.6,32.1)\end{array}$ \\
\hline & & Driving CMIP5 GCM & $\begin{array}{l}-0.3 \\
(-23.2,34.8)\end{array}$ & $\begin{array}{l}11.8 \\
(-1.4,33.0)\end{array}$ & $\begin{array}{l}7.3 \\
(0.6,13.0)\end{array}$ & $\begin{array}{l}6.2 \\
(-6.8,43.3)\end{array}$ & $\begin{array}{l}-0.7 \\
(-17.3,22.0)\end{array}$ & $\begin{array}{l}5.5 \\
(-14.6,23.9)\end{array}$ \\
\hline \multirow[t]{4}{*}{ RCP8.5 } & \multirow[t]{2}{*}{$2036-65$} & $\begin{array}{l}\text { Downscaled CORDEX } \\
\text { RCM }\end{array}$ & $\begin{array}{l}3.7 \\
(-13.8,22.3)\end{array}$ & $\begin{array}{l}9.1 \\
(-3.2,23.6)\end{array}$ & $\begin{array}{l}10.2 \\
(-5.1,22.2)\end{array}$ & $\begin{array}{l}12.8 \\
(-12.3,28.8)\end{array}$ & $\begin{array}{l}-1.3 \\
(-19.7,7.0)\end{array}$ & $\begin{array}{l}0.9 \\
(-13.2,24.4)\end{array}$ \\
\hline & & Driving CMIP5 GCM & $\begin{array}{l}3.6 \\
(-16.6,48.8)\end{array}$ & $\begin{array}{l}10.7 \\
(-4.1,28.3)\end{array}$ & $\begin{array}{l}5.7 \\
(-1.4,13.8)\end{array}$ & $\begin{array}{l}5.1 \\
(-10.9,36.0)\end{array}$ & $\begin{array}{l}-8.5 \\
(-25.5,2.1)\end{array}$ & $\begin{array}{l}0.7 \\
(-18.8,25.4)\end{array}$ \\
\hline & \multirow[t]{2}{*}{$2066-95$} & $\begin{array}{l}\text { Downscaled CORDEX } \\
\text { RCM }\end{array}$ & $\begin{array}{l}3.9 \\
(-14.9,60.0)\end{array}$ & $\begin{array}{l}19.1 \\
(-6.0,40.5)\end{array}$ & $\begin{array}{l}22.6 \\
(-6.1,49.0)\end{array}$ & $\begin{array}{l}12.9 \\
(-30.3,35.4)\end{array}$ & $\begin{array}{l}-8.8 \\
(-33.2,25.9)\end{array}$ & $\begin{array}{l}0.6 \\
(-16.6,35.7)\end{array}$ \\
\hline & & Driving CMIP5 GCM & $\begin{array}{l}5.0 \\
(-17.7,79.9)\end{array}$ & $\begin{array}{l}19.1 \\
(-1.1,34.0)\end{array}$ & $\begin{array}{l}9.7 \\
(-1.8,23.8)\end{array}$ & $\begin{array}{l}6.9 \\
(-20.9,54.7)\end{array}$ & $\begin{array}{l}-8.1 \\
(-35.5,14.2)\end{array}$ & $\begin{array}{l}6.0 \\
(-26.0,42.8)\end{array}$ \\
\hline
\end{tabular}

Future projections of summer monsoon precipitation over parts of the HKH, based on the CORDEX RCM, indicate a likely increase by 4-12\% in the near future and by 4-25\% in the long term (see Table 3.8). On the other hand, winter precipitation is projected to increase by $7 \%-15 \%$ in the Karakoram, but to decline slightly in the central Himalaya. It is important to mention that the CORDEX RCM have inherent limitations in reproducing the observed characteristics of the summer monsoon rainfall variability (Singh et al. 2017), and that future projections of precipitation extremes are unresolved, both across studies and across regions (e.g., Palazzi et al. 2013). Kapnick et al. (2014) emphasize the need to employ higher-resolution climate model simulations, as compared to the CMIP5 models, to better describe the distinct seasonal cycles and resulting climate change signatures of Asia's high-mountain ranges in the HKH.

Future projections of annual mean precipitation change, based on CMIP5 multi-model ensemble mean, have indicated an increase in precipitation over the HKH for both RCP4.5 and RCP8.5 scenarios (Fig. 3.11b). Similar to the surface temperature projections, simulation data from the CMIP5 models reveal enhanced precipitation change over the HKH compared to the global mean change by the end of the 21st century (Fig. 3.11d). The projected change in precipitation is similar for both scenarios until the 2050s, after which the RCP8.5 shows more increase until the end of the 21st century. Apart from a few projections for the near future, most of the projections show an increase in precipitation.
The magnitude and sign of the projected seasonal percent change was found to vary with region, season, averaging period, and scenario used. The spatial pattern of the seasonal ensemble mean projected percent changes in total precipitation based on high-resolution CORDEX South Asia RCM is shown over the HKH for the periods 2036-65 (near future; Fig. 3.12) and 2066-95 (far future; Fig. 3.13) relative to 1976-2005. The striping indicates where at least 10 of the 13 realizations concur on an increase (vertical) or decrease (horizontal) in total precipitation for the RCP. The individual RCM agree on a projected summer season increase in precipitation over the hilly regions in the central Himalaya (HKH2) and southeastern Himalaya and TP (HKH3) for both RCP4.5 and RCP8.5 scenarios in the near-future and far-future periods. There is less model agreement on the southern slopes of the Himalaya, and in the northwestern Himalaya and Karakoram (HKH1) region, during the summer season for both scenarios until the end of the 21 st century. The models agree well on the winter season increase in total precipitation over HKH1 for near-future and far-future periods and for both scenarios. The confidence among the models for projected reduction in winter precipitation over HKH2 and HKH3 is low for both scenarios in the two periods.

Table 3.8 shows the projected total precipitation changes in the hilly region (see Fig. 3.1) with RCP4.5 and RCP 8.5 scenarios for near-future and far-future periods. This detailed analysis further confirms that during summer (winter), relatively higher (lower) precipitation increase will occur over 
Fig. 3.15 The spatial distributions of annual mean precipitation change $(\%)$ over the Hindu Kush Himalayan region for (a, c) RCP4.5 and (b, d) RCP8.5 during (a, b) 2036-65 and (c, d) 2066-95
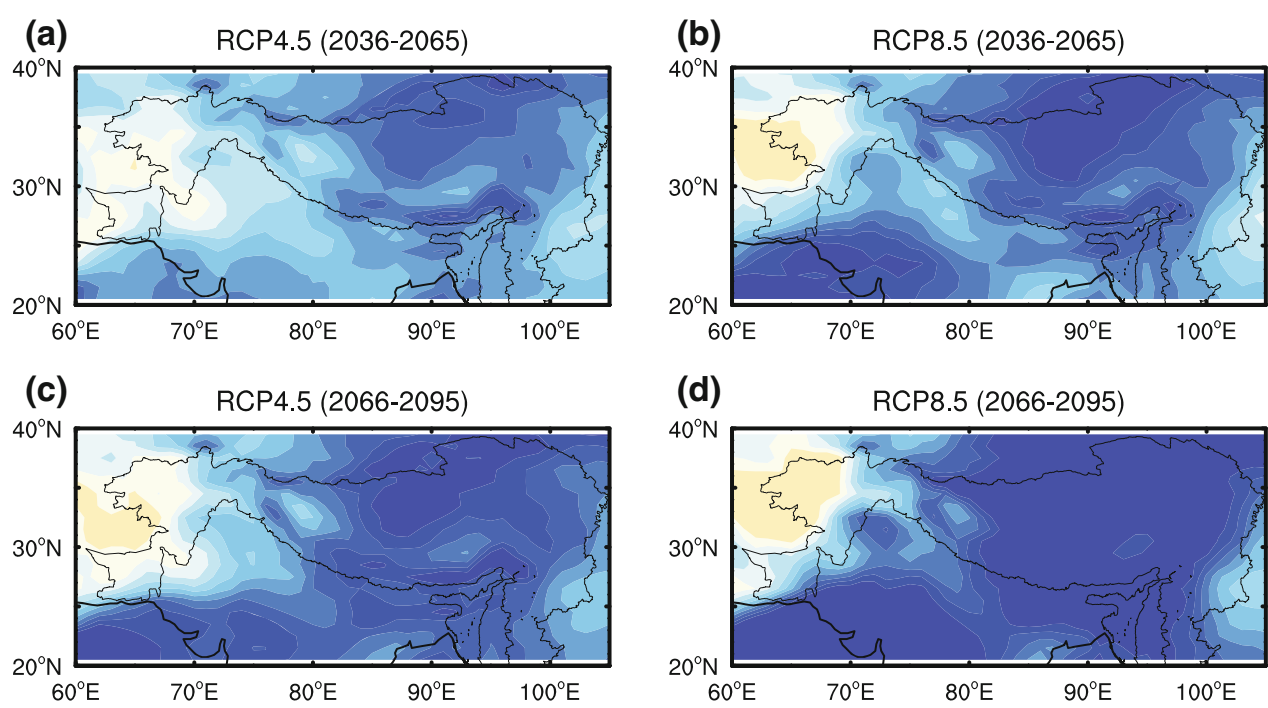

(d)
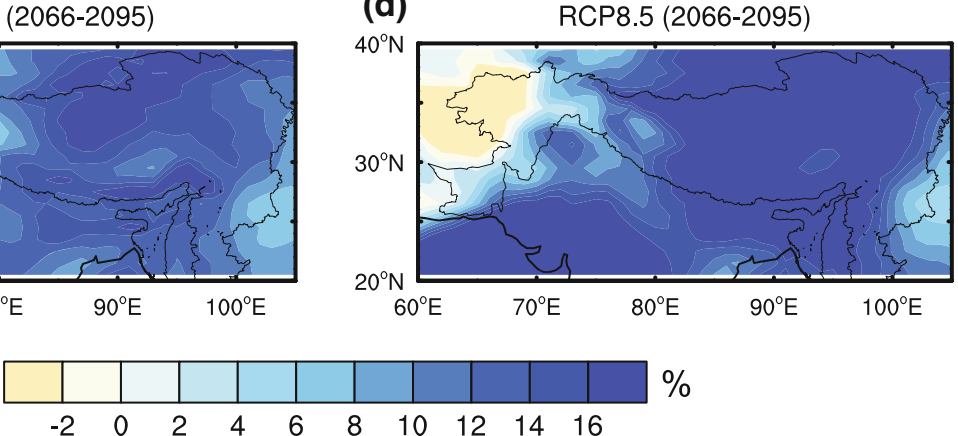

HKH2 and HKH3 than in HKH1 for both scenarios by the end of the 21 st century. The largest projected seasonal ensemble mean total precipitation increase for the high-resolution CORDEX RCM during the summer monsoon season is about $10 \%$ over HKH2 with the RCP4.5 scenario and about $22 \%$ over HKH3 with the RCP8.5 scenario. During winter the largest projected increase in precipitation is over HKH1 of about $14 \%$ and $13 \%$ with RCP4.5 and RCP8.5 scenarios, respectively. However, it can be seen that the spread among the models is large for the high-resolution CORDEX RCM, as well as for their driving CMIP5 GCM (Sanjay et al. 2017b).

Detailed analysis of the CMIP5 multi-model annual precipitation projections over HKH (Annex 3) suggests that the western part of this region tends to be drier and the Tibetan region tends to be wetter in the future (see Fig. 3.15). The large magnitudes of precipitation appear by the end of the 21st century under RCP4.5 and RCP8.5.

\subsection{Limitations and Gaps in the Analysis}

There is no previous study specifically for the $\mathrm{HKH}$ region as defined by HIMAP; therefore, a major part of this chapter is based on original analyses for both the historical period and the future. Large gaps in observations exist in the $\mathrm{HKH}$, especially in Afghanistan, Pakistan, Myanmar, Bhutan, and Nepal, and for the northwestern part of the TP. Monthly and daily pre-1950 data are lacking for most parts of the HKH, and the gap is particularly large for areas outside of India. The daily data post-1950 are also insufficient in some areas, including Afghanistan, Pakistan, Myanmar, Bhutan, and Nepal, and the northwestern part of the TP. The sparseness of observational data is the major source of uncertainties in the estimates of long-term trends of mean and extreme climatic indices in the HKH. Improvement in data coverage is under way, but time is needed to obtain records that are sufficiently long term to allow analysis of past climate change. An effective measure to increase the coverage of data is to recover and digitize the original records from earlier years still kept in paper documents in some countries, in coordination with the activities of Atmospheric Circulation Reconstructions over the Earth (ACRE) China, ACRE SE Asia, and ACRE Indian Ocean.

Uncertainties with the observational studies also result from the gaps in studies, including the data processing and analysing methods. Data inhomogeneities related to station relocations and instrumentation sometimes cause large biases in the estimates of trends of key climatic elements if proper adjustments have not been made. Major uncertainty with the estimates of extreme temperature trends comes from the systematic bias of the historical temperature data series caused by urbanization. Similar to the mean surface air temperature, urbanization also exerts a large effect on the long-term trends of the extreme temperature indices in a subcontinental region like mainland China (Ren et al. 2014; Sun et al. 2016; Zhou and Ren 2009, 2011). The effect of urbanization in annual and seasonal extreme temperature indices series in the TP region has not yet corrected. However, even if we take this effect into account, the baseline warming over the TP and the HKH, probably caused by global and regional drivers including the anthropogenic 
increase in atmospheric $\mathrm{CO}_{2}$ concentration, could be still significant. The sparseness of early-year observations in the TP, the Yunnan-Guizhou Plateau, and Pakistan and Afghanistan is also an important source of the uncertainties.

Scenarios or the pathways are the trajectories undertaken by climate models to derive future climate. Models use various pathways to create future climate scenarios; therefore, uncertainties are inherent in the model. In the present study, RCP4.5 and RCP8.5 have been used to analyse the future climate. Although future pathways are uncertain, a comparison of recent global trends in carbon dioxide emissions shows that the current emission is close to RCP8.5 (Friedlingstein et al. 2014; Peters et al. 2012).

The future temperature and precipitation presented in Sect. 3.4 are analyses of outputs from GCM and CORDEX South Asia models. Although many of the multi-model projections agree on the direction of changes, there are differences in magnitude and spatial distribution. CORDEX South Asia model outputs have not been validated over the $\mathrm{HKH}$, and the results provided only for the assessment of the trend and not of the magnitude of the event.

\section{Annex 1: Data and Methods for Analysis of Past Temperature}

For this assessment, the source of monthly mean temperature (Tmean), maximum temperature (Tmax), and minimum temperature (Tmin) data is the CMA GLSAT-V1.0 (Xu et al. 2014). The data in the CMA GLSAT-V1.0 have been quality-controlled and homogenized. The record length is 114 years (1901-2014). Only those stations with at least 15 years of records in the base period 1961-90 were selected for analysis and, at the same time, the station's records were required to be greater than or equal to 5 years during the first half and the last half of the analysis period (1901-60 and 1990-2014). The total numbers of stations used for the analysis was therefore 122 for Tmean, 94 for Tmax and 94 for Tmin in the HKH. In addition, if there were 6 months in 1 year without data, that year was not included for calculation. Distribution of the stations used is shown in Fig. 3.16a.

To reduce the biases caused by uneven station density or temporal variations in data coverage, the Climate Anomaly Method (CAM) (Jones and Moberg 2003) was employed. First, each station was assigned to a regular $2.5^{\circ} \times 2.5^{\circ}$ or $5^{\circ} \times 5^{\circ}$ latitude-longitude grid box. The grid boxes had at least one station. Then, grid box temperature anomalies were calculated by averaging anomalies for the stations within grid boxes. Finally, the HKH average temperature, maximum temperature, and minimum temperature anomalies were calculated by the area-weighted average (using the cosines of the mid-grid latitude as weights) of all grid box anomalies.
The reference period 1961-90 was chosen, mainly because of the better record of spatial coverage. Annual values were calculated by averaging all 12 monthly values. The linear trends of the temperature anomaly series were the linear regression coefficients between temperature and ordinal numbers of time obtained by using the least squares method (e.g., I $=1,2,3 \ldots 64$ for 1901-2014 or 1951-2014 for extreme analysis). The significance of the linear trends of temperature series was judged by using the two-tailed simple-test method. In this assessment, a trend is considered statistically significant if it is significant at the $5 \%(\mathrm{p}<0.05)$ level.

The source of daily Tmax and Tmin measurements for current analysis was the global land surface daily air temperature data set V1.0, developed by the CMA. The temperature data set has been quality controlled and includes daily Tmean, Tmax, and Tmin. The record length varied for stations, but a 55-year period (1961-2015) was used for the assessment in the HKH. All stations included in the report were required to have at least 30 years of records for the whole period and at least 15 years of records during the 196190 reference period. Stations were also required to have at least 10 months of records for every year with data. The total number of stations used was therefore 478 . The spatial distribution and record length of the temperature stations in the HKH are shown in Fig. 3.16, and the data sources and the numbers of stations used in this report are shown in Table 3.9.

Nine temperature-related indices of the 27 extreme climate events indices recommended by the ETCCDI are used in this report. They include cold nights (TN10p), cold days (TX10p), warm nights (TN90p), warm days (TX90p), monthly maximum value of daily maximum temperature (TXx), monthly minimum value of daily minimum temperature (TNn), frost days (FD), summer days (SU), and daily temperature range (DTR). The definitions of the indices can be found in Table 3.10 (You et al. 2015; Zhou and Ren 2011) (Tables 3.11 and 3.12).

\section{Annex 2: Data and Methods for Analysis of Past Precipitation}

The sources of monthly and daily precipitation measurement for current analysis are from the CMA GLMP-V1.0 and Global Land Daily Precipitation data set V1.0 (CMA GLDP-V1.0). The data in the GLMP-V1.0 have been quality controlled and the record length is 113 years (1901-2013), while the GLDP-V1.0 data have also been quality controlled but have not been homogenized, and they only have records of 53 years (1961-2013).

In the HKH, stations were selected that have at least 10 years of precipitation records in the base period 1961-90, at least 5 years in the period $1901-50$, and 5 years in the 
Fig. 3.16 Spatial distribution, record length, and gridboxes (grey area) of stations with daily temperature data in the $\mathrm{HKH}$ $\left(20-40^{\circ} \mathrm{N}, 60-105^{\circ} \mathrm{E}\right)$.

(a) 1901-2014 for monthly data;

(b) 1961-2015 for daily data (a) $\mathrm{HKH}\left(20^{\circ} \mathrm{N}-40^{\circ} \mathrm{N}, 60^{\circ} \mathrm{E}-105^{\circ} \mathrm{E}\right)$

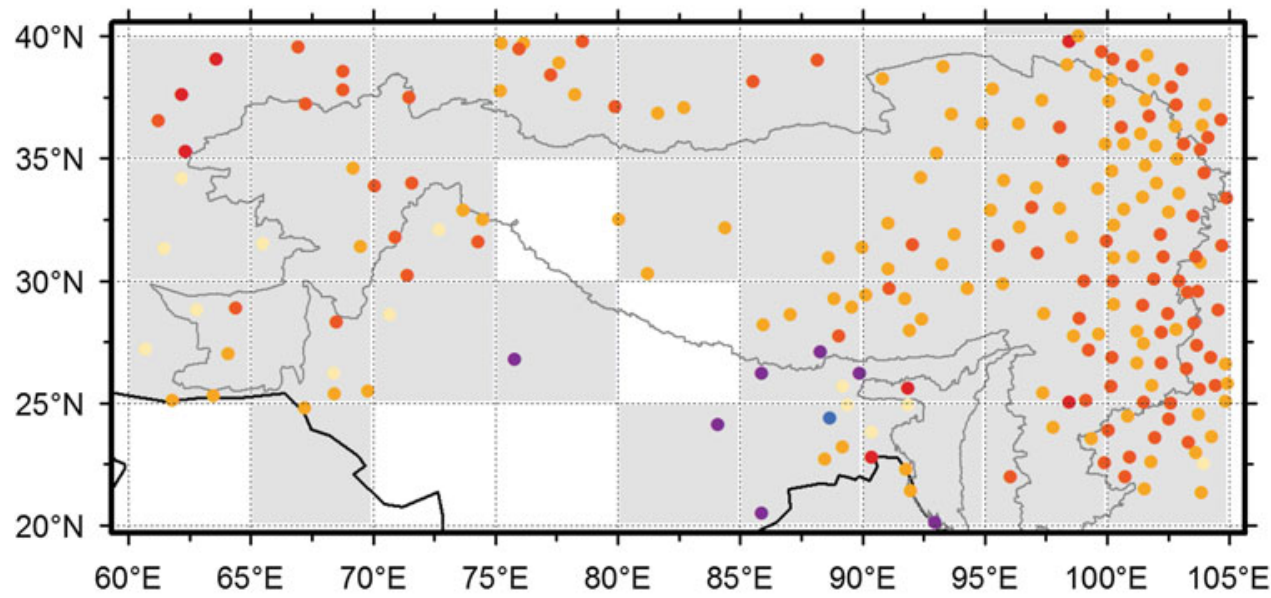

Records length

- <20 21-40・41-60・61-80・81-100・101-114 Year

(b) $\quad \mathrm{HKH}\left(20^{\circ} \mathrm{N}--40^{\circ} \mathrm{N}, 60^{\circ} \mathrm{E}--105^{\circ} \mathrm{E}\right)$

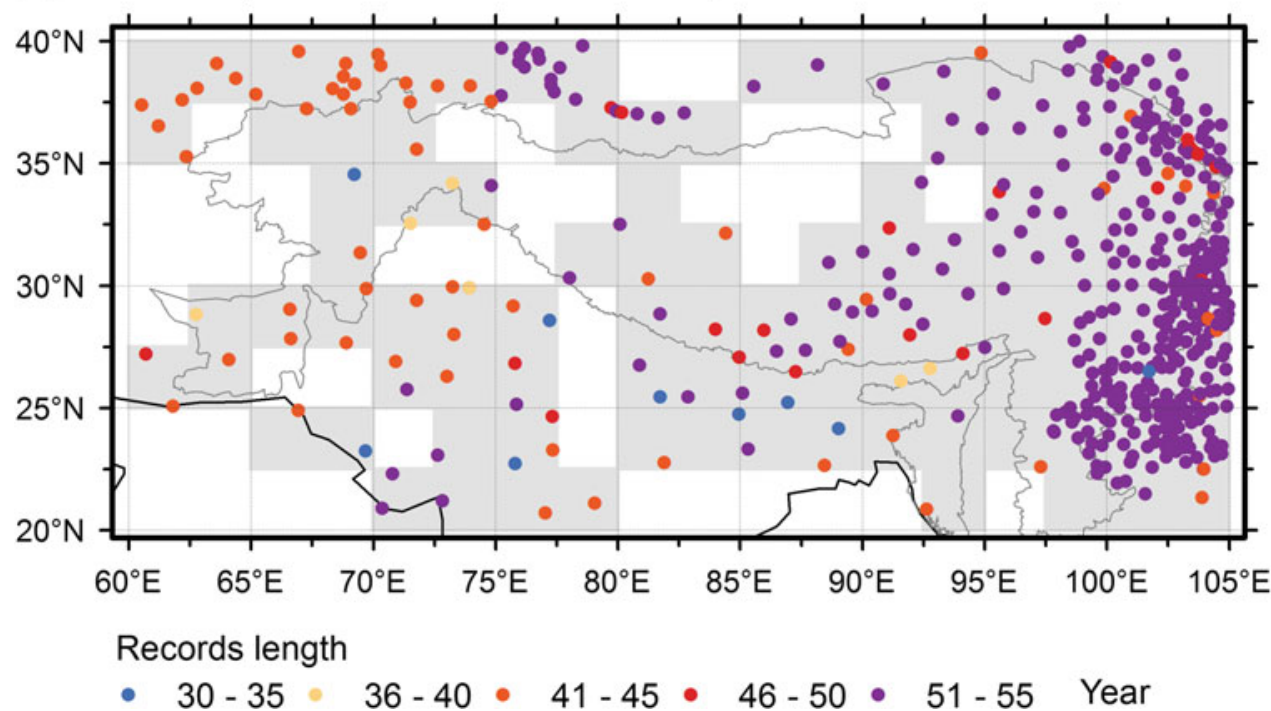

Table 3.9 Daily data sources and station numbers between 1951 and 2014

\begin{tabular}{l|l|l|l|l|l|l}
\hline Data set & CMA & GHCND & GSOD & ECA & Russia & Vietnam \\
\hline Number & 387 & 55 & 27 & 6 & 1 & 2 \\
\hline Percentage & 80.1 & 11.5 & 5.6 & 0.2 & 0.4 & 1.2 \\
\hline
\end{tabular}

CMA China Meteorological Administration; GHCND Global Historical Climatology Network-Daily; GSOD Global Surface Summary of the Day; ECA European Climate Assessment

period 1991-2013 for studying the precipitation change in the period 1901-2013. A total of 245 stations was selected, as shown in Fig. 3.17a. The stations are not dense enough, except for India and southwestern China.
For the analysis of extreme precipitation for the period 1961-2013, daily precipitation data were selected with at least 10 years of records in the base period 1961-90 and another 5 years in the period 1991-2013. In total, 1,024 stations were selected for use, and the spatial distribution was plotted in Fig. 3.17b. The stations are uniformly and densely distributed throughout this region, except for Afghanistan, Bangladesh, Bhutan, the Qinghai-Tibet Plateau, Myanmar, Nepal, and Pakistan, where the data coverage is relatively poor.

As the yearly precipitation records in the study region have huge discrepancies, PSA were used to calculate the regional averages of precipitation amount and to compare the changing trends in different parts of the HKH. PPA was 
Table 3.10 List of ETCCDI core extreme temperature indices used in this report

\begin{tabular}{l|l|l|l}
\hline & Indicator name & Definitions & Units \\
\hline DTR & $\begin{array}{l}\text { Diurnal } \\
\text { temperature } \\
\text { range }\end{array}$ & $\begin{array}{l}\text { Monthly mean difference } \\
\text { between TX and TN }\end{array}$ & ${ }^{\circ} \mathrm{C}$ \\
\hline FD & Frost days & $\begin{array}{l}\text { Annual count when TN (daily } \\
\text { minimum) }<0{ }^{\circ} \mathrm{C}\end{array}$ & Days \\
\hline SU & Summer days & $\begin{array}{l}\text { Annual count when TX (daily } \\
\text { maximum) }>25{ }^{\circ} \mathrm{C}\end{array}$ & Days \\
\hline TN10p & Cool nights & $\begin{array}{l}\text { Percentage of days when } \\
\text { TN }<10 t h \text { percentile }\end{array}$ & Days \\
\hline TN90p & Warm nights & $\begin{array}{l}\text { Percentage of days when } \\
\text { TN }>90 \text { th percentile }\end{array}$ & Days \\
\hline TNn & Min Tmin & $\begin{array}{l}\text { Monthly minimum value of } \\
\text { daily minimum temp }\end{array}$ & ${ }^{\circ} \mathrm{C}$ \\
\hline TX10p & Cool days & $\begin{array}{l}\text { Percentage of days when } \\
\text { TX }<10 \text { th percentile }\end{array}$ & Days \\
\hline TX90p & Warm days & $\begin{array}{l}\text { Percentage of days when } \\
\text { TX }>90 \text { th percentile }\end{array}$ & Days \\
\hline TXx & Max Tmax & $\begin{array}{l}\text { Monthly maximum value of } \\
\text { daily maximum temp }\end{array}$ & ${ }^{\circ} \mathrm{C}$ \\
\hline
\end{tabular}

Table 3.11 ETCCDI core extreme precipitation indices used in this chapter

\begin{tabular}{|c|c|c|c|}
\hline ID & Indicator name & Definitions & Units \\
\hline ATP & $\begin{array}{l}\text { Annual total } \\
\text { precipitation }\end{array}$ & $\begin{array}{l}\text { Annual total precipitation } \\
\text { when daily rainfall }>0.1 \mathrm{~mm}\end{array}$ & $\mathrm{~mm}$ \\
\hline $\mathrm{PA}$ & $\begin{array}{l}\text { Precipitation } \\
\text { anomaly }\end{array}$ & $\begin{array}{l}\text { The anomaly (based on 1961- } \\
\text { 90) of ATP }\end{array}$ & $\mathrm{mm}$ \\
\hline PSA & $\begin{array}{l}\text { Precipitation } \\
\text { standardized } \\
\text { anomaly }\end{array}$ & $\begin{array}{l}\text { PA divided by ATP standard } \\
\text { deviation (on 1961-90) }\end{array}$ & None \\
\hline PPA & $\begin{array}{l}\text { Precipitation } \\
\text { percentage } \\
\text { anomaly }\end{array}$ & $\begin{array}{l}\text { PA divided by ATP (on 1961- } \\
\text { 90) }\end{array}$ & $\%$ \\
\hline WD & Wet day & $\begin{array}{l}\text { Annual total days when daily } \\
\text { rainfall }>0.1 \mathrm{~mm}\end{array}$ & Day \\
\hline WDA & $\begin{array}{l}\text { Wet day } \\
\text { anomaly }\end{array}$ & $\begin{array}{l}\text { The anomaly (based on 1961- } \\
\text { 90) of WD }\end{array}$ & Day \\
\hline SDII & $\begin{array}{l}\text { Simple daily } \\
\text { intensity index }\end{array}$ & $\begin{array}{l}\text { ATP divided by WD, or } \\
\text { average daily precipitation }\end{array}$ & $\mathrm{mm} /$ day \\
\hline DPIA & $\begin{array}{l}\text { Daily } \\
\text { precipitation } \\
\text { intensity } \\
\text { anomaly }\end{array}$ & $\begin{array}{l}\text { The anomaly (based on 1961- } \\
\text { 90) of SDII }\end{array}$ & $\mathrm{mm} /$ day \\
\hline LR & Light rain & $\begin{array}{l}\text { Precipitation when daily } \\
\text { rainfall }<50 \text { th percentile }\end{array}$ & $\begin{array}{l}\mathrm{mm} \text { or } \\
\mathrm{d}\end{array}$ \\
\hline MR & Moderate rain & $\begin{array}{l}\text { Precipitation when daily } \\
\text { rainfall is between 50th and } \\
\text { 90th percentiles }\end{array}$ & $\begin{array}{l}\mathrm{mm} \text { or } \\
\mathrm{d}\end{array}$ \\
\hline IR & Intense rain & $\begin{array}{l}\text { Precipitation when daily } \\
\text { rainfall }>90 \text { th percentile }\end{array}$ & $\begin{array}{l}\mathrm{mm} \text { or } \\
\mathrm{d}\end{array}$ \\
\hline
\end{tabular}

Table 3.12 Basic information on the 24 CMIP5 models

\begin{tabular}{|c|c|c|}
\hline Model & Institution and country & $\begin{array}{l}\text { Resolution } \\
\text { (long. } \times \text { lat.) }\end{array}$ \\
\hline ACCESS1.0 & CSIRO-BOM/Australia & $192 \times 145$ \\
\hline BCC-CSM1.1 & $\begin{array}{l}\text { Beijing Climate Center, } \\
\text { CMA/China }\end{array}$ & $128 \times 64$ \\
\hline BNU-ESM & GCESS/China & $128 \times 64$ \\
\hline CanESM2 & $\begin{array}{l}\text { Canadian Centre for } \\
\text { Climate Modeling and } \\
\text { Analysis/Canada }\end{array}$ & $128 \times 64$ \\
\hline CCSM4 & NCAR/USA & $288 \times 192$ \\
\hline CESM1-BGC & $\begin{array}{l}\text { National Science } \\
\text { Foundation (NSF)- } \\
\text { Department of Energy } \\
\text { (DOE)-NCAR/USA }\end{array}$ & $288 \times 192$ \\
\hline CNRM-CM5 & $\begin{array}{l}\text { CNRM and } \\
\text { CERFACS/France }\end{array}$ & $256 \times 128$ \\
\hline CSIRO-Mk3-6-0 & $\begin{array}{l}\text { CSIRO and } \\
\text { QCCCE/Australia }\end{array}$ & $192 \times 96$ \\
\hline GFDL-ESM2G & NOAA/GFDL/USA & $144 \times 90$ \\
\hline GFDL-ESM2 M & NOAA/GFDL/USA & $144 \times 90$ \\
\hline HadGEM2-ES & $\mathrm{MOHC} / \mathrm{UK}$ & $192 \times 145$ \\
\hline HadGEM2-CC & $\mathrm{MOHC} / \mathrm{UK}$ & $192 \times 145$ \\
\hline HadCM3 & MOHC/UK & $96 \times 73$ \\
\hline INMCM4 & $\begin{array}{l}\text { Institute of Numerical } \\
\text { Mathematics (INM)/ } \\
\text { Russia }\end{array}$ & $180 \times 120$ \\
\hline IPSL-CM5A-LR & IPSL/France & $96 \times 96$ \\
\hline IPSL-CM5A-MR & IPSL/France & $144 \times 143$ \\
\hline MIROC5 & MIROC/Japan & $256 \times 128$ \\
\hline MIROC-ESM & MIROC/Japan & $128 \times 64$ \\
\hline MIROC-ESM-CHEM & MIROC/Japan & $128 \times 64$ \\
\hline MIROC4 h & MIROC/Japan & $640 \times 320$ \\
\hline MPI-ESM-LR & MPI-M/Germany & $192 \times 96 \mathrm{~L} 56$ \\
\hline MPI-ESM-MR & MPI-M/Germany & $192 \times 96 \mathrm{~L} 47$ \\
\hline MRI-CGCM3 & $\begin{array}{l}\text { Meteorological } \\
\text { Research } \\
\text { Institute/Japan }\end{array}$ & $320 \times 160$ \\
\hline NorESM1-M & $\begin{array}{l}\text { Norwegian Climate } \\
\text { Centre (NCC)/Norway }\end{array}$ & $144 \times 96$ \\
\hline
\end{tabular}

BOM Bureau of Meteorology; CMA China Meteorological Administration; CNRM Centre National de Recherches Météorologiques; CSIRO Commonwealth Scientific and Industrial Research Organisation; GCESS Global Change and Earth System Science; GFDL Geophysical Fluid Dynamics Laboratory; IPSL Institut Pierre-Simon Laplace; MIROC Model for Interdisciplinary Research on Climate; $M O H C$ Met Office Hadley Centre; MPI-M Max Planck Institute for Meteorology; NCAR National Center for Atmospheric Research; NOAA National Oceanic and Atmospheric Administration 
Fig. 3.17 Spatial distribution of precipitation stations in the Hindu Kush Himalaya. (a) 1901-2013 for monthly data; (b) 1961-2013 for daily data
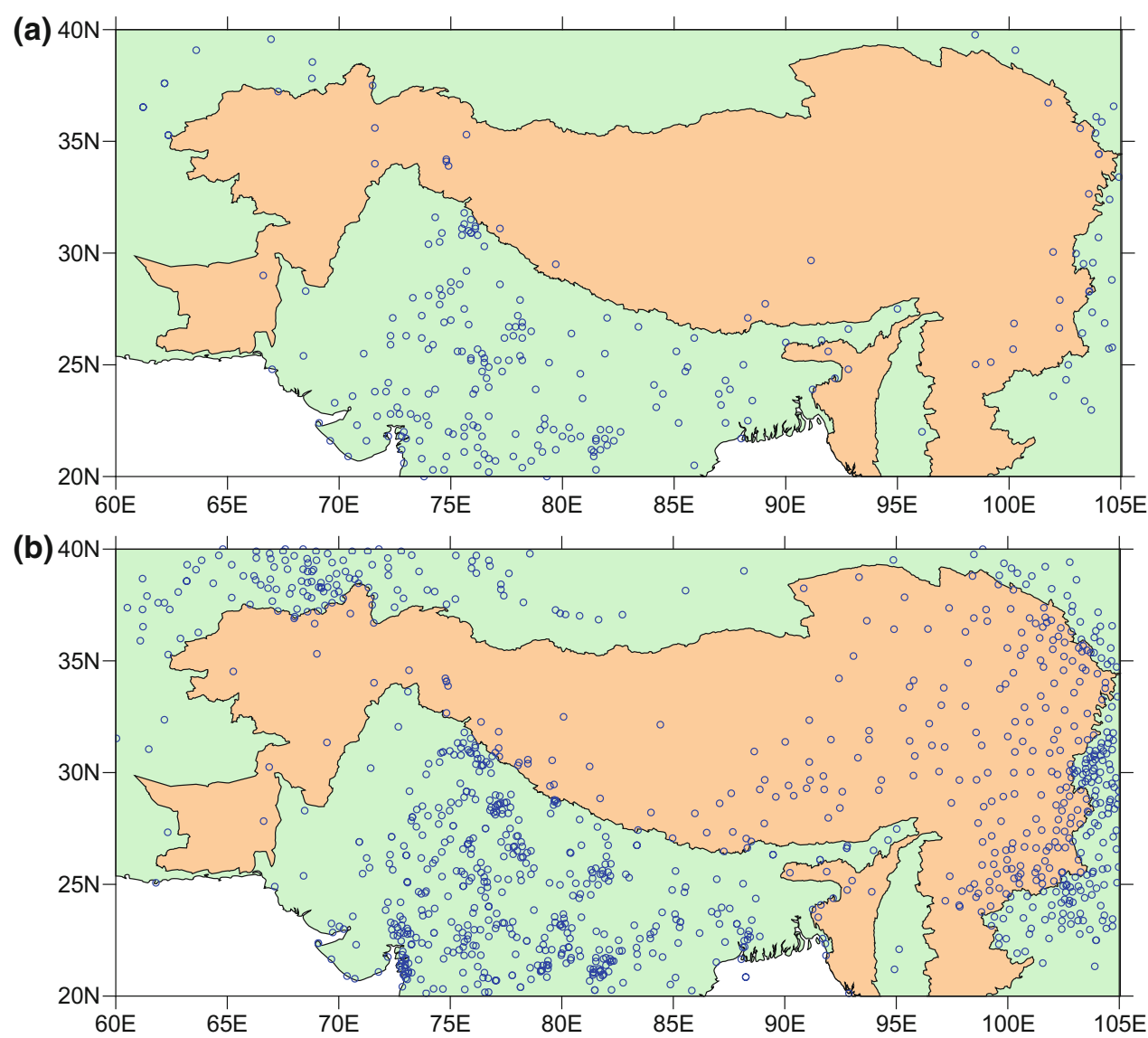

also used because it is sometimes a more useful indicator for comparing the regional and temporal differences of precipitation amount. For wet days or precipitation days, and simple daily intensity index (SDII) or daily precipitation intensity, however, the WDA and DPIA anomalies were applied for the analysis.

The relative threshold values were used to define the extreme precipitation events in the assessment report. A three-grade system was applied, with the light precipitation day defined as a day with the $24 \mathrm{~h}$ precipitation below the 50th percentile value of the reference period (1961-90). The moderate precipitation day was defined as a day with the $24 \mathrm{~h}$ precipitation between the 50th and 90th percentile values of the reference period. The intense precipitation day was defined as a day with the $24 \mathrm{~h}$ precipitation above the 90th percentile value of the reference period. The precipitation amount of the categories was the accumulated precipitation within the different grades of precipitation days, and the precipitation intensity was the precipitation amount divided by the precipitation days. The definitions of the indices used in this study are given in Table 3.11 (You et al. 2015; Zhang et al. 2011).

\section{Annex 3: Analysis of CMIP5 Data}

The projection of temperature and precipitation can help policy makers in their efforts to make decisions. The performance of climate models (for instance, in terms of their resolution and the complexity of the physical processes they can consider) has been improved greatly in recent years. As such, the outputs of these models have provided a solid basis for the projection of climate changes. Many researchers have, through historical analysis, been able to assess the capabilities of the climate models involved in CMIP3 and CMIP5. Based on these assessments, projections have been made with respect to the mean state and climate extremes over different regions in different periods of the 21 st century under various emissions scenarios.

In this study, we employed 24 model simulations from CMIP5 RCP4.5 and RCP8.5 (see Table 3.12 for model information). For comparison, the model outputs were interpolated onto a common $1 \times 1$. The equal weight averages of $24 \mathrm{GCM}$ were taken to be the projected changes, and the changes were relative to the baseline period (1976-2005). 
Fig. 3.18 Spatial distributions of mean temperature over the Hindu Kush Himalaya during 19762005 (units: ${ }^{\circ} \mathrm{C}$ ). (a) Observation; (b) the multi-model ensemble (a)

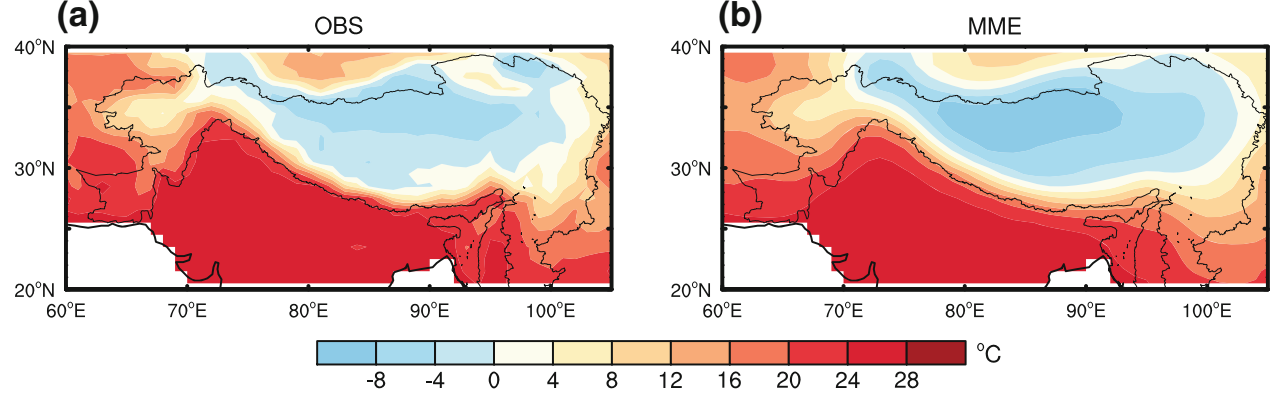

Fig. 3.19 Spatial distributions of mean precipitation over the Hindu Kush Himalaya during 19762005 (units: $\mathrm{mm}$ ); (a) observation; (b) the multi-model ensemble

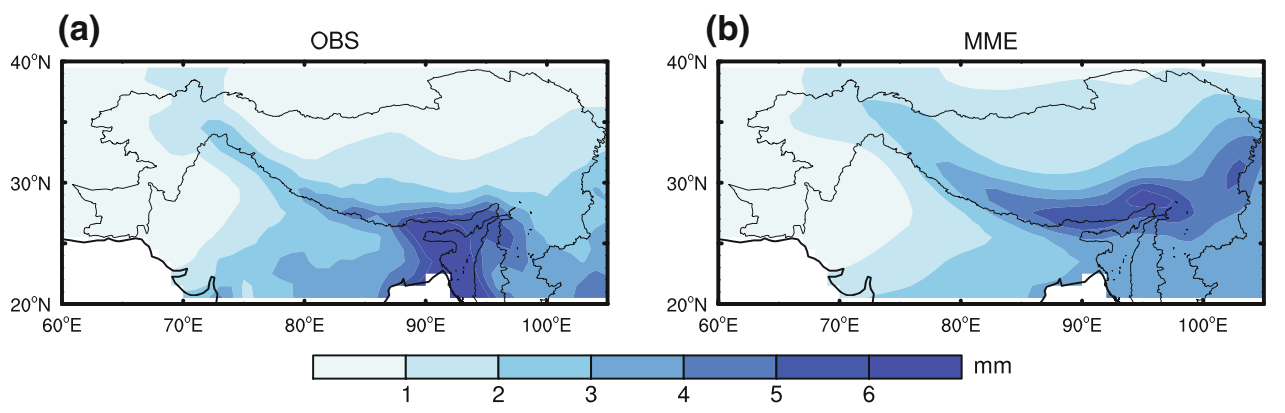

The assessments of temperature (Fig. 3.1) and precipitation (Fig. 3.2) over HKH during 1976-2005 were conducted using CRU data and CMIP5 model simulations. Overall, the multi-model ensemble can reproduce the spatial distribution of temperature and precipitation over $\mathrm{HKH}$, but it underestimates for temperature and overestimates for precipitation owing to lower resolution from CMIP5 global models (Figs. 3.18 and 3.19).

\section{Annex 4: Analysis of CORDEX Data}

A thorough understanding of the regional climate variability in the present and future time scales would enrich the information available for policy makers and stakeholders and allow them to make informed decisions. Since there is no pre-existing climate assessment of the HKH region, global climate projections available from CMIP using existing state-of-the-art coupled AOGCM need to be downscaled at high spatial resolution to resolve the complexities of the monsoon and other hydrological processes over regional scales. With this objective in mind, the Centre for Climate Change Research $\left(\mathrm{CCCR}^{12}\right)$ at the Indian Institute of Tropical Meteorology (IITM) and various international modelling centres are actively involved in the generation of regional climate change projections for South Asia by participating in CORDEX, the World Climate Research Programme (WCRP) initiative. ${ }^{13}$ These ensembles of dynamically downscaled projections of regional climate over the large domain covering South Asia (19.25oE$116.25 \mathrm{oE} ; 15.75 \mathrm{oS}-45.75 \mathrm{oN})$ using high-resolution $(50 \mathrm{~km})$ RCM are archived at CCCR-IITM, the nodal agency for CORDEX South Asia (Sanjay et al. 2017b). A high-end climate data server has been set up at CCCR-IITM for archiving and disseminating these high-resolution regional climate data sets through the CCCR web portal ${ }^{14}$ and by publishing on the CCCR-IITM Earth System Grid Federation (ESGF) data node. ${ }^{15}$ The list of models used in this study is provided in Table 3.13.

The WCRP's Working Group on Regional Climate and the Working Group on Coupled Modelling, the former coordinating body of CORDEX, and the responsible panel for CMIP5, are gratefully acknowledged. The climate modelling groups (listed in Table 3.12) are thanked sincerely for producing and making available their model output. The authors thank the ESGF infrastructure and the climate data portal hosted at the CCCR, IITM, for providing CORDEX South Asia data.

\footnotetext{
${ }^{12} \mathrm{http} / / / \mathrm{cccr}$. tropmet.res.in/home/index.jsp.
}

\footnotetext{
${ }^{13} \mathrm{http}: / /$ www.cordex.org/.

${ }^{14} \mathrm{http}: / /$ cccr.tropmet.res.in/home/data_portals.jsp.

${ }^{15} \mathrm{http} / / / \mathrm{cccr}$. tropmet.res.in/home/esgf_data.jsp.
} 
Table 3.13 The 13 CORDEX South Asia downscaled regional climate model simulations driven by 10 CMIP5 general circulation models

\begin{tabular}{|c|c|c|c|c|}
\hline $\begin{array}{l}\text { CORDEX South Asia } \\
\text { RCM }\end{array}$ & RCM description & $\begin{array}{l}\text { Contributing } \\
\text { CORDEX modelling } \\
\text { centre }\end{array}$ & Driving CMIP5 GCM ${ }^{\mathrm{a}}$ & $\begin{array}{l}\text { Contributing CMIP5 modelling } \\
\text { centre }\end{array}$ \\
\hline \multirow[t]{6}{*}{$\begin{array}{l}\text { IITM-RegCM4 (six } \\
\text { ensemble members) }\end{array}$} & \multirow{6}{*}{$\begin{array}{l}\text { Abdus Salam ICTP } \\
\text { Regional Climatic } \\
\text { Model version } 4 \\
\text { (RegCM4; Giorgi et al. } \\
\text { 2012) }\end{array}$} & \multirow[t]{6}{*}{ CCCR, IITM, India } & CCCma-CanESM2 & $\begin{array}{l}\text { Canadian Centre for Climate } \\
\text { Modelling and Analysis } \\
\text { (CCCma), Canada }\end{array}$ \\
\hline & & & NOAA-GFDL-GFDL-ESM2 M & NOAA, GFDL, USA \\
\hline & & & CNRM-CM5 & CNRM, France \\
\hline & & & MPI-ESM-MR & MPI-M, Germany \\
\hline & & & IPSL-CM5A-LR & IPSL, France \\
\hline & & & CSIRO-Mk3.6 & $\begin{array}{l}\text { Commonwealth Scientific and } \\
\text { Industrial Research } \\
\text { Organisation (CSIRO), } \\
\text { Australia }\end{array}$ \\
\hline \multirow[t]{6}{*}{$\begin{array}{l}\text { SMHI-RCA4 (six } \\
\text { ensemble members) }\end{array}$} & \multirow{6}{*}{$\begin{array}{l}\text { Rossby Centre regional } \\
\text { atmospheric model } \\
\text { version } 4 \text { (RCA4; } \\
\text { Samuelsson et al. } \\
\text { 2011) }\end{array}$} & \multirow{6}{*}{$\begin{array}{l}\text { Rossby Centre, } \\
\text { Swedish } \\
\text { Meteorological and } \\
\text { Hydrological Institute } \\
\text { (SMHI), Sweden }\end{array}$} & ICHEC-EC-EARTH & $\begin{array}{l}\text { Irish Centre for High-End } \\
\text { Computing (ICHEC), } \\
\text { European Consortium (EC) }\end{array}$ \\
\hline & & & MIROC-MIROC5 & $\begin{array}{l}\text { Model for Interdisciplinary } \\
\text { Research On Climate } \\
\text { (MIROC), Japan Agency for } \\
\text { Marine-Earth Sci. and Tech., } \\
\text { Japan }\end{array}$ \\
\hline & & & NOAA-GFDL-GFDL-ESM2 M & NOAA, GFDL, USA \\
\hline & & & CNRM-CM5 & CNRM, France \\
\hline & & & MPI-ESM-LR & MPI-M, Germany \\
\hline & & & IPSL-CM5A-MR & IPSL, France \\
\hline $\begin{array}{l}\text { MPI-CSC-REMO2009 } \\
\text { (one ensemble } \\
\text { member) }\end{array}$ & $\begin{array}{l}\text { MPI Regional model } \\
2009 \text { (REMO2009; } \\
\text { Teichmann et al. 2013) }\end{array}$ & $\begin{array}{l}\text { Climate Service } \\
\text { Center (CSC), } \\
\text { Germany }\end{array}$ & MPI-ESM-LR & MPI-M, Germany \\
\hline
\end{tabular}

${ }^{a}$ https://verc.enes.org/data/enes-model-data/cmip5/resolution). CCCR Centre for Climate Change Research; CNRM Centre National de Recherches Météorologiques; GFDL Geophysical Fluid Dynamics Laboratory; ICTP International Centre for Theoretical Physics; IITM Indian Institute of Tropical Meteorology; IPSL Institut Pierre-Simon Laplace; MPIM Max Planck Institute for Meteorology; NOAA National Oceanic and Atmospheric Administration; $R C M$ regional climate model

\section{References}

Alexander, L. V., Zhang, X., Peterson, T. C., Caesar, J., Gleason, B., Klein Tank, A. M. G., et al. (2006). Global observed changes in daily climate extremes of temperature and precipitation. Journal of Geophysical Research: Atmospheres, 111(D5).

An, C. B., Tang, L., Barton, L., \& Chen, F. H. (2005). Climate change and cultural response around $4000 \mathrm{cal}$ yr B.P. in the western part of Chinese Loess Plateau. Quaternary Research, 63(3), 347-352.

Archer, D. R., \& Fowler, H. (2004). Spatial and temporal variations in precipitation in the Upper Indus Basin, global teleconnections and hydrological implications. Hydrology and Earth System Sciences, 8 (1), 47-61.

Asahi, K., \& Watanabe, T. (2004). Paleoclimate of the Nepal Himalayas during the last glacial: Reconstructing from glacial equilibrium-line altitude. Himalayan Journal of Science, 2(Special Issue), 100-101.

Barlow, M., Matthew, W., Bradfield, L., \& Heidi, C. (2005). Modulation of daily precipitation over southwest Asia by the Madden-Julian oscillation. Monthly Weather Review, 133(12), 3579-3594.
Bharati, L., Gurung, P., Maharjan, L., \& Bhattarai, U. (2016). Past and future variability in the hydrological regime of the Koshi Basin, Nepal. Hydrological Sciences Journal, 61(1), 79-93.

Bhutiyani, M. R., Vishwas, S. K., \& Pawar, N. J. (2007). Long-term trends in maximum, minimum and mean annual air temperatures across the Northwestern Himalaya during the twentieth century. Climatic Change, 85(1-2), 159-177.

Bhutiyani, M. R., Kale, V. S., \& Pawar, N. J. (2009). Climate change and the precipitation variations in the northwestern Himalaya: 1866-2006. International Journal of Climatology, 30(4), 535-548.

Bookhagen, B., \& Burbank, D. W. (2006). Topography, relief, and TRMM-derived rainfall variations along the Himalaya. Geophysical Research Letters, 33(8).

Bookhagen, B., \& Burbank, D. W. (2010). Toward a complete Himalayan hydrological budget: Spatiotemporal distribution of snowmelt and rainfall and their impact on river discharge. Journal of Geophysical Research: Earth Surface, 115(3), F03019. https:// doi.org/10.1029/2009/2009JF001426.

Borgaonkar, H. P., Ram, S., \& Sikder, A. B. (2009). Assessment of tree-ring analysis of high-elevation Cedrus deodara D. Don from Western Himalaya (India) in relation to climate and glacier fluctuations. Dendrochronologia, 27(1), 59-69. 
Cannon, F., Carvalho, L. M. V., Jones, C., \& Bookhagen, B. (2015). Multi-annual variations in winter westerly disturbance activity affecting the Himalaya. Climate Dynamics, 44, 441-455. https://doi. org/10.1007/s00382-014-2248-8.

Cannon, F., Carvalho, L. M. V., Jones, C., Hoell, A., Norris, J., Kiladis, G. N., et al. (2017). The influence of tropical forcing on extreme winter precipitation in the western Himalaya. Climate Dynamics, 48 (3), 1213-1232.

Chen, B., Chao, W. C., \& Liu, X. (2003). Enhanced climatic warming in the Tibetan Plateau due to doubling CO2: A model study. Climate Dynamics, 20, 401-413.

Cho, C., Li, R., Wang, S. Y., Ho, J., \& Robert, Y. (2016). Anthropogenic footprint of climate change in the June 2013 Northern India flood. Climate Dynamics, 46, 797-805.

Choi, G., Collins, D., Ren, G., Trewin, B., Baldi, M., Fukuda, Y., et al. (2009). Changes in means and extreme events of temperature and precipitation in the Asia-Pacific Network region, 1955-2007. International Journal of Climatology, 29, 1906-1925. https://doi. org/10.1002/joc. 1979.

Choudhary, A., \& Dimri, A. P. (2017). Assessment of CORDEX-South Asia experiments for monsoonal precipitation over Himalayan region for future climate. Climate Dynamics. https://doi.org/10. 1007/s00382-017-3789-4.

Chu, Z. Y., Ren, G. Y., Shao, X. M., \& Liu, H. B. (2005). A preliminary reconstruction of mean surface air temperature over the past 1000 years in China. Climatic and Environmental Research, 10(4), 826-836.

Cook, E. R., Krusic, P. J., \& Jones, P. D. (2003). Dendroclimatic signals in long tree-ring chronologies from the Himalayas of Nepal. International Journal of Climatology, 23, 707-732.

Dhar, O. N., Soman, M. K., \& Mulye, S. S. (1984). Rainfall over the southern slopes of the Himalayas and the adjoining plains during breaks in the monsoon. Journal of Climatolgy, 4(6), 671-676.

Diaz, H. F., \& Bradley, R. S. (1997). Temperature variations during the last century at high elevation sites. Climatic Change, 36, 253-279.

Dimri, A. P., \& Chevuturi, A. (2016). Western disturbances-An Indian meteorological perspective (p. 127). Switzerland: Springer International Publishing.

Dimri, A. P., Niyogi, D., Barros, A. P., Ridley, J., Mohanty, U. C., Yasunari, T., et al. (2015). Western disturbances: A review. Reviews of Geophysics, 53(2), 225-246.

Ding, Y. H., \& Ren, G. Y. (2008). An introduction to China climate change science. Beijing: China Meteorological Press.

Ding, Y. H., \& Zhang, L. (2008). Intercomparison of the time for climate abrupt change between the Tibetan Plateau and other regions in China. Chinese Journal of Atmospheric Sciences, 32(4), 794-805.

Dixit, Y., Hodell, D. A., \& Petrie, C. A. (2015). Abrupt weakening of the summer monsoon in northwest India $\sim 4100 \mathrm{yr}$ ago. Geology, 42(4), 339-342.

Du, J. (2001). Change of temperature in Tibetan Plateau from 1961 to 2000. Acta Geographica Sinica, 56, 690-698. (in Chinese).

Duan, A. M., \& Wu, G. X. (2006). Change of cloud amount and the climate warming on the Tibetan Plateau. Geophysical Research Letters, 33(22), L22704.

Duan, A. M., \& Xiao, Z. X. (2015). Does the climate warming hiatus exist over the Tibetan Plateau? Scientific Reports, 5, 13711

Duan, A. M., Wu, G. X., Zhang, Q., \& Liu, Y. M. (2006). New proofs of the recent climate warming over the Tibetan Plateau as a result of the increasing greenhouse gases emissions. Chinese Science Bulletin, 51(11), 1396-1400.

Eriksson, M., Xu, J., Shrestha, A. B., Vaidya, R. A., Nepal, S., \& Sandström, K. (2009). The changing Himalayas: Impact of climate change on water resources and livelihoods in the greater Himalayas. Kathmandu: ICIMOD.
Fan, X., Wang, Q., Wang, M., \& Jimenez, C. V. (2015). Warming Amplification of minimum and maximum temperatures over high-elevation regions across the globe. PLOS ONE, 10, e0140213.

Forsythe, N., Fowler, H. J., Li, X.-F., Blenkinsop S., \& Pritchard, D. (2017). Karakoram temperature and glacial melt driven by regional atmospheric circulation variability. Nature Climate Change 7(9). https://doi.org/10.1038/nclimate3361.

Friedlingstein, P., Andrew, R. M., Rogelj, J., Peters, G. P., Canadell, J. G., Knutti, R., et al. (2014). Persistent growth of $\mathrm{CO}_{2}$ emissions and implications for reaching climate targets. Nature Geoscience, 7 (10), 709.

Gardelle, J., Berthier, E., \& Arnaud, Y. (2012). Slight mass gain of Karakoram glaciers in the early twenty-first century. Nature Geoscience, 5(5), 322-325. https://doi.org/10.1038/NGEO1450.

Giorgi, F., Coppola, E., Solmon, F., Mariotti, L., Sylla, M. B., Bi, X., et al. (2012). RegCM4: Model description and preliminary tests over multiple CORDEX domains. Climate Research, 52(1), 7-29.

Goswami, B. N., Venugopal, V., Sengupta, D., Madhusoodanan, M. S., \& Xavier, P. K. (2006). Increasing trend of extreme rain events over India in a warming environment. Science, 314(5804), 1442-1444.

Guo, D., Yu, E., \& Wang, H. (2016). Will the Tibetan Plateau warming depend on elevation in the future? Journal of Geophysical Research: Atmospheres, 121(8), 3969-3978.

Hasson, S., Lucarini, V., \& Pascale, S. (2013). Hydrological cycle over South and Southeast Asian river basins as simulated by PCMDI/CMIP3 experiments. Earth System Dynamics, 4(2), 199217. https://doi.org/10.5194/esd-4-199-2013.

Hasson, S., Lucarini, V., Khan, M. R., Petitta, M., Bolch, T., \& Gioli, G. (2014). Early 21 st century snow cover state over the western river basins of the Indus River system. Hydrology Earth System Sciences, 18(10), 4077-4100.

Hasson, S., Pascale, S., Lucarini, V., \& Böhner, J. (2015). Seasonal cycle of precipitation over major river basins in South and Southeast Asia: A review of the CMIP5 climate models data for present climate and future climate projections. Atmospheric Research, 180, 42-63.

Hewitt, K. (2005). The Karakoram anomaly? Glacier expansion and the "elevation effect" Karakoram Himalaya. Mountain Research and Development, 25(4), 332-340.

Hoffmann, U. (2013). Section B: Agriculture-A key driver and a major victim of global warming. Lead Article, 3, 5. Chapter 1. Hoffmann.

Houze, R. A., Jr., Wilton, D. C., \& Smull, B. F. (2007). Monsoon convection in the Himalayan region as seen by the TRMM precipitation radar. Quarterly Journal of Royal Meteorology Society, 133(627), 1389-1411.

Houze, R. A., Jr., Rassmussen, K. L., Medina, S., Brodzik, S. R., \& Romastshke, U. (2011). Anomolous atmospheric events leading to the summer 2010 floods in Pakistan. Bulletin of American Meteorological Society, 92I(2), 291-298. https://doi.org/10.1175/ 2010BAMS3173.1.

Immerzeel, W. W., \& Bierkens, M. F. P. (2012). Asia's water balance. Nature Geoscience, 5(12), 841-842.

Immerzeel, W. W., Droogers, P., Jong, S. M. D., \& Bierkens, M. F. P. (2009). Large-scale monitoring of snow cover and runoff simulation in Himalayan river basins using remote sensing. Remote Sensing of Environment, 113(1), 40-49.

Immerzeel, W. W., Van Beek, L. P. H., \& Bierkens, M. F. P. (2010). Climate change will affect the Asian water towers. Science, 328 (5984), 1382-1385.

IPCC. (2000). Special report on emmission scenarios (p. 570). Cambridge: Intergovernmental Panel on Climate Change.

IPCC. (2007). In: S. Solomon, D. Qin, M. Manning, Z. Chen, M. Marquis, K. B. Averyt, et al. (Eds.), Climate Change 2007: The Physical Science Basis. Contribution of Working Group I to the 
Fourth Assessment Report of the Intergovernmental Panel on Climate Change (p. 996) Cambridge, United Kingdom and New York, USA: Cambridge University Press.

IPCC. (2013). Climate change. The physical science basis. Work Group Contribution to the IPCC Fifth Assessment Report (AR5). Stockholm, Sweden: Intergovernmental Panel on Climate Change.

Jones, P. D., \& Moberg, A. (2003). Hemispheric and large-scale surface air temperature variations: An extensive revision and an update to 2001. Journal of Climate, 16(2), 206-223.

Kääb, A., Treichler, D., Nuth, C., \& Berthier, E. (2015). Brief Communication: Contending estimates of 2003-2008 glacier mass balance over the Pamir-Karakoram-Himalaya. The Cryosphere, 9 (2), 557-564. https://doi.org/10.5194/tc-9-557-2015.

Kang, S. C., Xu, Y. W., You, Q. L., Flugel, W. A., Pepin, N., \& Yao, T. D. (2010). Review of climate and cryospheric change in the Tibetan Plateau. Environmental Research Letters, 5(1).

Kapnick, S. B., Delworth, T. L., Ashfaq, M., Malyshev, S., \& Milly, P. C. D. (2014). Snowfall less sensitive to warming in Karakoram than in Himalayas due to a unique seasonal cycle. Nature Geoscience, 7(11), 834-840.

Kitoh, A. (2017). The Asian monsoon and its future change in climate models: A review. Journal of Meteorological Society of Japan. https://doi.org/10.2151/jmsj.2017-002.

Klein Tank, A. M. G., Peterson, T. C., Quadir, D. A., Dorji, S., Zou, X., Tang, H., et al. (2006). Changes in daily temperature and precipitation extremes in Central and South Asia. Journal of Geophysical Research, 111(D16). https://doi.org/10.1029/ $2005 \mathrm{jd} 006316$.

Kosaka, Y., \& Xie, S. (2013). Recent globalwarming hiatus tied to equatorial Pacific surface cooling. Nature, 501(7467), 403-407.

Kothawale, D. R., \& Rupa Kumar, K. (2005). On the recent changes in surface temperature trends over India. Geophysical Research Letters, 32(18). https://doi.org/10.1029/2005g1023528.

Krishna Kumar, K., Rajagapalan, B., Hoerling, M., Bates, G., \& Cane, M. (2006). Unraveling the mystery of Indian monsoon failure during El Nino. Science, 314(5796), 115-119.

Krishnan, R., Zhang, C., \& Sugi, M. (2000). Dynamics of breaks in the Indian summer monsoon. Journal of Atmospheric Sciences, 57(9), 1354-1372.

Krishnan, R., Ramesh, K. V., Samala, B. K., Meyers, G., Slingo, J. M., \& Fennessy, M. J. (2006). Indian Ocean-Monsoon coupled interactions and impending monsoon droughts. Geophysical Research Letters, 33(8), L08711. https://doi.org/10.1029/2006GL025811.

Krishnan, R., Kumar, V., Sugi, M., \& Yoshimura, J. (2009). Internal feedbacks from monsoon-midlatitude interactions during droughts in the Indian summer monsoon. Journal of Atmospheric Sciences, 66(3), 553-578.

Krishnan, R., Sabin, T. P., Ayantika, D. C., Kitoh, A., Sugi, M., Murakami, H., et al. (2013). Will the South Asian monsoon overturning circulation stabilize any further? Climate Dynamics, 40 (1-2), 187-211. https://doi.org/10.1007/s00382-012-1317-0.

Krishnan, R., Sabin, T. P., Vellore, R., Mujumdar, M., Sanjay, J., Goswami, B. N., et al. (2016). Deciphering the desiccation trend of the South Asian monsoon hydroclimate in a wamming world. Climate Dynamics, 47(3-4), 1007-1027. https://doi.org/10.1007/ s00382-015-2886-5.

Krishnan, R., Sabin, T. P., Ranade, M., Vellore, R., Mujumdar, M., Sanjay, J., et al. (2018). Non-monsoonal precipitation response over the Western Himalayas to climate change. Climate Dynamics, https://doi.org/10.1007/s00382-018-4357-2.

Kuang, X., \& Jiao, J. J. (2016). Review on climate change on the Tibetan Plateau during the last half century. Journal of Geophysical Research: Atmospheres, 121(8), 3979-4007.

Kulkarni, A., Patwardhan, S., Kumar, K. K., Ashok, K., \& Krishnan, R. (2013). Projected climate change in the Hindu Kush-Himalayan region by using the high-resolution regional climate model PRECIS. Mountain Research and Development, 33(2), 142-151.

Kumar, K. K., Patwardhan, S. K., Kulkarni, A., Kamala, K., Rao, K. K., \& Jones, R. (2011). Simulated projections for summer monsoon climate over India by a high-resolution regional climate model (PRECIS). Current Science, 101(3), 312-326.

Kutzbach, J. E. (1981). Monsoon climate of the early Holocene: Climate experiment with the earth's orbital parameters for 9000 years ago. Science, 214(4516), 59-61.

Kutzbach, J. E., \& Otto-Bliesner, B. L. (1982). The sensitivity of the African-Asian monsoonal climate to orbital parameter changes for 9000 years B.P. in a low-resolution general circulation model. Journal of the Atmospheric Sciences, 39(6), 1177-1188.

Lau, W. K., \& Kim, K.-M. (2012). The 2010 Pakistan flood and the Russia heat wave: Teleconnection of extremes. Journal of Hydrometeorology, 13(1), 392-403. https://doi.org/10.1175/JHM-D-11016.1 .

Liu, X., \& Chen, B. (2000). Climatic warming in the Tibetan Plateau during recent decades. International Journal of Climatology, 20 (14), 1729-1742.

Liu, X. H., Qin, D. H., Shao, X. M., Chen, T., \& Jiawen, R. (2005). Temperature variations recovered from tree-rings in the middle Qilian Mountain over the last millennium. Science in China Series D: Earth Sciences, 48(4), 521-529.

Liu, X., Yin, Z. Y., Shao, X., \& Qin, N. (2006). Temporal trends and variability of daily maximum and minimum, extreme temperature events, and growing season length over the eastern and central Tibetan Plateau during 1961-2003. Journal of Geophysical Research:Atmospheres, 111, D19109.

Liu, X., Cheng, Z., Yan, L., \& Yin, Z. Y. (2009a). Elevation dependency of recent and future minimum surface air temperature trends in the Tibetan Plateau and its surroundings. Global and Planetary Change, 68(3), 164-174.

Liu, X. F., Jiang, Y., Ren, G. Y., Liang, X. H., \& Zhang, C. W. (2009b). Influence of urbanization and observational setting change on data series of near-surface wind speed in Hebei Province, China. Plateau Meteorology, 28(2), 433-439.

Lutz, A. F., Immerzeel, W. W., Shrestha, A. B., \& Bierkens, M. F. P. (2014). Consistent increase in High Asia's runoff due to increasing glacier melt and precipitation. Climate Dynamics, 4(7), 587-592. https://doi.org/10.1038/nclimate2237.

Madhura, R. K., Krishnan, R., Revadekar, J. V., Mujumdar, M., \& Goswami, B. N. (2015). Changes in western disturbances over the Western Himalayas in a warming environment. Climate Dynamics, 44(3-4), 1157-1168. https://doi.org/10.1007/s00382-014-2166-9.

Mann, M. E., Raymond, S. B., \& Malcolm, K. H. (1999). Northern hemisphere temperatures during the past millennium: Inferences, uncertainties, and limitations. Geophysical Research Letters, 26(6), 759-762.

Medina, S., Houze, R. A., Kumar, A., \& Niyogi, D. (2010). Summer monsoon convection in the Himalayan region: Terrain and land cover effects. Quarterly Journal of the Royal Meteorological Society, 136(648), 593-616. https://doi.org/10.1002/qj.601.

Meinshausen, M., Smith, S. J., Calvin, K., Daniel, J. S., Kainuma, M. L. T., Lamarque, J. F., et al. (2011). The RCP greenhouse gas concentrations and their extensions from 1765 to 2300. Climatic Change, 109(1), 213.

Mishra, V. (2015). Climatic uncertainty in Himalayan water towers. Journal of Geophysical Research: Atmospheres, 120(7), 2680 2705. https://doi.org/10.1002/2014JD022650.

Mountain Research Initiative EDW Working Group. (2015). Elevation-dependent warming in mountain regions of the world. Nature Climate Change, 5(5), 424-430.

Mujumdar, M., Preethi, B., Sabin, T. P., Ashok, K., Saeed, S., Pai, D. S., et al. (2012). The Asian summer monsoon response to the La 
Nina event of 2010. Meteorological Applications, 19(2), 216-225. https://doi.org/10.1002/met.1301.

Nan, S., Zhao, P., Yang, S., \& Chen, J. (2009). Springtime tropospheric temperature over the Tibetan Plateau and evolution of the tropical Pacific SST. Journal of Geophysical Research: Atmospheres, 114 (10). https://doi.org/10.1029/2008jd011559.

Nepal, S., \& Shrestha, A. B. (2015). Impact of climate change on the hydrological regime of the Indus, Ganges and Brahmaputra river basins: A review of the literature. International Journal of Water Resources Development, 31(2), 201-218. https://doi.org/10.1080/ 07900627.2015.1030494.

Palazzi, E., Hardenberg, J., \& Provenzale, A. (2013). Precipitation in the Hindu-Kush Karakoram Himalaya: Observations and future scenarios. Journal of Geophysical Research: Atmospheres, 118, 85100.

Panday, P. K., Thibeaultb, J., \& Freyc, K. E. (2014). Changing temperature and precipitation extremes in the Hindu Kush-Himalayan region: An analysis of CMIP3 and CMIP5 simulations and projections. International Journal of Climatology, 35(10), 3058-3077. https://doi.org/10.1002/joc.4192.

Pepin, N. C., Bradley, S., Diaz, H. F., Baraer, M., Caceres, E. B., Forsythe, N., et al. (2015). Elevation-dependent warming in mountain regions of the world. Nature Climate Change, 5(5), 424-430.

Peters, G. P., Andrew, R. M., Boden, A. T., Canadell, J. G., Quéré, C. L., Marland, G., et al. (2012). The challenges to keep global warming below $2{ }^{\circ} \mathrm{C}$. Nature Climate Change, 3, 4-6.

Porter, J. R., Xie, L., Challinor, A. J., Cochrane, K., Howden, S. M., Iqbal, M. M., et al. (2014). Food security and food production systems. In: C. B. Field, V. R. Barros, D. J. Dokken, K. J. Mach, M. D. Mastrandrea, T. E. Bilir, M. Chatterjee, K. L. Ebi, Y. O. Estrada, R. C. Genova, B. Girma, E. S. Kissel, A. N. Levy, S. MacCracken, P. R. Mastrandrea, L. L. White (Eds.), Climate Change 2014: Impacts, Adaptation, and Vulnerability. Part A: Global and Sectoral Aspects. Contribution of Working Group II to the Fifth Assessment Report of the Intergovernmental Panel on Climate Change. (pp. 485-533). Cambridge University Press, Cambridge, United Kingdom and New York, NY, USA.

Prell, W. L., \& Kutzbach, J. E. (1987). Monsoon variability over the past 150,000 years. Journal of Geophysical Research, 92, 84118425 .

Qian, W.-H., Fu, J., Zhang, W., \& Lin, X. (2007). Changes in mean climate and extreme climate in China during the last 40 years. Advances in Earth Science, 23(7), 674-683.

Qin, D. H., Ding, Y. H., \& Su, J. L. (2005). Assessment of climate and environment changes in China (I): Climate and environment changes in China and their Projection. Advances in Climate Change Research, 1, 4-9.

Rajbhandari, R., Shrestha, A. B., Kulkarni, A., Patwardhan, S. K., \& Bajracharya, S. R. (2015). Projected changes in climate over the Indus river basin using a high resolution regional climate model (PRECIS). Climate Dynamics, 44(1), 339-357. https://doi.org/10. 1007/s00382-014-2183-8.

Rajbhandari, R., Shrestha, A. B., Nepal, S., \& Wahid, S. (2016). Projection of future climate over the Koshi River Basin based on CMIP5 GCMs. Atmospheric and Climate Sciences, 6(2), 190-204. https://doi.org/10.4236/acs.2016.62017.

Rajbhandari, R., Shrestha, A. B., Nepal, S., Wahid, S., \& Ren, G.-Y. (2017). Extreme climate projections over the transboundary Koshi River Basin using a high resolution regional climate model. Advances in Climate Change Research, 8(3), 199-211.

Rajeevan, M., Gadgil, S., \& Bhate, J. (2010). Active and break spells of the Indian summer monsoon. Journal of Earth System Science, 119 (3), 229-248.

Ramamurthy, K. (1969). Monsoon of India: Some aspects of the 'break' in the Indian southwest monsoon during July and August.
Forecasting Manual 1-57 No. IV 18.3, India Meteorological Department, Poona, India.

Rao, Y. P. (1976). Southwest monsoon (meteorological monograph). India Meteorological Department, New Delhi, p. 366.

Ren, G., \& Shrestha, A. B. (2017). Climate change in the Hindu Kush Himalaya. Advance in Climate Change Research 8(3), 130-140.

Ren, G. Y., \& Zhou, Y. Q. (2014). Urbanization effect on trends of extreme temperature indices of national stations over mainland China. 1961-2008. Journal of Climate, 27(6), 2340-2360.

Ren, G. Y., Wu, H., \& Chen, Z. H. (2000). Spatial patterns of change trend in rainfall of China. Quarterly Journal of Applied Meteorology, 11(3), 322-330. (in Chinese).

Ren, G.-Y., Guo, J., Xu, M. Z., Chu, Z. Y., Zhang, L., Zou, X. K., et al. (2005). Climate changes of China mainland over the past half century. Acta Meteorological Sinica, 53(6), 942-956. (in Chinese).

Ren, G., Ding, Y., Zhao, Z., Zheng, J., Wu, T., Tang, G., et al. (2012). Recent progress in studies of climate change in China. Advance in Atmospheric Sciences, 29(5), 958-977.

Ren, G., Ren, Y., Li, Q., \& Xu, W. (2014). An overview on global land surface air temperature change. Advances in Earth Science, 29(8), 934-946. (in Chinese).

Ren, Y.-Y., Parker, D., Ren, G.-Y., \& Dunn, R. (2015). Tempo-spatial characteristics of sub-daily temperature trends in mainland China. Climatic Dynamics, 46(9-10), 2737-2748. https://doi.org/10.1007/ s00382-015-2726-7.

Ren, Y.-Y., Ren, G.-Y., Sun, X.-B., Shrestha, A. B., You, Q.-L., Zhan, Y.-J., et al. (2017). Observed changes in surface air temperature and precipitation in the Hindu Kush Himalayan region during 19012014. Advance in Climate Change Research, 8(3). https://dx.doi. org/10.1016/j.accre.2017.08.001.

Ridley, J., Wiltshire, A., \& Mathison, C. (2013). More frequent occurrence of westerly disturbances in Karakoram up to 2100. Science of the Total Environment, 468-469, S31-S35.

Saeed, S., Müller, W. A., Hagamenn, S., \& Jacob, D. (2010). Circumglobal wave train and summer monsoon over northwestern India and Pakistan: The explicit role of the surface heat low. Climate Dynamics, 37(5), 1045-1060. https://doi.org/10.1007/ s00382-010-0888-x.

Saeed, S., Müller, W. A., Hagemann, S., Jacob, D., Mujumdar, M., \& Krishnan, R. (2011). Precipitation variability over the South Asian monsoon heat low and associated teleconnections. Geophysical Research Letters, 38(8). https://doi.org/10.1029/2011g1046984.

Sanjay, J., Ramarao, M. V. S., Mujumdar, M. \& Krishnan, R. (2017a). In: M. Rajeevan \& S. Nayak (Eds.), Regional climate change scenarios. Chapter 16 in the book: Observed climate variability and change over the Indian region (pp. 285-304). Springer Geology. https://doi.org/10.1007/978-981-10-2531-0.

Sanjay, J., Krishnan, R., Shrestha, A. B., Rajbhandari, R., \& Ren, G. Y. (2017b). Downscaled climate change projections for the Hindu Kush Himalayan region using CORDEX South Asia regional climate models. Advances in Climate Change Research, 8(3), 185198. https://doi.org/10.1016/j.accre.2017.08.003.

Samuelsson, P., Jones, C., Willen, U., Ullerstig, A., and co-authors. (2011). The Rossby Centre Regional Climate model RCAS3: model description and performance, Tellus, 63A, 4-23.

Shao, X., Huang, L., Liu, H., Liang, E., Fang, X., \& Wang, L. (2005). Reconstruction of precipitation variation from tree rings in recent 1000 years in Delingha, Qinghai. Science in China, Series D: Earth Sciences, 48, 939-949.

Shao, X. M., Xu, Y., Yin, Z. Y., Liang, E., Zhu, H., \& Wang, S. (2010). Climatic implications of a 3585-year tree-ring width chronology from the northeastern Qinghai-Tibetan Plateau. Quaternary Science Reviews, 29(17), 2111-2122.

Sharma, E., Molden, D., Wester, P., \& Shrestha, R. M. (2016). The Hindu Kush Himalayan monitoring and assessment programme: 
Action to sustain a global asset. Mountain Research and Development, 36(2), 236-239.

Shrestha, A. B. (2008a). Resouce Manual on Flash Flood Risk Management. Module 2: Non-structural Measures. (includes CD insert), ICIMOD, p. 91.

Shrestha, A. B. (2008b). Climate Change in the Hindu Kush-Himalayas and its impacts on water and hazards. APMN Bulletin (Newsletter of the Asia Pacific Mountain Network), 9, 1-5.

Shrestha, A. B., \& Aryal, R. (2011). Climate change in Nepal and its impact on Himalayan glaciers. Regional Environmental Change, 11, S65-S77.

Shrestha, A. B., \& Devkota, L. P. (2010). Climate change in the Eastern Himalayas: Observed trends and model projections (p. 20).

Shrestha, A. B., Wake, C. P., Mayewski, P. A., \& Dibb, J. E. (1999). Maximum temperature trends in the Himalaya and its vicinity: An analysis based on temperature records from Nepal for the period 1971-94. Journal of Climate, 12, 2775-2786.

Shrestha, A. B., Agrawal, N. K., Alfthan, B., Bajracharya, S. R., Maréchal, J., \& Van Oort, B. (2015). The Himalayan Climate and Water Atlas: Impact of climate change on water resources in five of Asia's major river basins. GRID-Arendal and CICERO: ICIMOD.

Singh, N., \& Ranade, A. (2010). Determination of onset and withdrawal dates of summer monsoon across India using NCEP/NCAR reanalysis (pp. 1-78). IITM Research Report No. RR-124, Indian Institute of Tropical Meteorology, Pune. ISSN 0252-1075.

Singh, S., Ghosh, S., Sahana, A. S., Vittal, H., \& Karmakar, S. (2017). Do dynamic regional models add value to the global model projections of Indian monsoon? Climate Dynamics, 48(3-4), 13751397. https://doi.org/10.1007/s00382-016-3147-y.

Singhvi, A. K., \& Krishnan, R. (2014). Past and the present climate of India. In: V. Kale (Ed.), Landscapes and landforms of India. World geomorphological landscapes (pp. 15-23). Dordrecht: Springer

Sperber, K. R., Annamalai, H., Kang, I. S., Kitoh, A., Moise, A., Turner, A., et al. (2013). The Asian summer monsoon: An intercomparison of CMIP5 vs. CMIP3 simulations of the late 20th century. Climate Dynamics, 41(9-10), 2711-2744.

Staubwasser, M., Sirocko, F., Grootes, P. M., \& Segl, M. (2003). Climate change at the $4.2 \mathrm{ka}$ BP termination of the Indus valley civilization and Holocene south Asian monsoon variability. Geophysical Research Letter, 30(8), 7.1-7.4.

Sun, Y., Zhang, X. B., Ren, G. Y., Zwiers, F. W., \& Hu, T. (2016). Contribution of urbanization to warming in China. Nature Climate Change, 6(7), 706-709. https://doi.org/10.1038/nclimate2956.

Sun, X. B., Ren, G. Y., Xu, W. H., Li, Q. X., \& Ren, Y. Y. (2017a). Global land-surface air temperature change based on the new CMA GLSAT dataset. Science Bulletin, 62(4), 236-238. https://doi. org/10.1016/j.scib.2017.01.017.

Sun, X.-B., Ren, G.-Y., Shrestha, A. B., Ren, Y.-Y., You, Q.-L., Zhan, Y.-J., et al. (2017b). Changes in extreme temperature events over the Hindu Kush Himalaya during 1961-2015. Advances in Climate Change Research, 8(3), 157-165. https://doi.org/10.1016/j.accre. 2017.07.001

Syed, M. A., \& Al Amin, M. (2016). Geospatial modeling for investigating spatial pattern and change trend of temperature and rainfall. Climate, 4(2), 21.

Tang, G. L., \& Ren, G. Y. (2005). Reanalysis of surface air temperature change of the last 100 years over China. Climatic and Environmental Research, 10(4), 791-798.

Teichmann, C., Eggert, B., Elizalde, A., Haensler, A., Jacob, D., Kumar, P., et al. (2013). How does a regional climate model modify the projected climate change signal of the driving GCM: A study over different CORDEX regions using REMO. Atmosphere, 4(2), 214-236.
Thompson, L. G., Mosley-Thompson, E., Davis, M. E., Lin, P. N., Henderson, K., \& Mashiotta, T. A. (2003). Tropical glacier and ice core evidence of climate change on annual to millennial time scales. Climate Change, 59(1-2), 137-155.

Trenberth, K. E., Fasullo, J. T., Branstator, G., \& Phillips, A. S. (2014). Seasonal aspects of the recent pause in surface warming. Nature Climate Change, 4(10), 911-916.

USGS. (2010). Why study paleoclimate? (p. 2). Reston, VA: United States Geological Survey.

Van Vuuren, D. P., Edmonds, J., Kainuma, M., Riahi, K., Thomson, A., Hibbard, K., et al. (2011). The representative concentration pathways: An overview. Climatic Change, 109(1), 5-31.

Vellore, R., Krishnan, R., Pendharkar, J., Choudhury, A. D., \& Sabin, T. P. (2014). On anomalous precipitation enhancement over the Himalayan foothills during monsoon breaks. Climate Dynamics, 43 (7), 2009-2031. https://doi.org/10.1007/s00382-013-2024-1.

Vellore, R. K., Kaplan, M., Krishnan, R., Lewis, J., Sabade, S., Deshpande, N., et al. (2015). Monsoon-extratropical circulation interactions in Himalayan extreme rainfall. Climate Dynamics, 46 (11-12), 3517-3546 (p. 30). https://doi.org/10.1007/s00382-0152784-x.

Wang, B., Bao, Q., Hoskins, B., Wu, G. X., \& Liu, Y. M. (2008). Tibetan plateau warming and precipitation changes in East Asia. Geophysical Research Letters, 35(14), L14702.

Wang, S.-Y., Yoon, J.-H., Gillies, R. R., \& Cho, C. (2013). What caused the winter drought in western Nepal during recent years? Journal of Climate, 26(21), 8241-8256. https://doi.org/10.1175/ JCLI-D-12-00800.1.

Wang, Q., Fan, X., \& Wang, M. (2014). Recent warming amplification over high elevation regions across the globe. Climate Dynamics, 43 (1-2), 87-101.

Wang, Q., Fan, X., \& Wang, M. (2016). Evidence of high-elevation amplification versus Arctic amplification. Scientific Reports, 6. https://doi.org/10.1038/srep19219.

Weiss, H., \& Bardley, R. S. (2001). What drives societal collapse? Science, 291, 609-610. https://doi.org/10.1175/bams-d-11-00074.1.

Wild, M. (2012). Enlightening global dimming and brightening. Bulletin of American Meteorological Society, 93(1), 27-37.

Wu, G. X., \& Zhang, Y. S. (1998). Thermal and mechanical forcing of the Tibetan Plateau and Asian monsoon onset. Part I: Situating of the onset. Chinese Journal of Atmospheric Science, 22(6), 825-838. (in Chinese)

Wu, G. X., Mao, J. Y., Duan, A. M., \& Qiong, Z. (2004). Recent progress in the study on the impacts of Tibetan Plateau on Asian summer climate. Acta Meteorologi Sinica, 62(5), 528-540. (in Chinese).

Wu, J., Xu, Y., \& Gao, X.-J. (2017). Projected changes in mean and extreme climates over Hindu Kush Himalayan region by 21 CMIP5 models. Advance in Climate Change Research, 8(3), 176-184. https://doi.org/10.1016/j.accre.2017.03.001.

Xu, J., Shrestha, A. B., Vaidya, R., Eriksson, M., Nepal, S., \& Sandstrom, K. (2008). The changing Himalayas. Impact of climate change on water resources and livlihoods in the Greater Himalayas. Kathmandu: ICIMOD.

Xu, W. H., Li, Q. X., Yang, S., \& Yan, X. (2014). Overview of global monthly surface temperature data in the past century and preliminary integration. Advances in Climate Change Research, 5(3), 111-117. https://doi.org/10.1016/j.accre.2014.11.003.

Yadav, R. R., Park, W.-K., Singh, J., \& Dubey, B. C. L. (2004). Do the western Himalayas defy global warming? Geophysical Research Letters, 31(17).

Yadav, R. K., Rupa Kumar, K., \& Rajeevan, M. (2009). Increasing influence of ENSO and decreasing influence of AO/NAO in the recent decades over northwest India winter precipitation. Journal of 
Geophysical Research Atmospheres, 114(D12112). https://doi.org/ 10.1029/2008jd011318.

Yadav, R. K., Yoo, J. H., Kucharski, F., \& Abid, M. A. (2010). Why is ENSO influencing northwest India winter precipitation in recent decades? Journal of Climate, 23(8), 1979-1993.

Yan, L. B., \& Liu, X. D. (2014). Has climatic warming over the Tibetan Plateau paused or continued in recent years? Journal of Earth, Ocean and Atmospheric Sciences, 1, 13-28.

Yan, L. B., Liu, Z., Chen, G., Kutzbach, J. E., \& Liu, X. (2016). Mechanisms of elevation-dependent warming over the Tibetan plateau in quadrupled $\mathrm{CO} 2$ experiments. Climatic Change, 135, 509-519.

Yanai, M. H., \& Li, C. (1994). Mechanism of heating and the boundary layer over the Tibetan Plateau. Monthly Weather Review, 122, 305323.

Yanai, M., Li, C., \& Song, Z. (1992). Seasonal Heating of the Tibetan Plateau and its effects on the evolution of the Asian summer monsoon. Journal of the Meteorological Society of Japan Ser. II, 70, 319-351.

Yang, B., Braeuning, A., Johnson, K. R., \& Yafeng, S. (2002). General characteristics of temperature variation in China during the last two millennia. Geophysical Research Letters, 29(9), 38:1-4.

Yang, K., Wu, H., Qin, J., Lin, C., Tang, W., \& Chen, Y. (2014). Recent climate changes over the Tibetan Plateau and their impacts on energy and water cycle: A review. Global and Planetary Change, 112, 79-91.

Yao, T. D. (1997). A record of climatic environment over the past 2000 years from Guliya ice core, China. Science of Quaternary, 1, $52-61$.

Yao, T., Thompson, L. G., Mosbrugger, V., Zhang, F., Ma, Y., Luo, T., et al. (2012a). Third Pole Environment (TPE). Environmental Development, 3(1), 52-64.

Yao, T., Thompson, L., Yang, W., Yu, W., Gao, Y., Guo, X., et al. (2012b). Different glacier status with atmospheric circulations in Tibetan Plateau and surroundings. Nature Climate Change, 2, 663 667.

Ye, D. Z. (1981). Some characteristics of the summer circulation over the Qinghai-Xizang (Tibet) Plateau and its neighborhood. Bulletin of the American Meteorology Society, 62(1), 14-19.

You, Q. L., Kang, S. C., Anguilar, E., \& Yan, Y. P. (2008a). Changes in daily climate extremes in the eastern and central Tibetan Plateau during 1961-2005. Journal of Geophysical Research: Atmospheres, 113(7).

You, Q. L., Kang, S. C., Pepin, N., \& Yan, Y. P. (2008b). Relationship between trends in temperature extremes and elevation in the eastern and central Tibetan Plateau, 1961-2005. Geophysical Research Letters, 35(4), L04704. https://doi.org/10.1029/2007GL032669.

You, Q. L., Kang, S. C., Flugel, W. A., Pepin, N., Yan, Y. P., \& Huang, J. (2010a). Decreasing wind speed and weakening latitudinal surface pressure gradients in the Tibetan Plateau. Climate Research, 42(1), 57-64.

You, Q. L., Kang, S. C., Flugel, W. A., Sanchez-Lorenzo, A., Yan, Y. P., Huang, J., et al. (2010b). From brightening to dimming in sunshine duration over the eastern and central Tibetan Plateau
(1961-2005). Theoretical and Applied Climatology, 101(3), 445457.

You, Q. L., Kang, S. C., Pepin, N., Flugel, W. A., Yan, Y. P., Behrawan, H., et al. (2010c). Relationship between temperature trend magnitude, elevation and mean temperature in the Tibetan Plateau from homogenized surface stations and reanalysis data. Global and Planetary Change, 71, 124-133.

You, Q. L., Fraedrich, K., Ren, G., Pepin, N., \& Kang, S. (2013a). Variability of temperature in the Tibetan Plateau based on homogenized surface stations and reanalysis data. International Journal of Climatology, 33(6), 1337-1347.

You, Q. L., Sanchez-Lorenzo, A., Wild, M., Folini, D., Fraedrich, K., Ren, G., et al. (2013b). Decadal variation of surface solar radiation in the Tibetan Plateau from observations, reanalysis and model simulations. Climate Dynamics, 40(7-8), 2073-2086.

You, Q. L., Min, J., Zhang, W., Pepin, N., \& Kang, S. (2015). Comparison of multiple datasets with gridded precipitation observations over the Tibetan Plateau. Climate Dynamics, 45, 791-806.

You, Q. L., Min, J., \& Kang, S. (2016). Rapid warming in the Tibetan Plateau from observations and CMIP5 models in recent decades. International Journal of Climatology, 36, 2660-2670.

You, Q. L., Ren, G. Y., Zhang, Y. Q., Ren, Y. Y., Sun, X. B., Zhan, Y. J., et al. (2017). An overview of studies of observed climate change in the Hindu Kush Himalayan (HKH) region. Advances in Climate Change Research, 8(3), 141-147. https://doi.org/10.1016/j.accre. 2017.04.001.

Zhai, P. F., Sun, A., Ren, F., Liu, X., Gao, B., \& Zhang, Q. (1999). Changes of climate extremes in China. Climatic Change, 42(1), 203-218.

Zhai, P. M., Zhang, X. B., Wan, H., \& Pan, X. (2005). Trends in total precipitation and frequency of daily precipitation extremes over China. Journal of Climate, 18(7), 1096-1108.

Zhan, Y.-J., Ren, G.-Y., Shrestha, A. B., Rajbhandari, R., Ren, Y.-Y., Sanjay, J., et al. (2017). Change in extreme precipitation events over the Hindu Kush Himalayan region during 1961-2012. Advance in Climate Change Research, 8(3). https://dx.doi.org/10.1016/j.accre. 2017.08.002.

Zhang, A. Y., Ren, G. Y., Guo, J., \& Wang, Y. (2009). An analysis of upper-air wind speed in mainland China, 1980-2006. Plateau Meteorology, 28(3), 680-687.

Zhang, X., Alexander, L., Hegerl, G. C., Jones, P., Tank, A. L., Peterson, T. C., et al. (2011). Indices for monitoring changes in extremes based on daily temperature and precipitation data. WIREs Climate Change, 2(6), 851-870.

Zhou, Y. Q., \& Ren, G. Y. (2009). The effect of urbanization on maximum, minimum temperatures and daily temperature range in North China. Plateau Meteorology, 28(5), 1158-1166. (in Chinese).

Zhou, Y. Q., \& Ren, G. Y. (2011). Change in extreme temperature events frequency over mainland China during 1961-2008. Climate Research, 50, 125-139.

Zhou, X., Zhao, P., Chen, J., Chen, L., \& Li, W. (2009). Impacts of thermodynamic processes over the Tibetan Plateau on the Northern Hemispheric climate. Science in China, Series D: Earth Sciences, 52(11), 1679-1693. 
Open Access This chapter is licensed under the terms of the Creative Commons Attribution 4.0 International License (http:// creativecommons.org/licenses/by/4.0/), which permits use, sharing, adaptation, distribution and reproduction in any medium or format, as long as you give appropriate credit to the original author(s) and the source, provide a link to the Creative Commons license and indicate if changes were made.
The images or other third party material in this chapter are included in the chapter's Creative Commons license, unless indicated otherwise in a credit line to the material. If material is not included in the chapter's Creative Commons license and your intended use is not permitted by statutory regulation or exceeds the permitted use, you will need to obtain permission directly from the copyright holder. 